UNIVERSIDADE DE SÃO PAULO

FACULDADE DE FILOSOFIA, CIÊNCIAS E LETRAS DE RIBEIRÃO PRETO

DEPARTAMENTO DE FÍSICA

PROGRAMA DE PÓS-GRADUAÇÃO EM CIÊNCIAS

ÁREA DE CONCENTRAÇÃO: FÍSICA APLICADA À MEDICINA E BIOLOGIA

LEONARDO LIRA DO AMARAL

\title{
Desenvolvimento de uma metodologia de avaliação dosimétrica de transmissão, usando filmes radiocrômicos em tratamentos radioterápicos
}




\section{Desenvolvimento de uma metodologia de avaliação dosimétrica de transmissão, usando filmes radiocrômicos em tratamentos radioterápicos}

Tese submetida ao programa de PósGraduação em Física Aplicada à Medicina e Biologia, da Faculdade de Filosofia, Ciências e Letras de Ribeirão Preto, da Universidade de São Paulo, como parte dos requisitos para a obtenção do título de Doutor em Ciências Área de Concentração: Física Aplicada à Medicina e Biologia.

Orientador:

Prof. Dr. Thomaz Ghilardi Netto

\section{VERSÃO CORRIGIDA}

Ribeirão Preto

2014 
Autorizo a reprodução e divulgação total ou parcial deste trabalho, por qualquer meio convencional ou eletrônico, para fins de estudo e pesquisa, desde que citada a fonte.

Amaral, Leonardo Lira

Desenvolvimento de uma metodologia de avaliação dosimétrica de transmissão, usando filmes radiocrômicos em tratamentos radioterápicos. Ribeirão Preto, 2014.

$$
112 \text { p. : il. ; } 30 \mathrm{~cm}
$$

Tese de Doutorado apresentada à Faculdade de Filosofia, Ciências e Letras de Ribeirão Preto/USP. Área de concentração: Física Aplicada à Medicina e Biologia.

Orientador: Ghilardi Netto, Thomaz.

1. Controle da Qualidade. 2. Avaliações in vivo. 3. Dosimetria in vivo 4. Filme Radiocrômico 5. IMRT 
Nome: Amaral, Leonardo Lira

Título: Desenvolvimento de uma metodologia de avaliação dosimétrica de transmissão, usando filmes radiocrômicos em tratamentos radioterápicos

Tese submetida ao programa de PósGraduação em Física Aplicada à Medicina e Biologia, da Faculdade de Filosofia, Ciências e Letras de Ribeirão Preto, da Universidade de São Paulo, como parte dos requisitos para a obtenção do título de Doutor em Ciências Área de Concentração: Física Aplicada à Medicina e Biologia.

\section{Aprovado em:}

\section{Banca Examinadora}

Prof. Dr. Instituição:

Julgamento: Assinatura:

Prof. Dr. Instituição:

Julgamento: Assinatura:

Prof. Dr. Instituição:

Julgamento: Assinatura:

Prof. Dr. Instituição:

Julgamento: Assinatura:

Prof. Dr. Instituição:

Julgamento: Assinatura: 
"Deus nos fez perfeitos e não escolhe os capacitados; capacita os escolhidos. Fazer ou não fazer algo só depende de nossa vontade $e$ perseverança."

Albert Einstein 
A meus pais, Amaral $e$ Fátima, pais exemplares, por me apoiarem em todas as etapas da vida, e minha esposa e filho, Milena e André Luiz, pela compreensão, carinho, presença e incansável apoio ao longo do período de elaboração deste trabalho. 
Agradecimentos 
A meus pais, Amaral e Fátima, que sempre me deram suporte para tudo e nunca me deixaram desistir, que me fizeram acreditar que vale a pena lutar por um sonho, mesmo sabendo da incerteza de realizá-lo.

A minha esposa, Milena, por saber me dividir com o trabalho, por compartilhar minhas conquistas como se fossem dela e por ter sido paciente sempre que me deixava dominar pelo cansaço e preocupação.

Ao meu filho, André Luiz, que me proporciona a maior felicidade do mundo. E por me motivar a trabalhar e estudar para lhe oferecer um futuro com mais oportunidades.

A minha irmã Manuela, por fazer parte da minha vida.

Ao meu orientador, Prof. Thomaz, por ter perdido tantas manhãs, tardes e noites me ensinando o que eu já deveria saber, por ter tido, sempre, muita paciência. E, principalmente, por ter me feito crescer, como pessoa e profissional.

Ao meu amigo e chefe, Dr. Harley, que me propiciou a oportunidade de poder conciliar o trabalho e o estudo.

Aos professores Paulo, Patrícia e Juliana, por terem me ajudado, mesmo que informalmente, no desenvolvimento deste trabalho.

Aos que me ensinaram a dar os primeiros passos na física da Radioterapia, Gustavo, Edenyse e Leandro. Por terem sido mais que colegas de trabalho, amigos e professores.

Aos aprimorandos da radioterapia Laís, Eduardo, Antônio Neto e Marcelo, que me ajudaram e contribuíram para a obtenção dos dados presentes nesta tese.

Ao Adriano, recente amigo, mas que me ajudou com afinco em boa parte deste trabalho.

Ao Francisco Sampaio, por ter simulado o espectro do feixe do acelerador linear em Monte Carlos.

À Bethe Brayn, por ser tão solícita em corrigir com tamanho zelo e dedicação a minha tese.

Aos funcionários do Hospital das Clínicas da Faculdade de Medicina de Ribeirão Preto, que fizeram do ambiente de trabalho um espaço de aprendizado agradável e prazeroso.

A minha família Lira, que contribuiu com meu caráter e me transformou numa pessoa feliz e melhor 
Aos meus amigos de Pernambuco, que, mesmo de longe, sempre estiveram tão perto.

Aos meus professores dos cursos de graduação em Matemática e Física, que contribuíram para o meu amadurecimento intelectual. Em particular, aos professores Airton e Paulo Figueiredo, da Matemática, e Albino, do curso de Física, por serem sempre tão solícitos e conselheiros.

Ao Aziane, pela contribuição nos acessórios presentes nesta tese.

Às secretárias do Departamento de Física, em especial à Nilza, secretária do programa de pós-graduação em Física Aplicada à Medicina e Biologia, por todo o suporte durante o período de pós-graduação.

A todos que, de alguma forma, contribuíram direta ou indiretamente para este trabalho.

Finalmente, e o agradecimento mais importante, a Deus, por nunca ter me abandonado, por ser meu conforto nas horas mais difíceis e por ter colocado todas essas pessoas em minha vida. 
Resumo 
Amaral, L. L. Desenvolvimento de uma metodologia de avaliação dosimétrica de transmissão, usando filmes radiocrômicos em tratamentos radioterápicos. Tese (Doutorado). Ribeirão Preto: Faculdade de Filosofia, Ciências e Letras de Ribeirão Preto, Universidade de São Paulo; 2014. 112 p.

Apesar da introdução do controle da qualidade individual nas técnicas complexas de tratamentos, tem-se comprovado que, mesmo assim, é possível a ocorrência de erros na aplicação da dose no momento da aplicação. No entanto, ainda não estão bem estabelecidas as ferramentas de redundância a fim de controlar a dose no momento da terapêutica, além do que, as técnicas mais modernas de tratamento radioterápico desenvolvem as aplicações com feixes rotacionais e os dosímetros tradicionalmente utilizados em controle da qualidade oferecem limitações angulares. Assim, este trabalho vem contribuir para o desenvolvimento de uma metodologia de controle da qualidade de transmissão in vivo utilizando filmes radiocrômicos acoplados ao cabeçote do acelerador linear, durante aplicações radioterápicas nas técnicas de tratamento conformacional e IMRT. A metodologia de controle da qualidade desenvolvida neste trabalho baseia-se na obtenção da distribuição de dose in vivo de tratamentos radioterápicos com um filme radiocrômico EBT2 posicionado em um suporte acrílico, semelhante a uma bandeja, a uma distância fonte-superfície de 56,8 cm, acoplado ao acessório holder do acelerador linear durante a aplicação de todo o tratamento teleterápico. Posteriormente, foi realizada uma análise gama para comparação da distribuição de dose medida pelo filme com a esperada pelo sistema de planejamento, obtida no plano coronal e central de um objeto simulador, com dimensões semelhantes ao suporte acrílico, posicionado à distância de $100 \mathrm{~cm}$, como resultado da transferência do plano em questão. Com os resultados encontrados na seção conformacional, avaliando tanto a simulação Monte Carlo quanto as irradiações, pode-se concluir que a diferença entre a distribuição de dose do sistema de planejamento, na distância foco detector de $100 \mathrm{~cm}$, e do filme, na distância de $56,8 \mathrm{~cm}$, é diminuta e, desta forma, é viável criar uma metodologia para verificação dosimétrica de transmissão utilizando o filme radiocrômico acoplado ao cabeçote do acelerador. O controle da qualidade proposto na técnica de IMRT concordou com o esperado em 24 das 25 situações testadas, apresentando apenas um resultado diferente, ou seja, uma concordância de $96 \%$ com o esperado. As avaliações in vivo concordaram com $98 \%$ dos controles avaliados. Desta forma, pode-se concluir que a metodologia proposta neste trabalho é factível para o controle da qualidade de transmissão in vivo, em tratamentos radioterápicos que usam a técnica de tratamento conformacional e IMRT e, como ela não oferece dificuldades para o deslocamento angular do gantry, ela poderá ser aplicada em técnicas teleterápicas mais modernas.

Palavras-chave: Controle da qualidade, filme radiocrômico, avaliações in vivo, dosimetria in vivo, IMRT. 
Abstract 
Amaral,L.L. Development of a methodology for transmission dosimetric evaluation using radiochromic film in radiotherapy treatments. Thesis PhD. Ribeirão Preto: Faculty of Philosophy, Sciences and Letters of Ribeirão Preto, University of São Paulo; 2014.112 p.

Even with the introduction of the individual quality control in the complex techniques of radiation therapy treatments, the occurrence of errors in the release of the dose at the time of application is possible. However, in order to monitor the dose at the time of therapy, redundancy tools are not yet well established, Besides that, the most modern techniques of radiation treatment use rotational beams to deliver the desired dose distributions and the dosimeters traditionally used in quality control of radiation therapy suffer angular limitations. In this way, this work aims to contribute to the development of a methodology of transmission quality control in vivo presenting a dose control technique using radiochromic film coupled to the headstock linear accelerator for radiotherapy applications to monitor conformational techniques and IMRT treatment. The quality control methodology developed in this work is based on obtaining the in vivo dose distribution of radiotherapy treatments with a radiochromic film EBT2, positioned on an acrylic stand, similar to a tray at a source-surface distance of $56.8 \mathrm{~cm}$, coupled to the linear accelerator accessory holder during application of any treatment. It was subsequently performed a gama analysis for comparison of the dose distribution measured by the film with the expected dose distribution by the treatment planning system. The expected dose distribution was obtained in the coronal and central plane of a phantom, with similar dimensions to the acrylic stand and positioned on a source-surface distance of $100 \mathrm{~cm}$ as a result of the transfer of the plan in question. Based on the results presented in the conformational section, evaluating both, Monte Carlo simulation and irradiation results, it can be concluded that the difference between the distribution of the dose planning system, focus distance $100 \mathrm{~cm}$ detector, and the film, on distance of $56.8 \mathrm{~cm}$, are small, and in this way it is feasible to create a methodology for dosimetry verification using radiochromic film coupled to the head of the accelerator. The proposed quality control in IMRT technique agreed with expected in 24 simulations of the 25 situations tested, showing only one different result, i.e., there was a $96 \%$ concordance with the expected. In this way, it can be concluded that the methodology proposed in this work is feasible for the in vivo quality control of radiation therapy treatments that use the conformational and IMRT treatment techniques, and also can be applied to the most modern radiotherapy techniques since, it does not offer difficulties with the angular displacement of the gantry.

Keywords: quality assurance, radiochromic film, in vivo evaluations, in vivo dosimetry, IMRT. 
Siglas e Abreviaturas 
ADC: $\quad$ Analogue-to-digital converter

AL: $\quad$ Acelerador linear

CQ: $\quad$ Controle da qualidade

DD: $\quad$ Distribuição de dose

DFD: $\quad$ Distância foco detector

DICOM: $\quad$ Digital imaging and communications in medicine

Desv. \%: Desvio percentual

DR: $\quad$ Densidade relativa

DTA: $\quad$ Distance-to-agreement

EPID: $\quad$ Electronic portal imaging device

HCFMRP-USP: Hospital das clínicas da faculdade de medicina de Ribeirão Preto

IGRT: $\quad$ Image guided radiation therapy

IMRT: $\quad$ Intensity modulated radiation therapy

LINAC: $\quad$ Linear accelerator

MAPS: $\quad$ monolithic active pixel sensors

MLC: $\quad$ Multleaf collimator

MOSFET: $\quad$ Metal oxide semiconductor field effect transistor

UM: $\quad$ Unidade monitora

OR: $\quad$ Orgão de risco

PENELOPE: Penetration and energy loss of positron and electrons

PTV: $\quad$ Planning target volume

PDP: $\quad$ Porcentagem de dose em profundidade

QA: $\quad$ Quality assurance

RT: $\quad$ Radiotherapy

SNC: $\quad$ Sistema nervoso central

S\&R: $\quad$ Sistema de registro e verificação

SSD: $\quad$ Source skin distance

TC: $\quad$ Tomógrafo computadorizado

TLD: $\quad$ Thermoluminescent dosimeter

TPS: $\quad$ Treatment planning systems

USP: $\quad$ Universidade de São Paulo

$\Delta \mathrm{D}: \quad$ Variação de distância 
$\Delta \%$ :

Variação da porcentagem da dose

V-MAT:

Volumetric-modulated arc therapy 
Figura 1 - Exemplo de restrições e objetivos usados no processo de otimização de um planejamento de IMRT.

Figura 2 - Mapa de fluência de um campo de IMRT 10

Figura 3 - Exemplo das intensidades variáveis em campos de IMRT 10

Figura 4 - Curva de isodose côncava em um caso de IMRT para diminuir a dose no reto

Figura 5 - Ilustração do conceito da função gama. A curva azul representa a distribuição da dose de referência e a vermelha, a DD analisada

Figura 6 - (A) Suporte acrílico confeccionado neste trabalho para posicionar o filme no acessório holder do acelerador linear. (B) Suporte acrílico com filme posicionado no centro. (C) Suporte acrílico acoplado ao acessório holder do acelerador linear. (D) Tabela e gráfico de calibração (E) Imagem da função gama (F) Imagem, do TPS, de um planejamento de próstata com 5 campos. (G) Imagem, no TPS, do cálculo da distribuição da dose formado pelos campos do planejamento.

Figura 7 - Esquema da calibração descrita na metodologia de controle da qualidade com filme no suporte acrílico. À esquerda configuração utilizada para adquirir a dose calculada pelo TPS. À direita configuração realizada para encontrar os valores de pixel das imagens digitalizadas dos filmes irradiados no suporte acrílico indexado ao acessório holder do LINAC. Na região inferior, a associação da dose calculada pelo TPS e os valores de pixel encontrados na irradiação do filme com as mesmas UM

Figura 8 - À esquerda, o filme posicionado na posição " 0 ". À direita, retângulo vermelho representando definição de área .

Figura 9 - Exemplo de filme de apoio, região da borda mais escura, na digitalização

Figura 10 - Exemplo de filme com película

Figura 11 - À esquerda filme na posição " 0 " e, à direita filme na posição "90"

Figura 12 - À esquerda filme na posição normal e à direita filme invertido.

Figura 13 - Visualização das estruturas internas do cabeçote simulado (alvo em vermelho claro; colimador primário em azul, na região superior; filtro achatador em verde; câmara de ionização em vermelho; espelho em amarelo e azul claro e colimadores secundários em azul, na região inferior da imagem) através de um corte, (A) no eixo axial e (B) no eixo sagital. ............................................... 31

Figura 14 - Interface gráfica do programa desenvolvido

Figura 15 - Fluxograma do programa desenvolvido

Figura 16 - Esquema da metodologia de controle da qualidade desenvolvido. À esquerda distribuição de dose gerada pelo TPS e à direita configuração da distribuição da dose encontrada pelo filme. Na região inferior da imagem pode-se observar a função gama

Figura 17 - À esquerda filme localizado acima do MatriXX. À direita configuração usada na irradiação 
Figura 18 - Exemplo de problema encontrado na digitalização no escâner Vidar do Serviço de Radioterapia do HCFMRP-USP.

Figura 19 - Gráfico da comparação da PDP simulada em Monte Carlo e as medidas com câmaras de ionização no campo $5 \mathrm{~cm}$ x $5 \mathrm{~cm}$. 50

Figura 20 - Gráfico da comparação da PDP simulada em Monte Carlo e as medidas com câmaras de ionização no campo $10 \mathrm{~cm}$ x $10 \mathrm{~cm}$.

Figura 21 - Gráfico da comparação da PDP simulada em Monte Carlo e as medidas com câmaras de ionização no campo $15 \mathrm{~cm}$ x $15 \mathrm{~cm}$.

Figura 22 - Função gama comparando o corte coronal da simulação Monte Carlo a 56,8 cm com a distribuição de dose posicionada a $100 \mathrm{~cm}$ para o campo de $5 \mathrm{~cm} \times 5 \mathrm{~cm}$

Figura 23 - Função gama comparando o corte coronal da simulação Monte Carlo a 56,8 cm com a distribuição de dose posicionada a $100 \mathrm{~cm}$ para o campo de $10 \mathrm{~cm}$ x $10 \mathrm{~cm}$

Figura 24 - Função gama comparando o corte coronal da simulação Monte Carlo a 56,8 cm com a distribuição de dose posicionada a $100 \mathrm{~cm}$ para o campo de $15 \mathrm{~cm}$ x $15 \mathrm{~cm}$ 54

Figura 25 - Calibração associando o conversor digital analógico (ADC) dos filmes digitalizados com as dose calculadas pelo TPS, onde as barras de erro correspondem ao desvio padrão das medidas..... 55

Figura 26 - Calibração associando os valores de pixel dos filmes digitalizados com as dose descritas pelo TPS, onde as barras de erro correspondem ao desvio padrão das medidas..... 59

Figura 27 - Distribuição de fluência do campo retirado do paciente 2 no estudo da irradiação sem um campos. 62

Figura 28 - Distribuição da fluência relativa ao campo posterior (gantry 180) do paciente 4. À esquerda a distribuição sem a imagem de projeção da próstata e à direita com a imagem projetada do órgão de risco em questão. 63

Figura 29 - Calibração associando os valores de pixel dos filmes digitalizados com as dose coletadas no meio da imagem do objeto simulador no TPS, onde as barras de erro correspondem ao desvio padrão das medidas.

Figura 30 - Calibração associando os valores de pixel dos filmes digitalizados com as dose coletadas no limite inferior do objeto simulador no TPS, onde as barras de erro correspondem ao desvio padrão das medidas 
Lista de Tabelas 
Tabela 1- Resultados das medidas realizadas com o MatriXX para aquisição do fator de transmissão 47

Tabela 2 - Resultado da função gama na comparação da matriz de dose liberada pelo TPS e as imagens digitalizadas nas diversas configurações

Tabela 3 - Resultado da comparação entre a distribuição de dose gerada pelo TPS e a distribuição de dose gerada pelo filme.

Tabela 4 - Resultado das diferenças percentuais no caso de IMRT de próstata entre as funções gama realizadas no programa desenvolvido e o OmniPro I'mrt

Tabela 5 - Resultado das diferenças no caso de IMRT de SNC entre as funções gama realizadas no programa desenvolvido e o OmniPro I'mrt.

Tabela 6 - Resultados do controle da qualidade proposto agrupados em função da configuração da irradiação.

Tabela 7 - Resultado do desvio percentual da dose esperada pelo TPS e obtida pelo filme no ponto de normalização para as duas digitalizações do filme

Tabela 8 - Resultado da função gama na comparação entre as distribuições de dose esperada pelo TPS e obtida pelo filme para as duas digitalizações

Tabela 9 - Desvios percentuais entre a dose no ponto de normalização esperada pelo TPS e obtida pelo filme nas duas irradiações com o filme no suporte

Tabela 10 - Resultado da função gama na comparação entre as distribuições de dose esperada pelo TPS e obtida pelo filme para as duas irradiações

Tabela 11 - Comparação entre os percentuais de pontos aprovados na análise gama no controle da qualidade de transmissão proposto e no controle da qualidade realizado com o MatriXX

Tabela 12 - Comparação entre os percentuais de pontos aprovados na análise gama no controle da qualidade de trasmissão proposto e no controle da qualidade realizado com o filme radiocrômico no isocentro 68

Tabela 13 - Resultados da avaliação in vivo referentes à distribuição da dose coletada no centro da imagem do objeto simulador no TPS 71

Tabela 14 - Resultados da avaliação in vivo referentes à distribuição da dose coletada na região inferior da imagem do objeto simulador no TPS

Tabela 15 - Resultados das comparações entre o controle da qualidade convencional e o controle da qualidade de transmissão proposto neste trabalho 
Sumário 


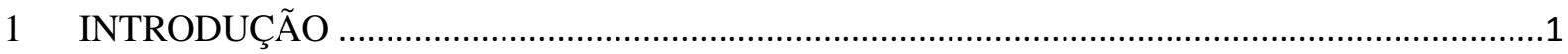

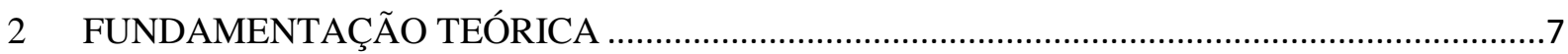

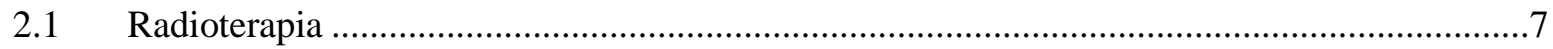

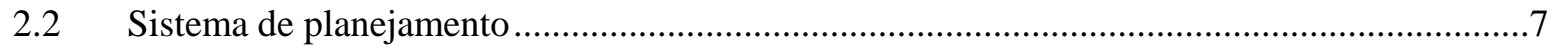

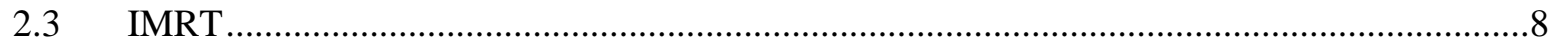

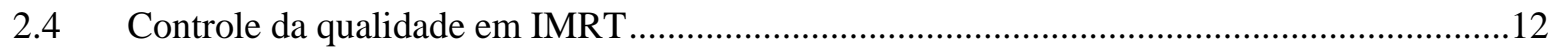

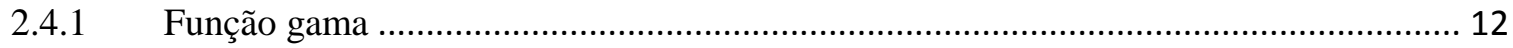

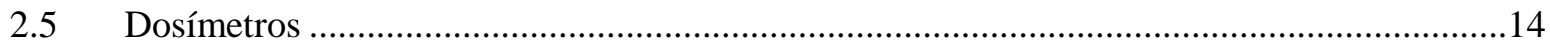

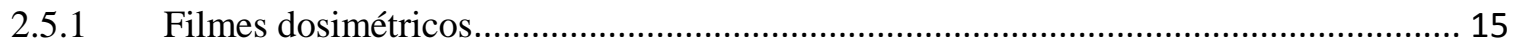

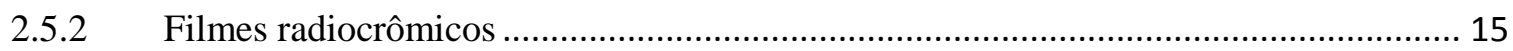

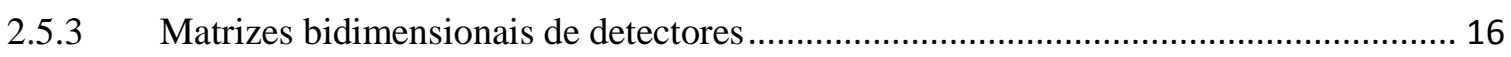

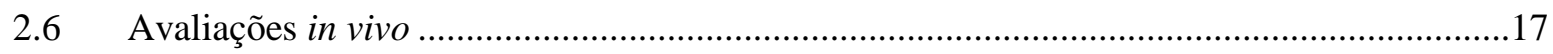

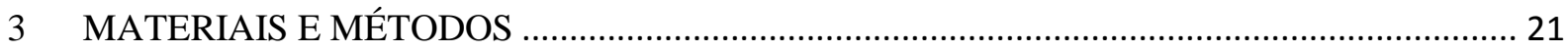

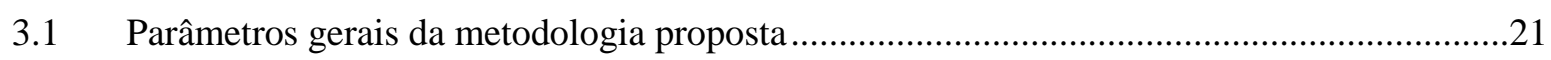

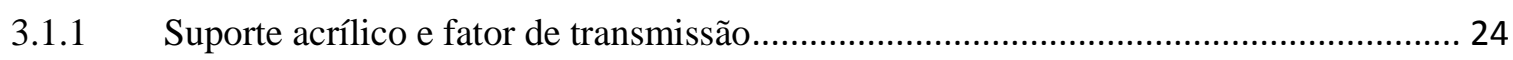

3.1.2 Metodologia da calibração ................................................................................... 24

3.1.3 Metodologia da digitalização dos filmes ................................................................... 26

3.2 Estudo da metodologia em campos quadrados e de planejamento conformacional................30

3.2.1 Simulação Monte Carlo...................................................................................... 30

3.2.2 Calibração das avaliações dosimétricas conformacionais ............................................. 32

3.2.3 Comparação entre as distribuições de dose calculadas no TPS e a adquirida pelo filme em campos quadrados e conformacionais ............................................................................. 32

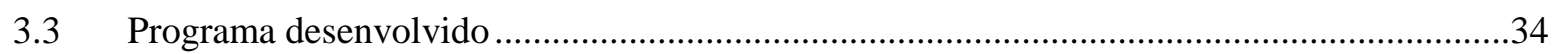

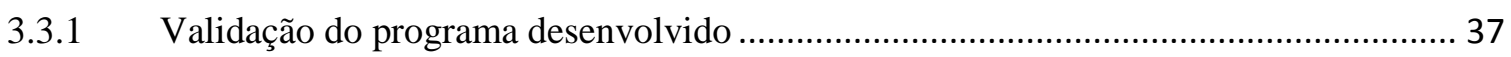

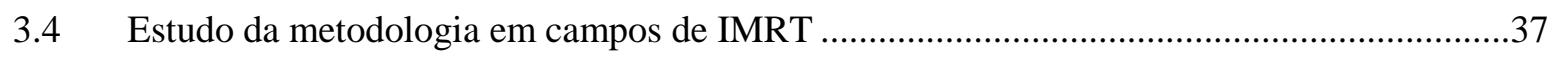

3.4.1 Calibração da avaliação dosimétrica da técnica de IMRT ............................................. 39

3.4.2 Validação da metodologia do controle da qualidade com filme no suporte acrílico..... 39

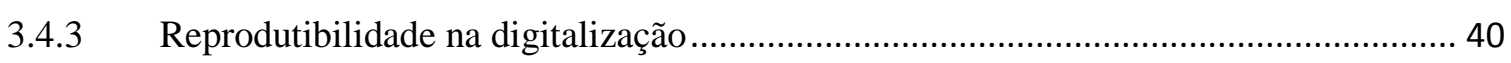

3.4.4 Reprodutibilidade do controle da qualidade de transmissão ....................................... 40

3.4.5 Comparação da metodologia do controle da qualidade de transmissão com a

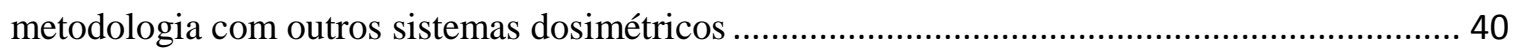

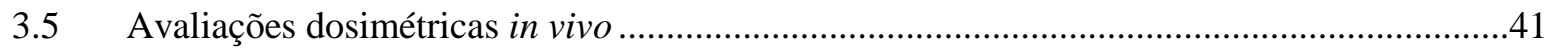

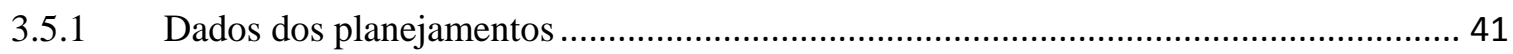

3.5.2 Programa de controle da qualidade no serviço de radioterapia ...................................... 42 


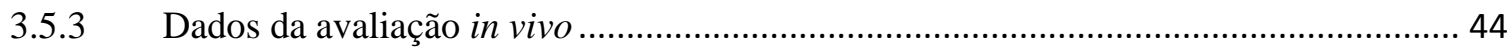

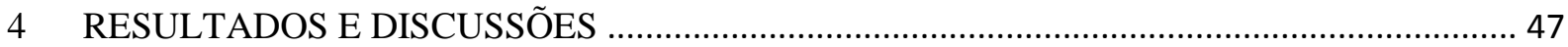

4.1.1 Suporte acrílico e fator de transmissão....................................................................... 47

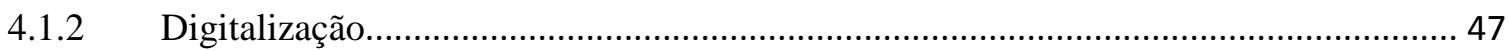

4.2 Estudo da metodologia de transmissão em campos quadrados e de planejamento

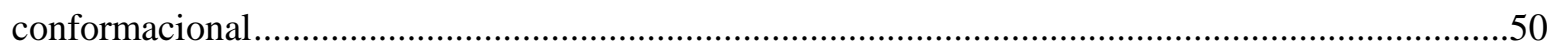

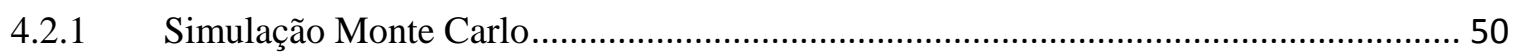

4.2.2 Calibração para as avaliações dosimétricas com campos quadrados e conformacionais . .54

4.2.3 Comparação entre a distribuição de dose calculada pelo TPS e a adquirida pelo filme 55

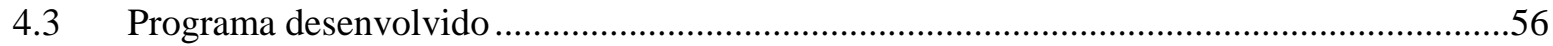

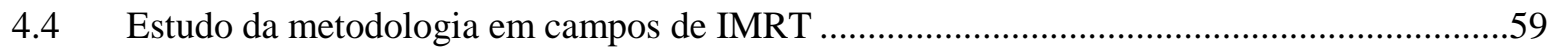

4.4.1 Calibração para a avaliação dosimétrica da técnica de IMRT ........................................ 59

4.4.2 Validação da metodologia do controle da qualidade com filme no suporte acrílico..... 60

4.4.3 Reprodutibilidade na digitalização na técnica de IMRT ................................................ 63

4.4.4 Reprodutibilidade do controle da qualidade de transmissão na técnica de IMRT ......... 65

4.4.5 Comparação entre o controle da qualidade de transmissão e de outros sistemas

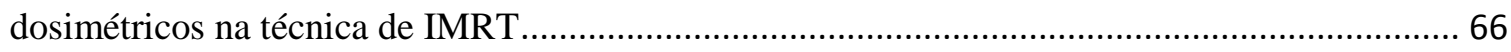

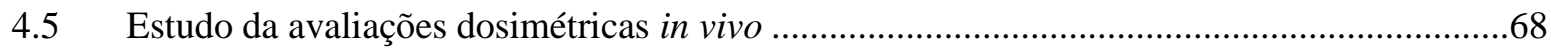

4.5.1 Calibrações para as avaliações dosimétricas in vivo ...................................................... 68

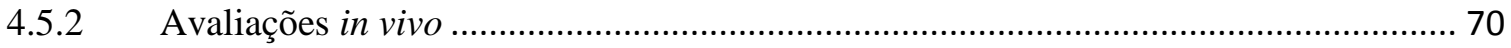

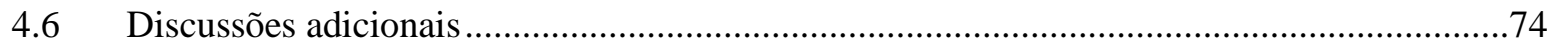

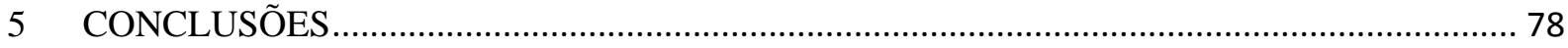

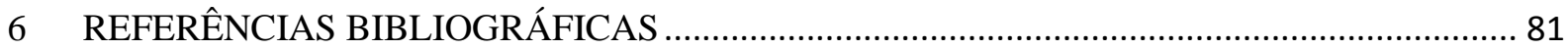


Capítulo 1 - Introdução 


\section{INTRODUÇÃO}

A radioterapia é uma técnica de tratamento que utiliza radiação ionizante a fim de eliminar células não desejadas do organismo humano. Ela se baseia na destruição do tumor pela absorção da energia da radiação incidente, tendo como princípio maximizar o dano ao tumor e minimizar o dano em tecidos vizinhos, normais. As técnicas de tratamento em radioterapia estão em contínuo desenvolvimento e, atualmente, usando técnicas complexas como a radioterapia com intensidade modulada de feixe (IMRT, do inglês Intensity Modulated Radiation Therapy), é possível aumentar a conformidade da radiação aos volumes alvos, depositando altas doses no tumor e diminuindo as doses nos tecidos sadios ao redor (BASKAR et al., 2012) (ELSHAIKH et al., 2006).

Apesar das técnicas complexas de tratamento resultarem em um benefício significativo no tratamento de tumores, é imperativo que os equipamentos usados para estas práticas passem por um programa de controle da qualidade (QA, do inglês Quality Assurance) mais elaborado, uma vez que qualquer erro nestes equipamentos pode causar lesões severas ao paciente (MANS et al., 2010). O programa de controle da qualidade em radioterapia abrange todos os procedimentos que garantam a consistência da prescrição médica, e consequentemente, a entrega da dose desejada no volume alvo, minimizando, na medida do possível, a dose no tecido normal (WORLD HEALTH ORGANIZATION (WHO), 1988).

Os principais testes realizados no programa de controle da qualidade dos equipamentos verificam dados mecânicos e dosimétricos a fim de garantir a realização dos tratamentos. Porém, nas técnicas mais complexas, como o IMRT, há a necessidade de se avaliar a distribuição de dose (DD) individual de cada planejamento, além das doses absolutas entregues (HARDING e GOMEZ, 2006). Para essa avaliação, é necessário que os detectores sejam adequados aos objetivos das medidas, o que exige a utilização de diferentes sistemas dosimétricos. As matrizes bidimensionais de detectores e os filmes dosimétricos, em conjunto com as câmaras de ionização, são alguns dos detectores mais usados.

As matrizes bidimensionais de detectores, ou array, são dispositivos formados para avaliar um mapa de dose ou a distribuição da dose em duas dimensões. Esses dispositivos são 
muito usados por serem de fácil manipulação, entretanto existem dificuldades relacionadas com a sua resolução espacial e dependência angular (POPPE et al., 2007).

Os filmes dosimétricos convencionais são muito utilizados em dosimetrias clínicas, tendo como principal vantagem a sua alta resolução espacial (BANCI BUONAMICI et al., 2007). Porém, os resultados alcançados com este tipo de filme podem ser influenciados por variações na temperatura ou contaminação no processo de revelação. Esses possíveis efeitos podem ser solucionados através da utilização de filmes radiocrômicos. Este tipo de filme possui em seu volume sensível um polímero que muda sua coloração quando submetido a um feixe radioativo, sem a necessidade de nenhum processamento físico ou químico. As principais vantagens dos filmes radiocrômicos atuais são: a equivalência de sua densidade com a da água, alta resolução espacial (LEE, FUNG e KWOK, 2006), alto intervalo de dose, baixa dependência energética e, principalmente, a sua insensibilidade à luz visível (BUTSON et al., 2003).

Apesar da introdução do controle da qualidade (CQ) individual pré-tratamento nas técnicas radioterápicas complexas, tem-se comprovado que, mesmo assim, é possível a ocorrência de erros na liberação da dose no momento da aplicação (MANS et al., 2010). Com o aumento da complexidade dos tratamentos, principalmente com o advento do IMRT, diversos trabalhos vêm reiterando a necessidade de um programa de controle da qualidade adequado. Com isso, Mans e colaboradores apresentaram resultados da avaliação da dosimetria in vivo de 4337 tratamentos de IMRT e concluíram que o controle da qualidade individual do paciente antes do tratamento não é suficiente para assegurar a qualidade do tratamento, tendo em vista que 17 erros foram encontrados apenas nesta última análise (MANS et al., 2010). Desta forma, passa a ser de fundamental importância a realização de um controle da qualidade individual in vivo no momento do tratamento (MIJNHEER, 2008).

A avaliação in vivo tem como propósito averiguar se a dose foi liberada na localização e com a intensidade correta. Em radioterapia externa, teleterapia, a dosimetria in vivo geralmente é realizada posicionando o dosímetro na pele do paciente na entrada do feixe. Entretanto, para técnicas mais complexas esta metodologia está sujeita a algumas dificuldades (MIJNHEER, 2008) (MOHAMMADKARIM et al., 2013) como, por exemplo, em radiocirurgia e em radioterapia estereotáxica, nas quais utilizam-se vários campos não coplanares com dimensões reduzidas ou quando o feixe é rotacional, onde existe uma dificuldade de se encontrar o posicionamento correto dos dosímetros na pele do paciente para 
as medidas das doses de entrada do feixe. Além disso, o tempo necessário para este posicionamento passa a ser limitante para a realização deste controle. Em IMRT, o maior problema é determinar a distribuição de dose dos campos na posição dos dosímetros colocados na pele do paciente, pois a irregularidade da superfície, somada à modulação da intensidade do feixe, dificulta esta análise (MIJNHEER, 2008).

Tendo em vista a necessidade de uma avaliação da dose de redundância no momento da terapêutica, e que a avaliação in vivo ainda não está bem estabelecida para as técnicas mais complexas de tratamento, atualmente diversos pesquisadores estão se dedicando ao desenvolvimento de métodos para o controle da qualidade e para dosimetria in vivo utilizando o EPID (do inglês Electronic Portal Imaging Device) (MANS et al., 2010) (MCDERMOTT et al., 2007), uma vez que estes dispositivos estão acoplados aos aceleradores lineares (LINAC, do inglês Linear Accelerator) mais modernos. Porém, estes dispositivos não estão disponíveis em todos os aceleradores lineares que realizam essas técnicas especiais de tratamento. Além disso, várias instituições, que possuem equipamentos com EPID, não o utilizam para dosimetria in vivo, pois o método ainda não está bem estabelecido para todos os aparelhos.

A primeira vez que se tratou de uma avaliação independente da unidade monitora em um LINAC não computadorizado foi descrita por Paliwal e colaboradores (PALIWAL, 1996). Poppe e colaboradores (POPPE, B et al., 2006) avaliaram uma matriz de câmaras de ionização acoplada ao cabeçote do acelerador, a fim de realizar um controle da qualidade prétratamento e também durante as aplicações terapêuticas. McCurdy e colaboradores (MCCURDY et al., 2008) testaram o MatriXX da IBA acoplado no cabeçote do aparelho para realização do controle da qualidade em IMRT. Esta configuração apresentou-se bastante adequada por não apresentar dependência angular, e podendo ainda ser utilizada por vários campos em diversas angulações (KATHIRVEL et al., 2013) (HARDER, 2010) (NAKAGUCHI et al., 2012). Contudo, alguns pesquisadores descrevem que o MatriXX possuem limitações intrínsecas relativas a resolução espacial do dosímetro (GODART et al., 2011).

Recentemente, diversos autores vêm desenvolvendo dispositivos com possibilidades de serem colocados no cabeçote de equipamentos, a fim de realizar o controle da qualidade de transmissão (POPPE et al., 2006) (NAKAGUCHI et al., 2012) (KATHIRVEL et al., 2013) (POPPE et al., 2010) (MYERS et al., 2013) (NAKAGUCHI et al., 2012) (ISLAM et al., 
2009) (HARDER, 2010) (VENKATARAMAN et al., 2009). A principal vantagem de acoplar o dispositivo no cabeçote do acelerador linear é que o feixe fica sempre perpendicular a seu volume sensível e, desta forma, não apresenta variações na resposta em função do deslocamento angular do gantry. Outra vantagem importante é que, dependendo do detector, esta metodologia pode ser utilizada para avaliações in vivo (MYERS et al., 2013) (PAGE et al., 2013) (ISLAM et al., 2009) (VENKATARAMAN et al., 2009).

Uma das publicações mais recentes apresenta uma câmara de transmissão baseada no princípio do "multi-wire" ou "multi-strip", onde os fios são colocados entre duas janelas de policarbonato com espessura total de $1,4 \mathrm{~cm}$, submetidas a uma diferença de potencial de 400V. Durante a irradiação, diferentes comprimentos e pares de fios são expostos e os íons são coletados por um eletrômetro (ALMEIDA, 2012). Com um sistema semelhante, Page e colaboradores (PAGE et al., 2013) também realizaram testes para a avaliação in vivo, demostrando que a mesma pode ser conseguida através da colocação de um sistema de câmara usando um ultrafino Monolitic Active Pixel Sensor (MAPS). Com este objetivo, Amaral e colaboradores realizaram um trabalho inserindo segmentos de filme no cabeçote do acelerador linear a fim de avaliar exposições em tratamentos de radioterapia estereotáxica. Esses autores conseguiram formular uma metodologia para verificação in vivo apenas através da avaliação da densidade relativa dos segmentos de filme radiocrômico (AMARAL et al., 2012).

Apesar de diversos trabalhos estarem desenvolvendo dispositivos para avaliações dosimétricas de transmissão, nenhum estudo foi publicado até o momento descrevendo uma metodologia com filmes radiocrômicos acoplados na saída do feixe e, também, ainda não estão bem estabelecidas as avaliações in vivo para as técnicas complexas de tratamento radioterápicos. Desta forma, este trabalho vem contribuir para o desenvolvimento de uma metodologia de controle da qualidade de transmissão in vivo, utilizando filme radiocrômico, para aplicações radioterápicas nas técnicas de tratamentos conformacionais e de IMRT.

Os principais capítulos deste trabalho, Matérias e Métodos e Resultados e Discussões possuem três seções principais. A primeira, intitulada Estudo da metodologia em campos quadrados e de planejamento conformacional, apresenta o desenvolvimento da metodologia para campos simples, iniciando com campos quadrados, posteriormente, campo irregular e, por último, a avaliação de um tratamento conformacional. A segunda seção, Estudo da metodologia em campos de IMRT, apresenta a metodologia para a técnica de 
Intensidade Modulada do Feixe, mostrando a avaliação da metodologia em 25 situações, além da avaliação da reprodutibilidade e a comparação com outras metodologias de controle da qualidade convencionais. E a última, Avaliações dosimétricas in vivo, avalia a metodologia de transmissão in vivo para pacientes do serviço de radioterapia do Hospital das Clínicas da Faculdade de Medicina de Ribeirão Preto (HCFMRP).

No Capítulo 2, é apresentada a fundamentação teórica, abordando aspectos teóricos, físicos e clínicos importantes para o entendimento desta tese. Este capítulo é subdividido em Radioterapia, Sistema de Planejamento, IMRT, Controle da Qualidade em IMRT, Dosímetros e Avaliações in vivo.

Os materiais e métodos aplicados no desenvolvimento deste trabalho são descritos no Capítulo 3, onde são expostos os objetos simuladores empregados e os dosímetros, além das metodologias empregadas no desenvolvimento da técnica de controle da qualidade de transmissão.

Os dados envolvidos neste trabalho são apresentados, analisados e discutidos no Capítulo 4. Assim como no Capítulo 3, os resultados e discussões possuem três seções principais: Estudo da metodologia em campos quadrados e de planejamento conformacional; Estudo da metodologia em campos de IMRT e Avaliações dosimétricas in vivo.

No Capítulo 5, são apresentadas as conclusões, abordando os aspectos mais relevantes da metodologia empregada para o desenvolvimento do controle da qualidade de transmissão in vivo. 
Capítulo 2 - Fundamentação Teórica 


\section{FUNDAMENTAÇÃO TEÓRICA}

\subsection{Radioterapia}

A radiação ionizante possui o poder de lesar as estruturas biológicas e, com essa finalidade, a radioterapia a utiliza para danificar células cancerígenas, o que é alcançado através de diferentes técnicas, que podem ser aplicadas conforme a necessidade, dependendo da localização e do tipo da doença envolvida (OLDHAM, 2001).

A radioterapia divide-se em dois grandes grupos: teleterapia e braquiterapia. Em procedimentos teleterápicos, a fonte de radiação se encontra distante do paciente, enquanto que os tratamentos braquiterápicos são realizados próximo ou em contato com as lesões. $\mathrm{Na}$ teleterapia, existem diferentes técnicas importantes, entre as quais se destacam a radioterapia conformacional e o IMRT (KHAN, 2010).

\subsection{Sistema de planejamento}

O Sistema de Planejamento (TPS, do inglês Treatment Planning Systems) é uma ferramenta importante em radioterapia, o qual possibilita simular rapidamente as interações do feixe radioativo no organismo humano. A base de cálculo de um sistema de planejamento são as imagens radiológicas por ele recebidas. Os dados da imagem radiológica, geralmente produzida por tomografia computadorizada (TC), são usados em conjunto com uma descrição matemática que, através de um modelo anatômico detalhado do paciente, ilustra a distribuição de dose com elevado grau de exatidão (MARZI e LIAN, 2011).

Dependendo do modelo, o TPS constitui-se de algoritmos de cálculos de dose diferentes, cuja escolha deve levar em consideração a rapidez e a precisão. O cálculo da dose deve ser rápido o suficiente para viabilizar o planejamento do tratamento, contudo deve apresentar no mínimo uma precisão adequada para tornar confiável a correlação entre a dose planejada e a administrada (MARZI e LIAN, 2011). Entre os algoritmos de cálculo de dose mais usados estão o Pencil Beam, Superposition, Convolution e Monte Carlo. 
Para que o sistema de planejamento admita os dados do acelerador linear é necessário que o usuário transcreva os dados do comissionamento do LINAC para o TPS. Nos sistemas mais modernos, isto é realizado através da modelagem do feixe, na qual são modificados alguns parâmetros no sistema, a fim de que o feixe do TPS fique o mais próximo possível do feixe do acelerador linear, sendo que, nestes parâmetros, são definidos vários aspectos, como o espectro do acelerador e a penumbra do feixe. Em geral, a modelagem é realizada pelo usuário do sistema de planejamento e, por isso, sujeito a falhas e imprecisões, justificando, assim, testes sofisticados que garantam a precisão no cálculo da dose pelo TPS.

\subsection{IMRT}

Na IMRT, o planejamento é realizado de forma inversa no TPS, ao contrário das técnicas mais simples, como a conformacional, em que primeiro são colocados os pesos dos campos e depois se avalia a dose nas estruturas. Na IMRT, primeiro se colocam as doses que as estruturaras podem receber, como mostra a Figura 1, e o TPS verifica qual é a melhor configuração de pesos que os subcampos terão. A IMRT divide seu campo em diversos elementos matriciais de intensidades, onde cada retângulo da matriz é chamado de beamlets, como mostra a Figura 2. No processo de otimização, o sistema de planejamento tenta encontrar o mapa de intensidade ideal, variando a intensidade dos beamlets, a fim de encontrar o valor mínimo da função objetiva. Essa função leva em conta as doses que os alvos devem receber e o quanto os órgãos de risco são poupados. Assim, quanto mais próxima for a dose prevista para o alvo e quanto menor for a dose nos órgãos de risco, a função objetiva tende a diminuir e, devido a isto, o mapa de intensidade vai se aproximando do ideal. $\mathrm{Na}$ Figura 2, pode-se observar que a intensidade dos beamlets são menores no centro da imagem devido ao fato do órgão de risco estar na projeção do campo (ALMEIDA, 2012). 


\begin{tabular}{|c|c|c|c|c|c|c|c|c|}
\hline Structure & Type & Rank & objective & Dose (cGy) & Volune (\%) & Weight & Power & Status \\
\hline \multirow[t]{2}{*}{ PTV1 } & Target & 1 & Maximum & 7200 & 0 & 100 & 2.0 & On \\
\hline & & & Minimum & 7000 & 100 & 200 & 2.0 & On \\
\hline \multirow[t]{2}{*}{ AUXX2 } & OAR & 7 & Maximum & 4500 & 0 & 100 & 2.0 & on \\
\hline & & & Dose Volume & 3226 & 37 & 100 & 2.0 & on \\
\hline Femur dir & $\mathrm{OAR}$ & 2 & Maximuנn & 5000 & 0 & 100 & 2.0 & on \\
\hline Femur esq & OAR & 3 & & & & & & \\
\hline \multirow[t]{5}{*}{ reto } & $0 \mathrm{AR}$ & 2 & MaximuJ & 6722 & 0 & 100 & 2.0 & $0 \mathrm{n}$ \\
\hline & & & Dose Volume & 6036 & 7 & 100 & 2.0 & on \\
\hline & & & Dose Volume & 5432 & 17 & 100 & 2.0 & on \\
\hline & & & Dose volume & 4433 & 29 & 100 & 2.0 & on \\
\hline & & & Dose Volume & 3040 & 56 & 100 & 2.0 & on \\
\hline \multirow[t]{4}{*}{ bexiga } & $0 \mathrm{AR}$ & 2 & Maximưn & 7000 & 0 & 100 & 2.0 & On \\
\hline & & & Dose Volume & 6134 & 14 & 100 & 2.0 & on \\
\hline & & & Dose Volume & 5476 & 26 & 100 & 2.0 & on \\
\hline & & & Dose Volume & 4543 & 31 & 100 & 2.0 & on \\
\hline LOJA_PROSTATIC & $\mathrm{OAR}$ & 6 & & & & & & \\
\hline RETO_POST & OAR & 2 & Maximum & 4800 & 0 & 100 & 2.0 & on \\
\hline \multirow[t]{4}{*}{ ACESS } & OAR & 8 & Maximuנn & 6650 & 0 & 100 & 2.0 & On \\
\hline & & & Dose Volume & 5992 & 17 & 100 & 2.0 & on \\
\hline & & & Dose Volume & 4576 & 37 & 100 & 2.0 & on \\
\hline & & & Dose Volume & 3270 & 70 & 100 & 2.0 & on \\
\hline patient & $\mathrm{OAR}$ & 9 & & & & & & \\
\hline DK & CANCEL & & & & & & & \\
\hline
\end{tabular}

Figura 1 - Exemplo de restrições e objetivos usados no processo de otimização de um planejamento de IMRT

Além do processo de otimização, o TPS é responsável pela segmentação e transferência do mapa de intensidades ideal, ou mapa de fluência ideal, para um conjunto de segmentos que formam o campo final. Ou seja, quando é obtido o processo de otimização, gerando uma matriz de beamlets ideais, ainda não se alcançou a fase final, pois é necessário passar pelo processo de segmentação para que a fluência ideal se transforme em vários segmentos e, assim, o conjunto formado por esses segmentos forme o campo de tratamento. Nesta fase, é natural que as curvas de isodose e as doses nos órgãos se modifiquem, tendo em vista que, inicialmente, o TPS exibe o mapa de dose ideal e só após a segmentação disponibiliza o mapa de dose real. 


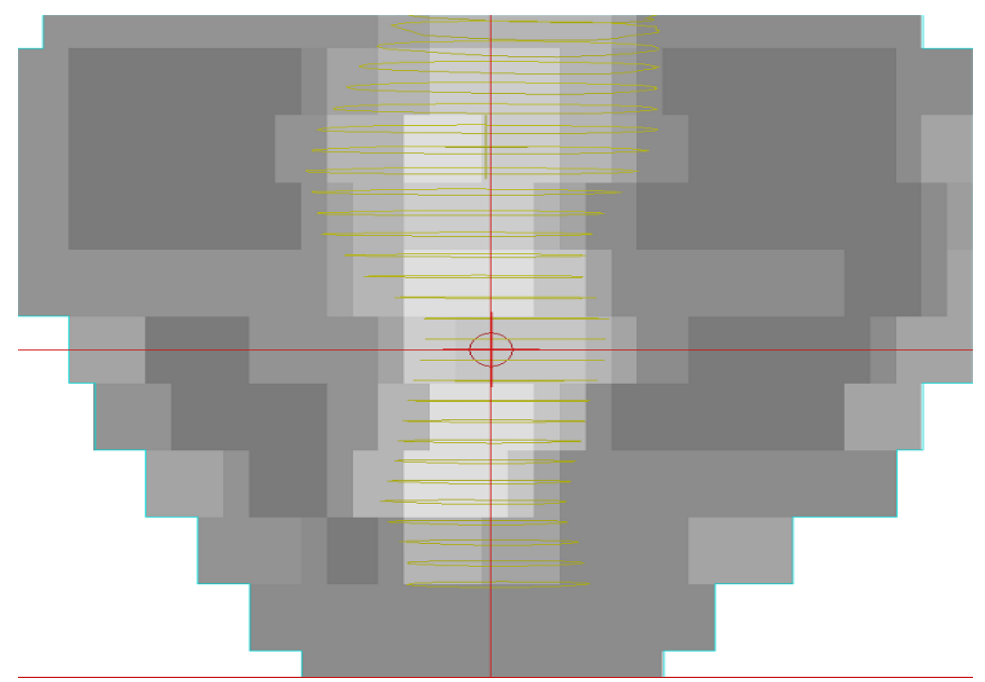

Figura 2- Mapa de fluência de um campo de IMRT

A Figura 3 possui três campos de tratamento em IMRT. Observa-se que todos os campos possuem uma intensidade menor quando estão projetados para o órgão que necessita proteger, ou órgão de risco (OR), e também mostra que a intensidade é maior quando a projeção do campo tem apenas o volume alvo do planejamento (PTV, do inglês Planning Target Volume). Como cada campo pode ter intensidades diferentes, esta técnica pode aumentar a dose na região do tratamento e diminuí-la nos órgãos de risco, órgãos sadios que, por isso, devem ser preservados.

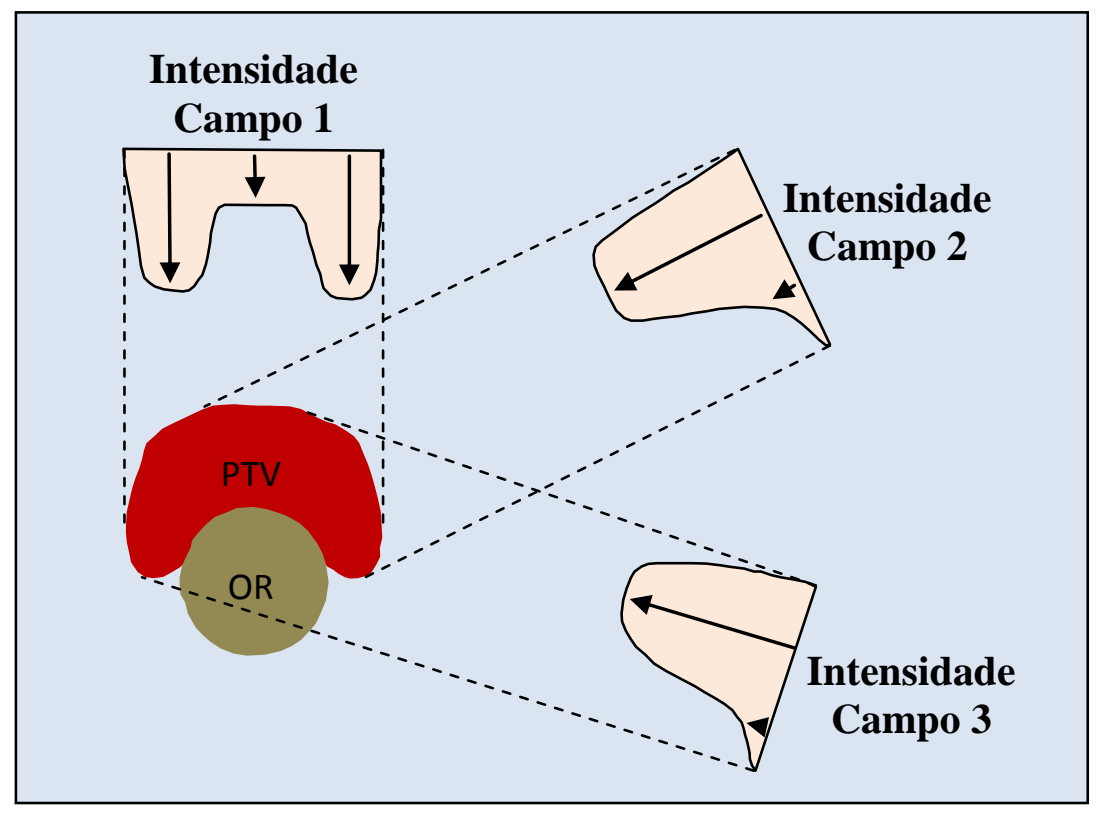

Figura 3 - Exemplo das intensidades variáveis em campos de IMRT 
Uma característica importante na técnica de IMRT é que, em geral, podem-se encontrar curvas de isodose côncavas, como mostra a Figura 4, as quais são importantes para reduzir a dose nos órgão de risco.

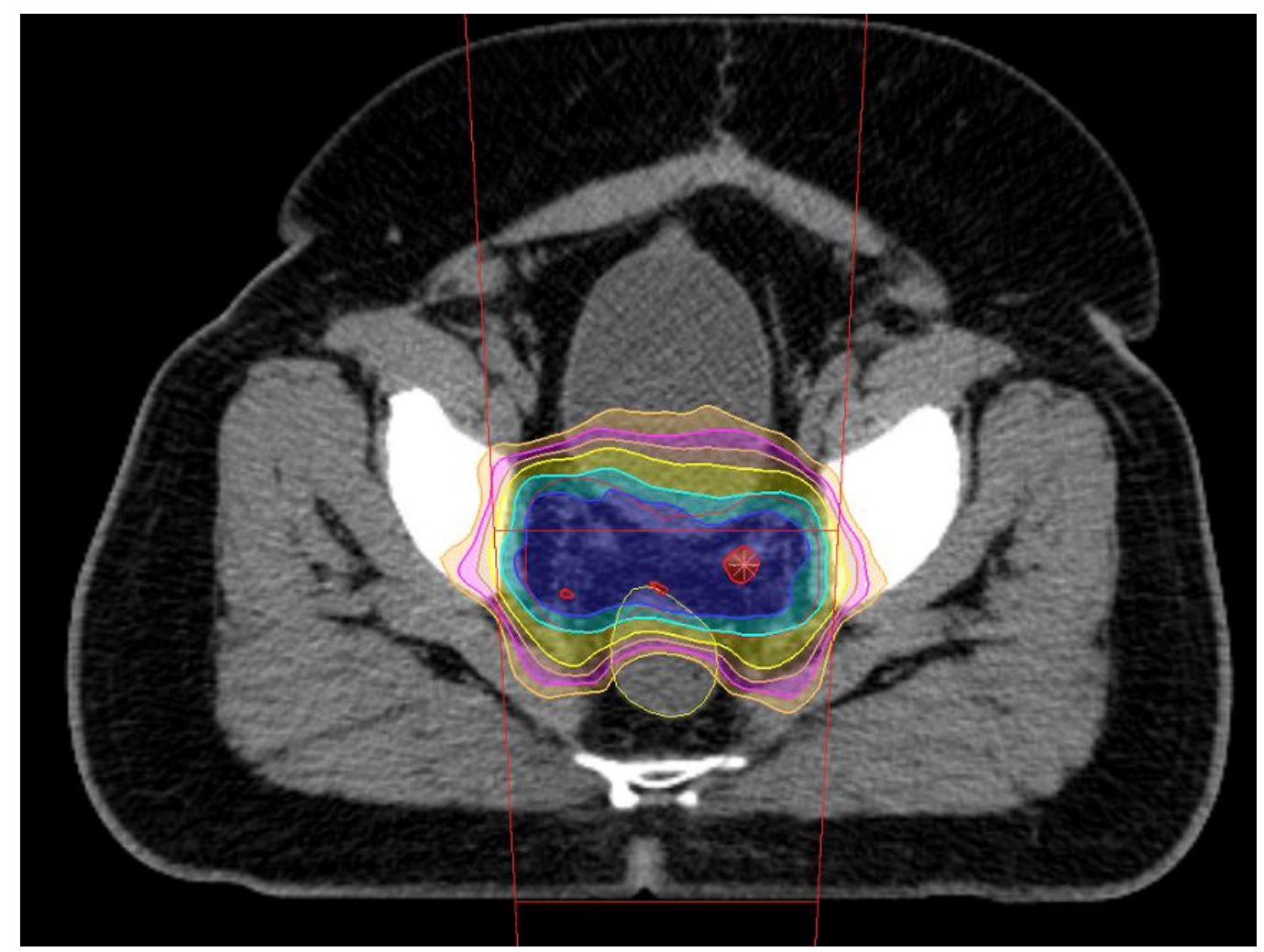

Figura 4 - Curva de isodose côncava em um caso de IMRT para diminuir a dose no reto

Como os campos de tratamento são bastante complexos na IMRT, eles não devem ser passados manualmente para o acelerador e sim a partir de um sistema de registro e verificação $(\mathrm{S} \& \mathrm{~V})$. O S\&V é utilizado para receber os dados do planejamento calculado no TPS, via DICOM RT (do inglês Digital Imaging and Communications in Medicine in Radiotherapy), mas a principal função do $\mathrm{S} \& \mathrm{~V}$ é importar os dados do planejamento para o LINAC e verificar, no momento do tratamento, se o acelerador está nas mesmas configurações planejadas. Nesta verificação, o S\&V só libera o tratamento se o LINAC estiver de acordo com o planejado. Porém, mesmo com o sistema de registro e verificação, existe a possibilidade do cálculo realizado pelo TPS, ou algum outro sistema do LINAC, não estar 
devidamente calibrado e, devido a isto, o sistema de registro e verificação pode não detectar a inconsistência (POLEDNIK et al., 2007).

\subsection{Controle da qualidade em IMRT}

Para evitar erros e acidentes, diversos órgãos recomendam um controle da qualidade individual pré-tratamento (HARDING e GOMEZ, 2006)(EZZELL et al., 2003). Assim, para realizar esse controle, transfere-se o planejamento do paciente para um objeto simulador e avalia-se se a liberação da dose no acelerador está compatível com a planejada. Estes testes fazem parte de um programa de controle da qualidade e dosimetria (FURNARI, 2009). Desta forma, o programa requer que a unidade esteja em conformidade com as recomendações do fabricante e as tolerâncias especificadas nos requisitos clínicos aplicáveis. A aplicação dos testes mais importantes garante o perfeito alinhamento do feixe, como também uma maior precisão na aplicação da dose, alcançando-se, assim, uma correta irradiação dos tecidos alvos. A distribuição bidimensional da dose também deve ser verificada através da análise da função gama entre os dados coletados no aparelho e os dados oferecidos pelo sistema de planejamento (HARDING e GOMEZ, 2006) (FURNARI, 2009) (ALMEIDA, 2012).

\subsubsection{Função gama}

A função gama é um índice que compara diferenças da distância e da dose a partir de critérios de aceitação predefinidos pelo usuário. Os critérios usados são a variação da porcentagem máxima da dose $\left(\Delta \%_{\max }\right)$ e a distância de concordância da distribuição de dose, chamada em inglês de DTA (distance-to-agreement). A DTA é a maior variação da distância $(\Delta \mathrm{D})$ apresentada na elipse da Figura 5. Quando é necessário comparar duas distribuições de dose, a função gama checa cada ponto da primeira com todos os outros pontos da segunda distribuição e analisa se cada um desses pontos está de acordo com os critérios determinados pelo usuário. Estes critérios são representados pela elipse na Figura 5; se um ponto da primeira curva encontrar algum ponto da segunda, estando o $\Delta \%$ e o $\Delta \mathrm{D}$ dentro dos critérios, ou seja, dentro da elipse mencionada, então o índice gama é considerado aceitável e seu valor 
será menor que 1; caso contrário, não será aceito e seu valor será maior que 1 (LOW et al., 1998). O cálculo da função gama ou índice gama é dado pela equação presente na Figura 5.

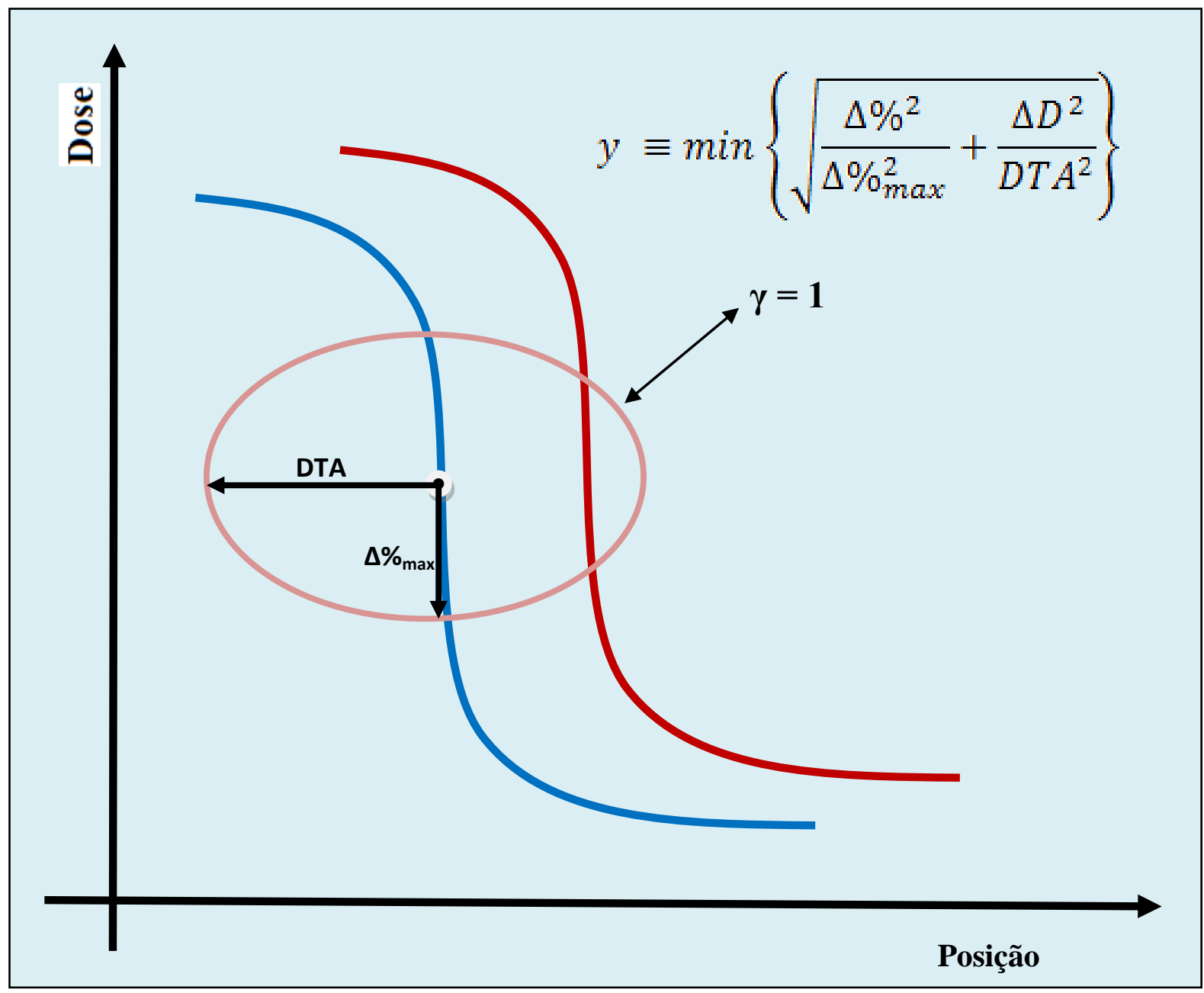

Figura 5 - Ilustração do conceito da função gama. A curva azul representa a distribuição da dose de referência e a vermelha, a DD analisada

A função gama pode ter uma avaliação absoluta, quando se avalia a dose de cada distribuição, ou relativa, quando se dividem todas as doses das distribuições por um valor de dose determinada por uma coordenada de referência, geralmente chamada de ponto de normalização. Assim, quando a avaliação é relativa, todos os valores de dose das distribuições são divididos pelo valor da dose encontrado pelo ponto de normalização. Outro conceito importante é o valor de corte ou threshold, valor este que determina qual é o intervalo de dose que a função gama avaliará. Abaixo desse valor não é aplicada a função gama e, assim, os 
pontos da distribuição de dose que estão fora do valor de corte não serão considerados na porcentagem de pontos aprovados ou reprovados na função gama.

\subsection{Dosímetros}

Dosímetros são dispositivos capazes de fornecer uma leitura que permite determinar a dose, quando seu volume sensível recebe uma radiação ionizante. Logo, para assegurar o rigor dos testes de controle da qualidade é importante ter um conjunto de dosímetros para se adequar e permitir a necessária avaliação dosimétrica em cada situação (BANCI BUONAMICI et al., 2007) (ALMEIDA, 2012). Câmara de ionização, filmes dosimétricos e matriz bidimensional de detectores são alguns dos mais usados para controle da qualidade, especialmente em IMRT.

A câmara de ionização é um detector capaz de coletar, em seu volume sensível, os íons gerados por uma radiação ionizante. Estes íons coletados no volume sensível da câmara são transferidos para um eletrômetro que quantifica este sinal. O sistema dosimétrico é o conjunto formado pela câmara de ionização e o eletrômetro. Este sistema é um dos mais usados para determinação de dose com precisão exigida nas aplicações radioterápicas e, devido a isto, é amplamente utilizado como instrumento padrão internacional (ALMEIDA, 2012).

Existem vários tipos de câmara de ionização, as quais dependem do fabricante, do modelo e, principalmente, do seu volume sensível. A produção de íons depende diretamente do volume sensível da câmara; quanto maior o volume, maior será o sinal produzido. Porém, a resolução espacial diminui com o aumento do volume; quanto menor o volume sensível, menor será o sinal. Logo, a câmara de ionização é um ótimo instrumento para se determinar a dose em condições de referência, mas o baixo sinal pode ser um fator limitante para câmaras com volume reduzido (PAPPAS et al., 2008). Uma alternativa é usar os filmes dosimétrico pois possui alta resolução espacial. 


\subsubsection{Filmes dosimétricos}

Os filmes dosimétricos convencionais são muitas vezes usados para avaliações dosimétricas, pois possuem alta resolução espacial, favorecendo, com isto, estudos em duas dimensões (BUCCIOLINI, BANCI BUONAMICI e CASATI, 2004). O filme dosimétrico convencional é formado basicamente de duas partes: a base e a emulsão. A base é responsável por proporcionar uma estrutura rígida para que a emulsão possa ser fixada. A emulsão é uma mistura de gelatina e cristais de haleto de prata que a radiação ao interagir possibilita a transferência da informação (BUSHONG SC, 2008).

A radiação que incide sobre o filme convencional deposita energia, primeiramente, na emulsão nos átomos dos cristais de haleto de prata, responsável pela formação da imagem latente. Esta imagem não é visível porque corresponde a uma mudança microscópica nos cristais de haleto de prata. Com um processamento químico próprio, ou seja, com a revelação do filme, a imagem latente é convertida em imagem visível (BUSHONG SC, 2008).

\subsubsection{Filmes radiocrômicos}

Nos filmes convencionais o controle dosimétrico pode ser prejudicado por uma contaminação química ou por uma variação indesejada da temperatura no momento da revelação. Esta situação pode ser contornada utilizando os filmes radiocrômicos modernos, pelo fato deste filme não precisar de processamento químico para visualização da imagem. Os filmes radiocrômicos possuem um polímero em seu volume sensível que altera sua coloração quando é submetido a um feixe de radiação, sem a necessidade de qualquer processo de revelação (BUSHONG SC, 2008).

Os filmes radiocrômicos modernos, como o EBT2 e o EBT3, da empresa International Specialty Products (ISP), possuem número atômico efetivo equivalente ao da água ( $Z$ variando de 6 a 6,5), sua densidade ótica praticamente estabiliza-se em torno de 24 horas após a irradiação, sua dependência energética é menor que a dos filmes convencionais (CHEUNG, BUTSON e YU, 2006), são quase insensíveis à luz visível, mas necessitam ficar em lugar escuro, além do que a temperatura deve ser controlada, pois apresentam sensibilidade à alta temperatura, como também à radiação ultravioleta. Por esta razão, esse tipo de filme não deve 
permanecer muito tempo exposto à luz fluorescente, nem deve ser exposto ao sol (GIRARD, BOUCHARD e LACROIX, 2012) (EBONGUE et al., 2012) (SOARES, 2006). Outra preocupação com filmes com emulsão EBT (BUTSON, CHEUNG e YU, 2006) relaciona-se à sua digitalização, pois ele tem dependência direcional na digitalização; desta forma ele deve sempre ser digitalizado na mesma direção, a fim de propiciar melhor resultado nas atividades dosimétricas (DESROCHES, BOUCHARD e LACROIX, 2010) (ALNAWAF et al., 2010). Alguns pesquisadores descrevem que o filme radiocrômico Gafchromic EBT3 possui menos dependência direcional que seus antecessores (REINHARDT et al., 2012)(CASANOVA BORCA et al., 2013)(MOYLAN, ALAND e KAIRN, 2013).

Os filmes radiocrômicos com emulsão EBT2 foram avaliados na verificação de dose para as diversas técnicas de radioterapia. Zeidan (2006) concluiu que existem diversas características favoráveis que permitem sua utilização na rotina de controle da qualidade em IMRT (ZEIDAN et al., 2006). Wilcox e Daskalov (2007) avaliaram o filme Gafchromic EBT para dosimetria e caracterização da radiocirurgia por CyberKnife ${ }^{\circledR}$, como também avaliaram as características peculiares de campos pequenos e altos gradientes de dose, comparando os resultados com outros dosímetros (diodo e câmaras de ionização) e concluíram que, para campos maiores que $10 \mathrm{~mm}$, o filme Gafchromic produz medidas semelhantes aos outros dosímetros. Porém, para campos menores que $10 \mathrm{~mm}$, houve grande perda de sensibilidade na dose medida pela câmara de ionização e pelo diodo, devido principalmente ao equilíbrio eletrônico lateral e ao alcance máximo dos elétrons secundários, descrevendo assim que o filme é um dosímetro mais adequado para campos pequenos e, por isso, mais apropriados para os segmentos dos campos de IMRT. Os mesmos autores investigaram, em outro estudo, a precisão das medidas de dose e fizeram comparação dos cálculos por Monte Carlo dentro e fora de tecidos heterogêneos com 6 campos de fótons de dimensões menores que $4 \mathrm{~cm}$ em radiocirurgia por CyberKnife ${ }^{\circledR}$. Concluíram que o filme Gafchromic EBT é um dosímetro adequado para medir a dose em materiais heterogêneos e campos reduzidos (WILCOX e DASKALOV, 2007)(WILCOX e DASKALOV, 2008)(BANCI BUONAMICI et al., 2007).

\subsubsection{Matrizes bidimensionais de detectores}

Nos tratamentos pela técnica de IMRT, as doses liberadas para cada campo são bastante heterogêneas; desta forma, a avaliação mais completa da distribuição de dose não 
deve ser realizada pontualmente com apenas um detector, mas sim em duas dimensões. Estes detectores podem ser os filmes ou os chamados arrays, os quais são matrizes de detectores compostos por câmaras de ionização ou diodos, que possuem a capacidade de avaliar os diversos pontos de dose simultaneamente (HARDING e GOMEZ, 2006)(EZZELL et al., 2003)(ALMEIDA, 2012)(FURNARI, 2009).

Existem vários tipos de detectores bidimensionais, variando o número de detectores, os espaçamentos entre eles, suas dimensões e, principalmente, o tipo de detector.

Apesar das matrizes bidimensionais de detectores serem muito convenientes para uso clínico, pela praticidade do manuseio, sua principal restrição está relacionada à resolução espacial, pois as técnicas de IMRT podem possuir gradientes de dose muito intensos e, devido à separação entre os detectores e suas dimensões, as medidas podem ficar prejudicadas (GODART et al., 2011) (POPPE, BJOERN et al., 2006). Poppe e colaboradores (2007) e outros autores comentam esta situação e descrevem que as convoluções nos mapas de dose do TPS podem melhorar os índices gama nas avaliações com matrizes bidimensionais, especialmente para o MatriXX (IBA, Dosimetry) (KATHIRVEL et al., 2013)(POPPE et al., 2007).

O sistema MatriXX é formado por 1020 câmaras de ionização aberta, com área ativa de $24 \mathrm{~cm}$ x $24 \mathrm{~cm}$, associada a um sistema de leitura paralelo de todas as câmaras, com tempo morto desprezível. Este sistema opera com o auxílio de um software OmniPro I'mrt (IBA, Dosimetry), útil para verificações dosimétricas com índice gama (ALMEIDA, 2012)(HERZEN et al., 2007).

\subsection{Avaliações in vivo}

A comunidade científica, especialmente em radioterapia, vem discutindo sobre a necessidade de métodos mais eficazes de controle da qualidade, tendo em vista que diversos acidentes foram relatados tanto em artigos científicos quanto na imprensa pública. Vários países estão desenvolvendo normas para minimizar a ocorrência desses efeitos e as principais recomendações dessas publicações descrevem as avaliações in vivo como uma das principais práticas para reduzir a ocorrência de incidentes (WILLIAMS, 2007)(COSSET e GOURMELON, 2002)(BAUS et al., 2012). 
As avaliações in vivo têm como propósito verificar se a dose foi entregue na localização e com intensidade correta no momento da terapêutica. A dosimetria de referência no equipamento deve ser realizada periodicamente, para garantir com precisão a liberação da radiação pelo aparelho, mas não garante que o sistema de planejamento calcule a dose adequadamente. Desta forma, uma dosimetria individual antes do tratamento é fundamental para confirmar o processo do planejamento. Por outro lado, isso ainda não é suficiente para garantir a correta liberação da dose no momento da terapêutica. Logo, é de fundamental importância que seja realizada uma avaliação dosimétrica no momento do tratamento, a qual é chamada de dosimetria in vivo ou avaliação dosimétrica in vivo (COSTA et al., 2010)(CIOCCA et al., 2003)(MIJNHEER, 2008)(DULIU, 2012).

A avaliação in vivo, utilizando a técnica de IMRT, ainda não é uma rotina na maioria dos centros, porém alguns estudos comprovam que sua utilização é fundamental para evitar erros e acidentes (MANS et al., 2010). Existem alguns tipos de sistemas dosimétricos capazes de realizar dosimetrias in vivo com detectores pontuais, tais como diodos, detectores termoluminescentes (TLD, do inglês Thermoluminescent dosimeter) e os MOSFET (do inglês Metal Oxide Semiconductor Field Effect Transistor); estes são alguns dos dosímetros mais populares. Apesar da grande utilidade para verificação in vivo, nas técnicas convencionais, como a radioterapia conformacional, esses dosímetros não são eficientes para avaliação em técnicas mais complexas e avançadas, como a IMRT, pois os campos presentes nestas técnicas apresentam gradientes de dose elevados (MIJNHEER, 2008). Por este motivo, outras metodologias devem ser exploradas para verificar a entrega do tratamento em duas ou três dimensões, tais como a utilização dos sistemas de imagem portal (EPID), ou técnicas de avaliação in vivo de transmissão.

As técnicas mais usadas atualmente para verificação in vivo utilizam EPID (MANS et al., 2010)(MIJNHEER, 2008). Os EPID são matrizes bidimensionais de detectores presentes em alguns aceleradores lineares para verificação de filmes portais a fim de verificar o posicionamento do isocentro no paciente (ENGSTRÖM et al., 2005). Seus detectores são geralmente formados de silício amorfos, que transformam o sinal digital em imagem visível. Os EPIDs foram construídos para formação de imagem. Logo, para utilização em dosimetria e controle da qualidade, eles necessitam muitas correções e softwares específicos para transformar o sinal digital em dose (ZIJTVELD, VAN et al., 2009)(BARBI et al., 2012). Depois de transformar o sinal em dose deve ser realizada uma comparação entre os resultados determinados e os adquiridos pelo sistema de planejamento a partir da função gama. 
Recentemente alguns pesquisadores estão desenvolvendo técnicas de avaliação in vivo de transmissão, esta metodologia é importante porque não existe limitação com relação ao deslocamento angular do gantry. Nessas técnicas, o dosímetro fica acoplado ao cabeçote do LINAC, geralmente na região da bandeja de proteção, entre o alvo e o paciente. As avaliações de transmissão possuem a desvantagem de absorver parte da radiação, além de não avaliar o posicionamento dos pacientes, contudo podem ser usadas em qualquer LINAC, além de não apresentarem limitação na dimensão máxima do campo, como acontece nos EPIDs. 
Capítulo 3 - Materiais e Métodos 


\section{MATERIAIS E MÉTODOS}

\subsection{Parâmetros gerais da metodologia proposta}

A metodologia de controle da qualidade transmissão desenvolvida neste trabalho baseia-se na obtenção da distribuição de dose in vivo, com um filme radiocrômico Gafchromic EBT2 (ISP Corporation, Wayne, NJ) posicionado em um suporte acrílico, semelhante a uma bandeja para fixação de blocos (Figura 6 - A), acoplado ao acessório holder do LINAC, Oncor Impression (Siemens/Germany) (Figura 6 - B), durante todos os campos de irradiação do tratamento avaliado.
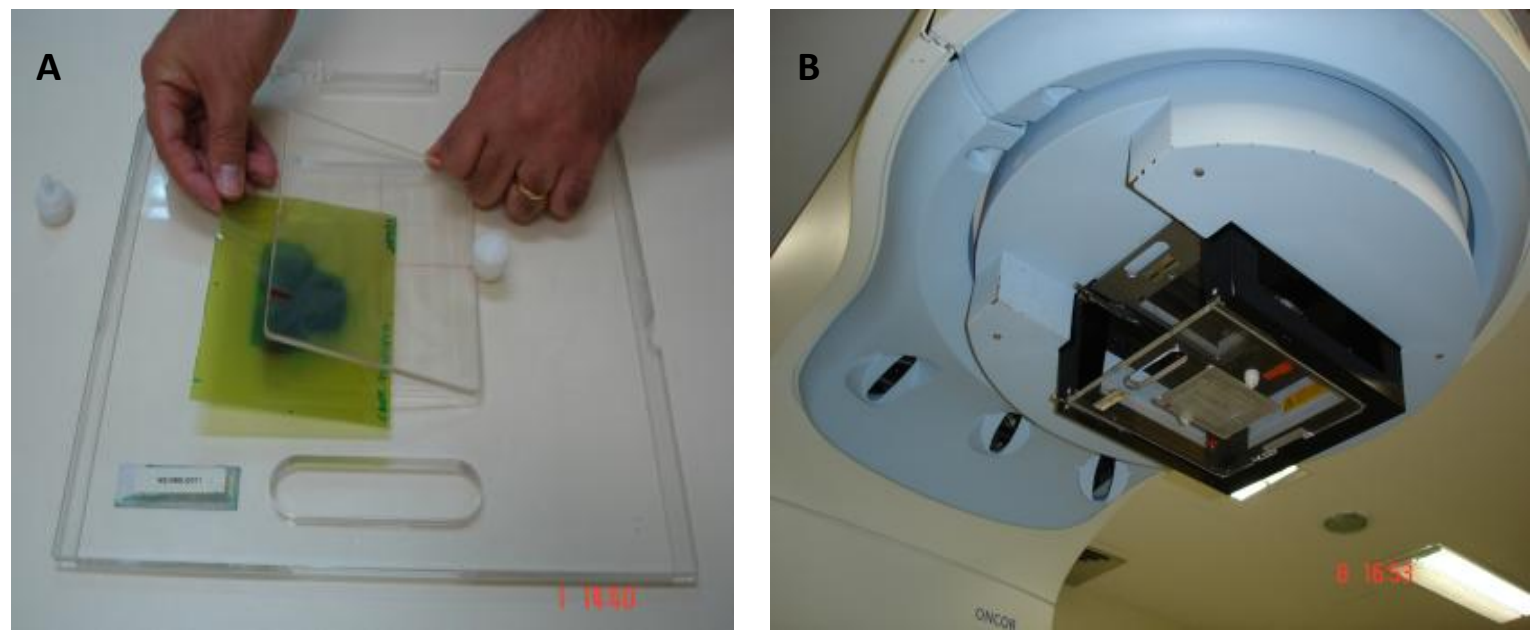

Figura 6 - (A) Imagem do suporte acrílico confeccionado para avaliação dosimétrica de transmissão. (B) Suporte acrílico acoplado ao cabeçote do LINAC 
A distribuição de dose no filme é obtida pela aplicação de uma calibração aos valores de pixel da imagem digitalizada do filme irradiado nesta geometria. Posteriormente, é realizada uma análise gama para comparar a distribuição de dose medida com a DD esperada pelo sistema de planejamento XiO (versão 3.62, Elekta), que equivale à distribuição de dose do plano coronal e central de um objeto simulador, com dimensões semelhantes ao suporte usado na irradiação, obtida pela transferência do plano em questão (Figura 7 - A), com todos os campos posicionados com gantry na vertical, ou seja, direcionados perpendicularmente à imagem tomográfica do objeto simulador (Figura 7 B).

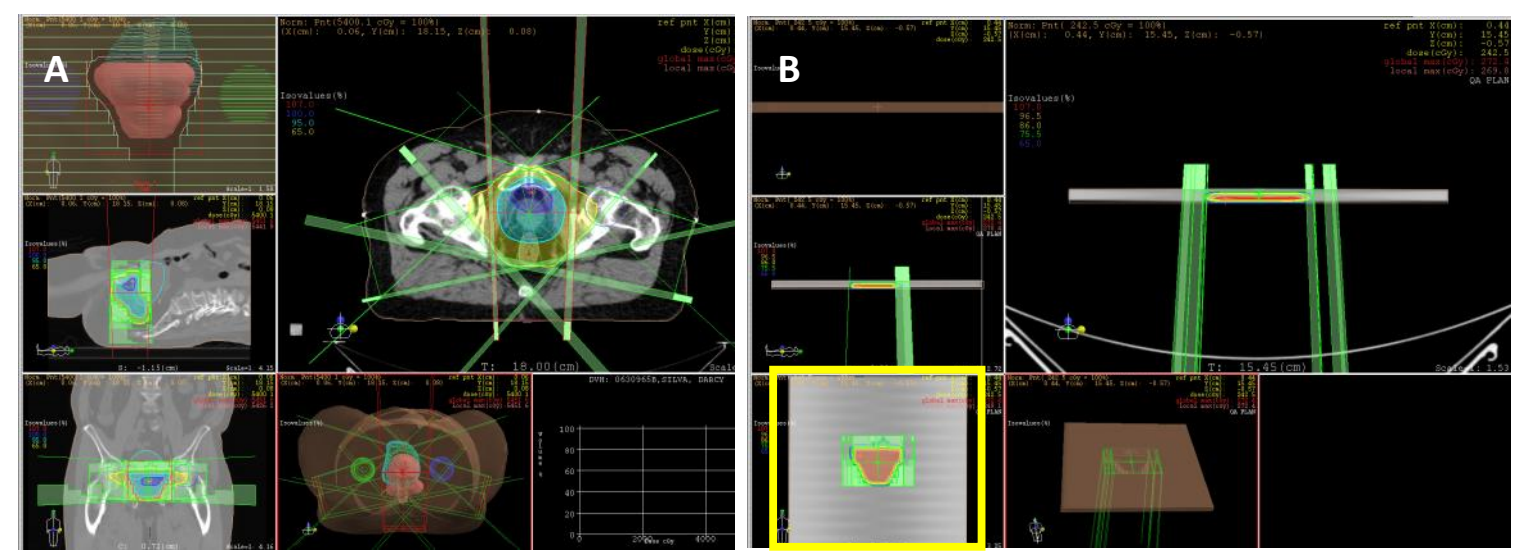

Figura 7 - (A) imagem do planejamento no TPS. (B) configuração da distribuição de dose calculada pelo TPS no objeto simulador com dimensões semelhantes ao suporte acrílico, no quadro amarelo pode-se observar a distribuição calculada no plano coronal 
Na Figura 8 - A pode-se observar o suporte acrílico confeccionado neste trabalho para posicionar o filme no acessório holder do acelerador linear. Nota-se que o filme fica no centro do suporte, a uma profundidade de $0,5 \mathrm{~cm}$. Na Figura $8-\mathrm{C}$ observa-se o suporte acrílico acoplado ao acessório holder do acelerador linear. Na imagem da Figura 8 - D, pode-se analisar a função gama entre a distribuição de dose gerada no plano coronal, no centro do objeto simulador, no TPS, com a imagem digitalizada e calibrada do filme irradiado no acessório holder do acelerador linear. A Figura 8 - E apresenta a imagem, do TPS, de um planejamento de próstata com 5 campos, enquanto que a imagem F mostra, no TPS, o resultado do cálculo da distribuição da dose formado pelos campos do planejamento, perpendiculares ao objeto simulador de $1 \mathrm{~cm}$ de espessura. Na região inferior esquerda da Figura 8 - F pode-se observar a distribuição da dose no plano coronal do objeto simulador.
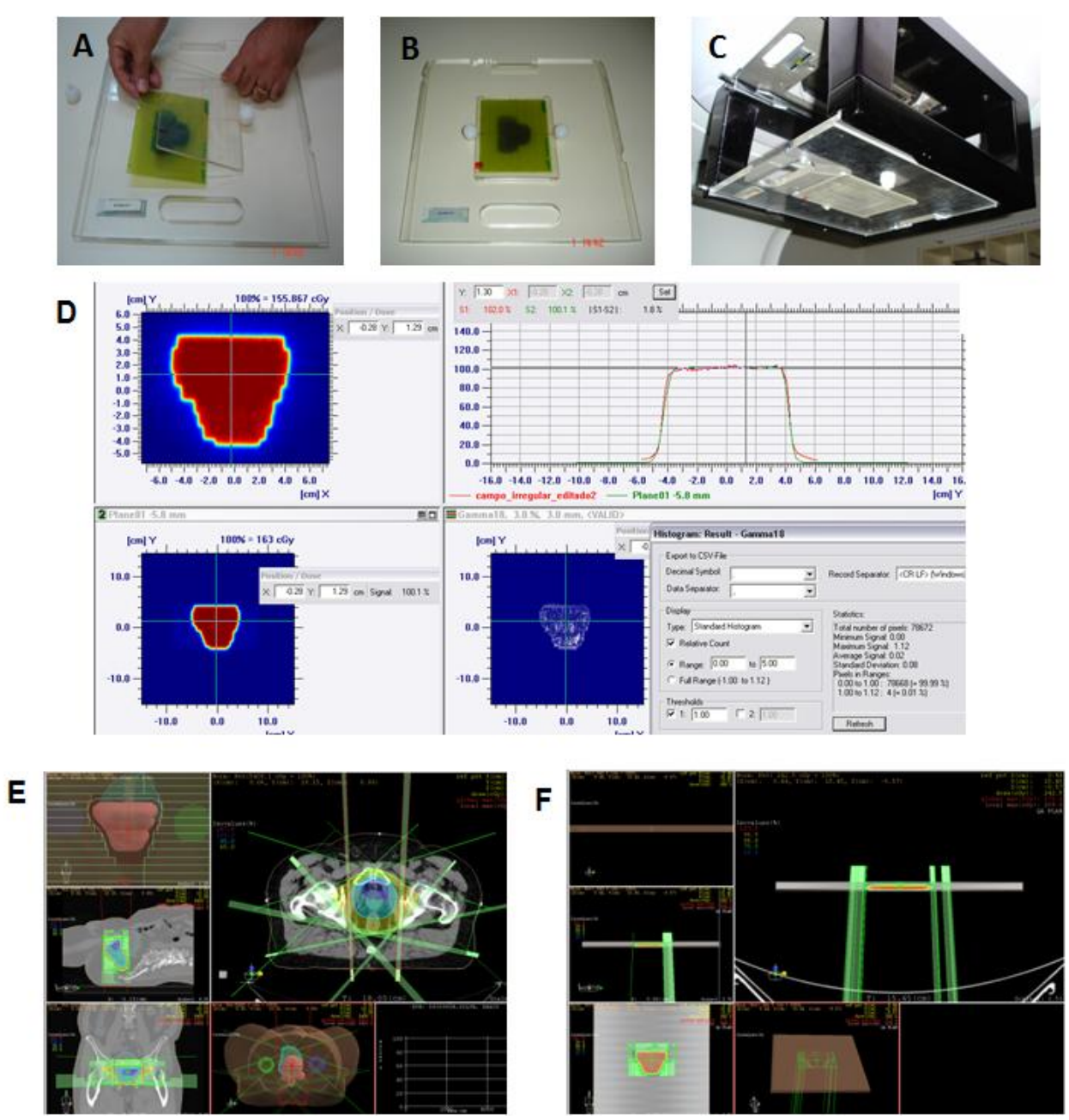

Figura 8 - (A) Suporte acrílico confeccionado neste trabalho para posicionar o filme no acessório holder do acelerador linear. (B) Suporte acrílico com filme posicionado no centro. (C) Suporte acrílico acoplado ao acessório holder do acelerador linear. (E) Imagem da função gama (F) Imagem, do TPS, de um planejamento de próstata com 5 campos. (G) Imagem, no TPS, do cálculo da distribuição da dose formado pelos campos do planejamento. 


\subsubsection{Suporte acrílico e fator de transmissão}

O suporte acrílico desenvolvido neste trabalho (Figura $6-\mathrm{A}, \mathrm{B}$ ) possui em seu centro um soquete de $20 \mathrm{~cm}$ x $15 \mathrm{~cm}$ x $0,5 \mathrm{~cm}$ para colocação do filme, que fica coberto por uma placa de acrílico com dimensões iguais ao soquete, ambos presos por dois parafusos, para impedir sua queda com o deslocamento angular do gantry. A transmissão do suporte foi medida pelo MatriXX Evolution (IBA Dosimetry) na distância de $100 \mathrm{~cm}$, usando $10 \mathrm{~cm}$ de água sólida sobre o dosímetro e $5 \mathrm{~cm}$ abaixo dele para garantir o retroespalhamento. $\mathrm{O}$ fator de transmissão foi encontrado dividindo-se o valor da dose média sem o suporte acrílico com o valor da dose média com o suporte acrílico.

\subsubsection{Metodologia da calibração}

As calibrações usadas na metodologia proposta por esse trabalho foram realizadas irradiando os filmes radiocrômicos, no suporte acrílico, acoplado ao acessório holder do LINAC na distância foco detector (DFD) de 56,8 cm, no campo $10 \mathrm{~cm}$ x $10 \mathrm{~cm}$. Os filmes foram digitalizados, após 24 horas da irradiação, no escâner Vidar Diagnostic Pro Advantage com resolução de 75 dpi e 12 bit, os resultados dos valores de pixel obtidos foram associados com as respectivas doses absorvidas para formar a calibração. As doses absorvidas foram obtidas em uma simulação no TPS no meio da imagem tomográfica do objeto simulador composto por acrílico, com dimensões semelhantes ao suporte acrílico, a uma DFD de $100 \mathrm{~cm}$ para as mesmas unidades monitoras (UM) e dimensão de campo usada nas irradiações. Então, as calibrações foram realizadas agrupando-se os valores de pixel dos filmes digitalizados com os valores de dose adquiridos com o cálculo realizado pelo TPS com as mesmas UM que os filmes foram irradiados, como mostra a Figura 9. 


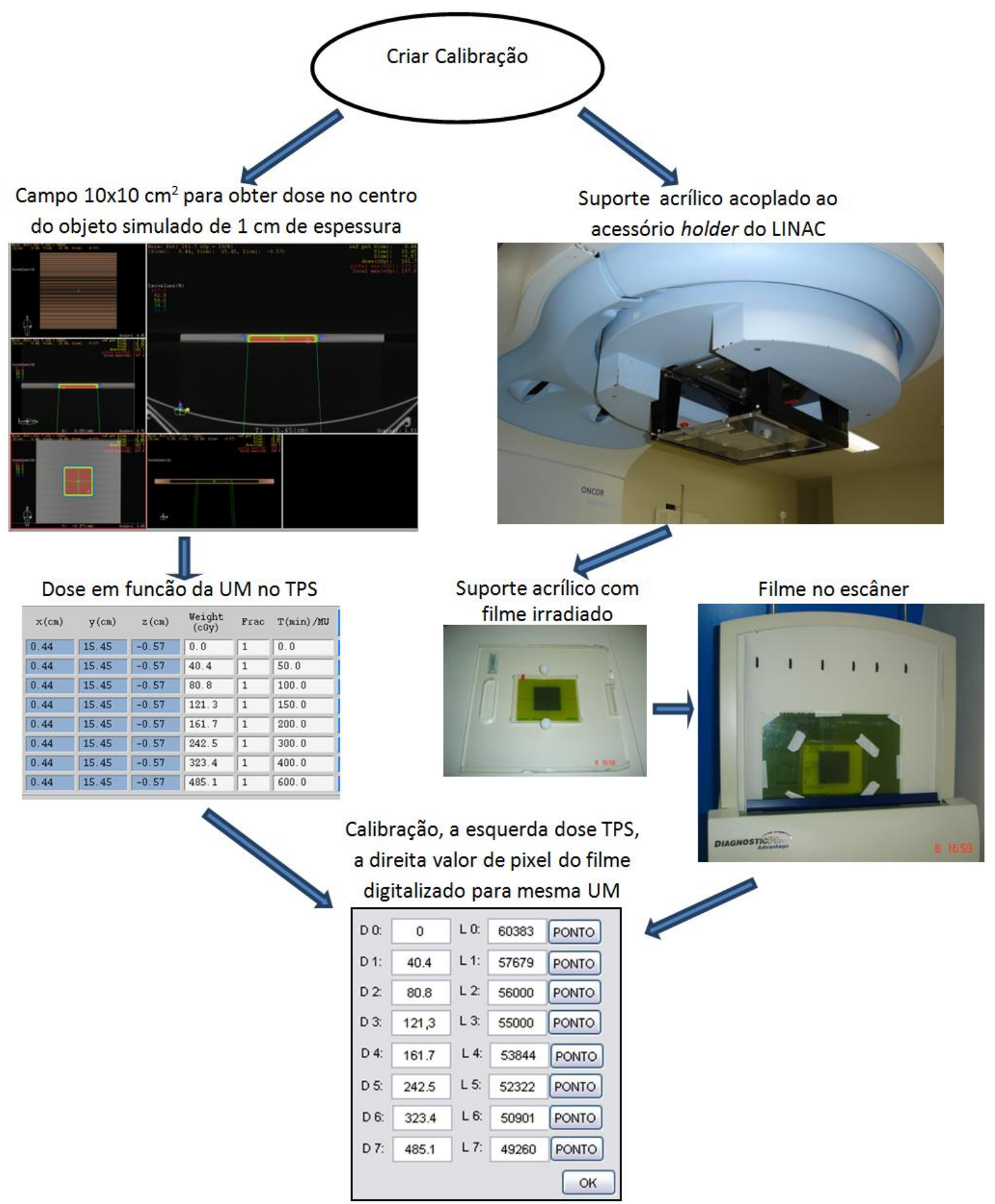

Figura 9 - Esquema da calibração descrita na metodologia de controle da qualidade com filme no suporte acrílico. À esquerda configuração utilizada para adquirir a dose calculada pelo TPS. À direita configuração realizada para encontrar os valores de pixel das imagens digitalizadas dos filmes irradiados no suporte acrílico indexado ao acessório holder do LINAC. Na região inferior, a associação da dose calculada pelo TPS e os valores de pixel encontrados na irradiação do filme com as mesmas UM 


\subsubsection{Metodologia da digitalização dos filmes}

Diversos autores descrevem dificuldades em digitalizar filmes radiocrômicos, a depender da posição do filme, do canal e, principalmente, das especificidades dos diversos escâneres (LOW et al., 2011)(DEVIC, 2011)(GIRARD, BOUCHARD e LACROIX, 2012)(CRIJNS et al., 2013). Esta seção descreve a metodologia e o estudo sobre digitalização utilizada neste trabalho, tendo em vista que o escâner utilizado possui algumas peculiaridades, que serão discutidas no capitulo Resultados e Discussões. Os filmes foram manipulados com luvas para evitar marcas das mãos no mesmo, assim como houve cuidado nas marcações de referência, a fim de fazer a irradiação e sua leitura na mesma orientação, como mostra o retângulo amarelo na Figura 10. O cuidado com o tempo mínimo de 24 horas entre a exposição e a digitalização também foi obedecido. Os filmes ficaram armazenados com temperatura e iluminação controladas, a fim de não prejudicar o controle dosimétrico.

Tendo em vista que o objetivo principal deste trabalho é comparar imagens digitalizadas e calibradas de filmes radiocrômicos com matrizes de dose geradas pelo TPS, através da função gama, foram realizadas algumas digitalizações em posições diferentes, para serem comparadas com os dados do TPS.

A primeira digitalização do estudo foi realizada na posição "0”, sem nenhuma película de apoio, sem nenhum filme de apoio, mas na pré-digitalização foi realizada uma definição de área como mostra o retângulo vermelho à direita da Figura 10.

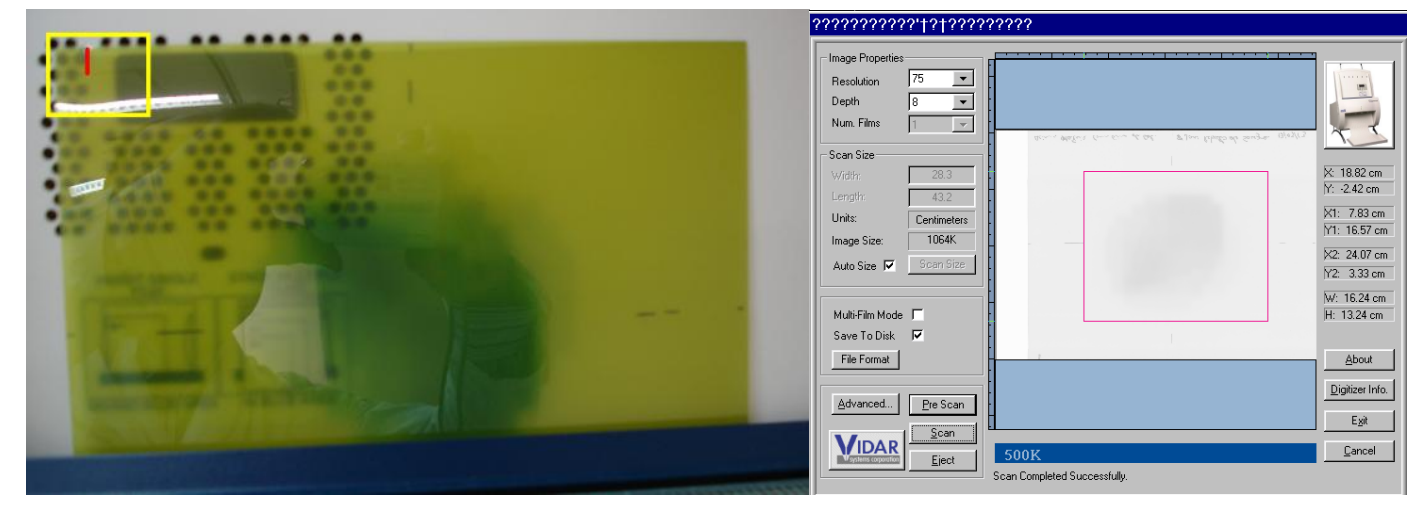

Figura 10 - À esquerda, o filme posicionado na posição "0". À direita, retângulo vermelho representando definição de área 
A segunda digitalização foi realizada da mesma forma que a primeira, mas na prédigitalização não houve uma definição de área, ou seja, o filme foi completamente digitalizado.

A terceira digitalização foi realizada na posição "0", sem película, com definição de área e com filme de apoio que esta representado pela moldura mais escura na Figura 11. O filme avaliado foi acoplado ao filme de apoio através de fita colante que está do outro lado do filme e, por isso, não está aparente.

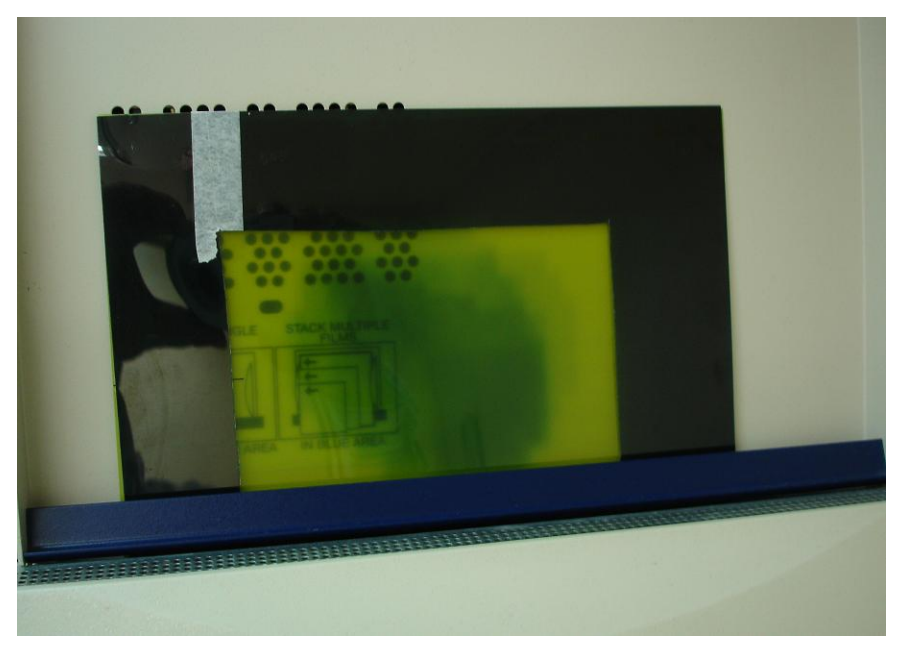

Figura 11 - Exemplo de filme de apoio, região da borda mais escura, na digitalização

A quarta digitalização foi realizada com película e com filme de apoio, sem definição de área, na posição “0”, como mostra a Figura 12. 


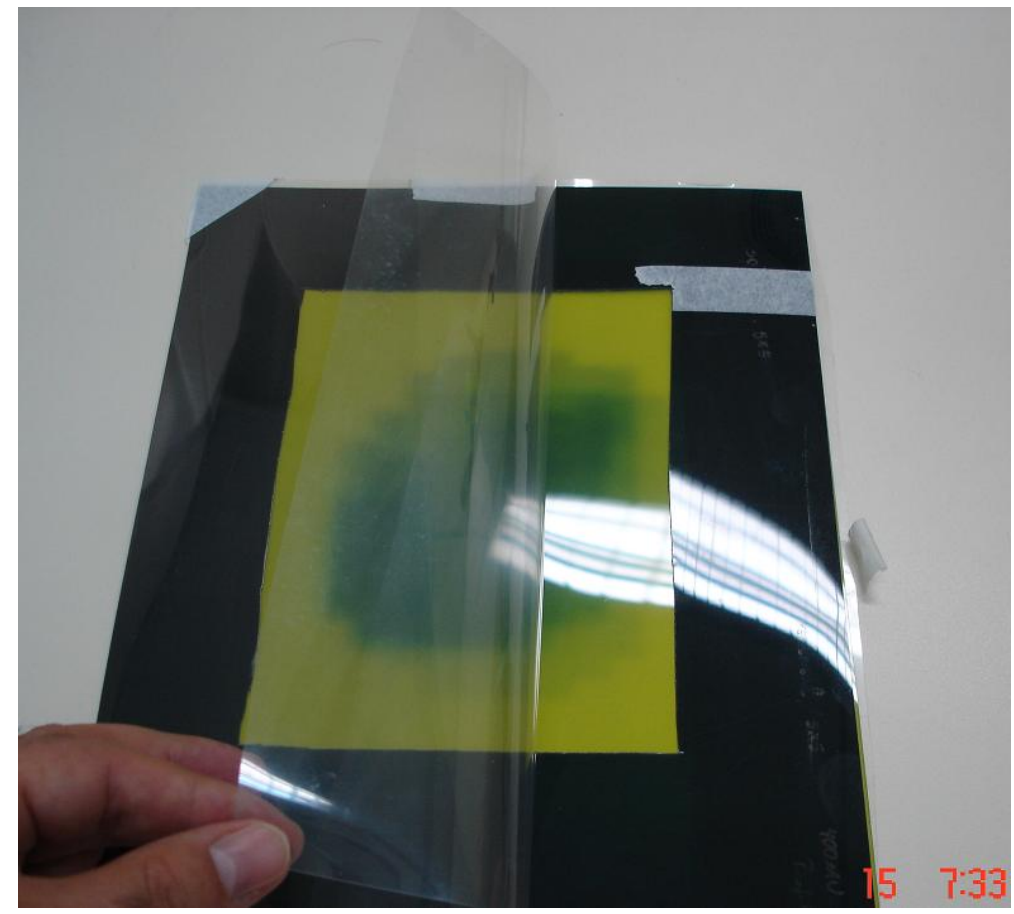

Figura 12 - Exemplo de filme com película

A quinta, sexta, sétima e oitava digitalizações foram realizadas com a película, com o filme de apoio e com definição de área, nas posições "0”, “90”, “180”, “270”, respectivamente. Na Figura 13 são apresentadas as posições dos filmes nas posições “0” e “90”, sendo que as demais foram adquiridas continuando a rotação em sentido horário.

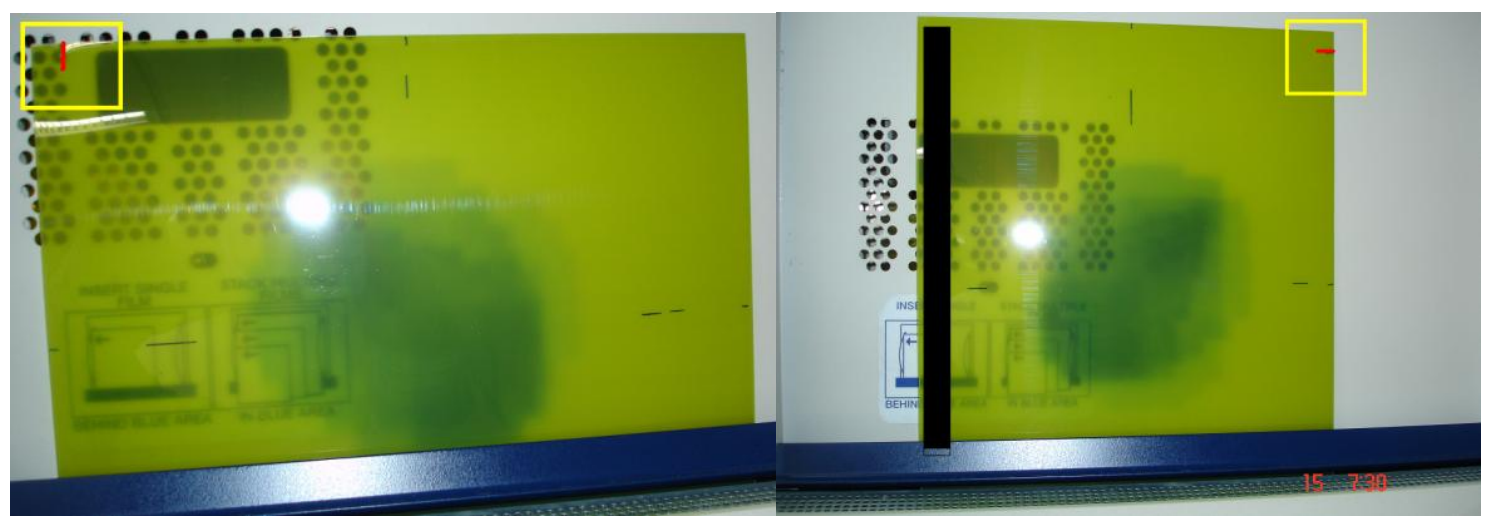

Figura 13 - À esquerda filme na posição "0" e, à direita filme na posição "90" 
As imagens da nona à décima segunda digitalizações foram realizadas seguindo os procedimentos das quatro anteriores, porém com os filmes invertidos, como mostra a Figura 14.

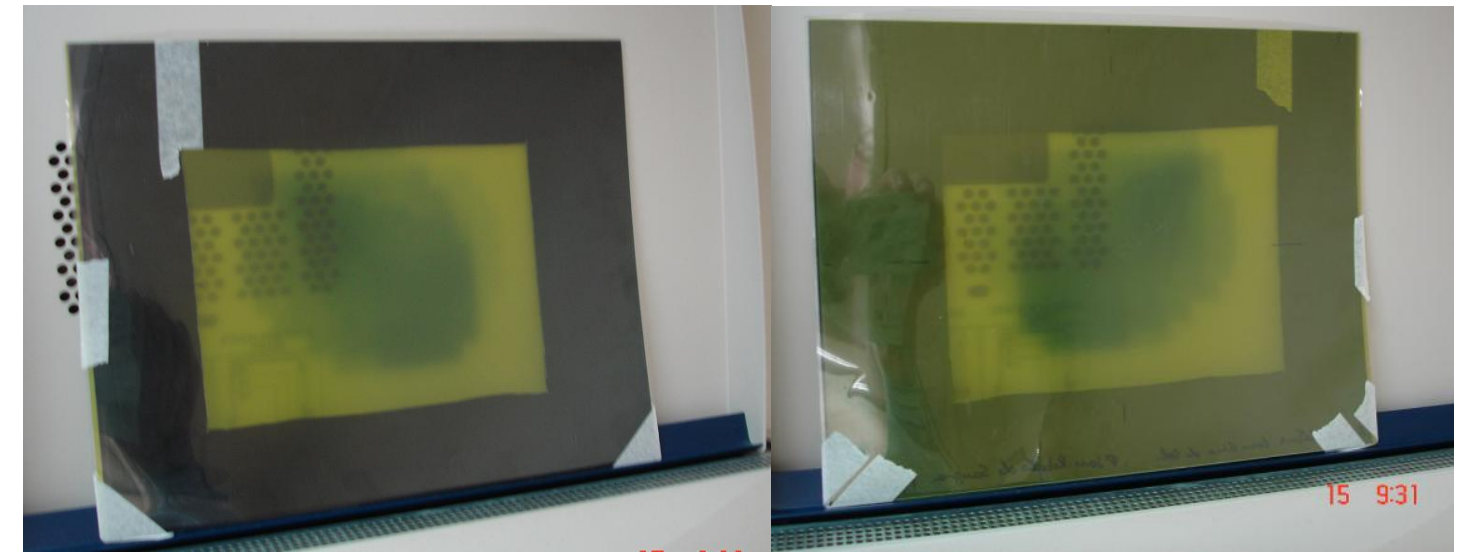

Figura 14 - À esquerda filme na posição normal e à direita filme invertido

Para a avaliação da melhor técnica de digitalização, o filme digitalizado foi irradiado seguindo a metodologia da configuração proposta neste trabalho, ou seja, no meio do suporte acrílico especialmente confeccionado neste estudo. Assim, o filme foi irradiado no campo $10 \mathrm{~cm}$ x $10 \mathrm{~cm}$ com 400 unidades monitoras e comparado com a matriz gerada pelo TPS, no campo $10 \mathrm{~cm}$ x $10 \mathrm{~cm}$, com objeto simulador com geometria semelhante ao suporte acrílico e também com 400 UM. A imagem do filme digitalizado foi magnificada no software ImageJ, versão $1.45 \mathrm{~s}$, da empresa Wayne Rasband, para possibilitar a comparação da distribuição de dose gerada pelo TPS através da função gama. Todas as digitalizações foram realizadas duas vezes no escâner Vidar DiagnostcPro e as funções gama foram obtidas no software OmniPro I'mrt (IBA Dosimetry) com critérios de variação de porcentagem de dose máxima de 3\%, variação de distância máxima (DTA) de $3 \mathrm{~mm}$ e corte de $20 \%$. 


\subsection{Estudo da metodologia em campos quadrados e de planejamento conformacional}

Para validação da metodologia na técnica conformacional, primeiramente desenvolveu-se uma simulação Monte Carlo para verificar a diferença entre a distribuição de dose gerada a uma DFD de $56,8 \mathrm{~cm}$ e de $100 \mathrm{~cm}$. Em seguida, comparou-se experimentalmente as distribuições de dose obtidas com filme radiocrômico na posição do acessório holder e a distribuição de dose calculada pelo TPS na DFD de $100 \mathrm{~cm}$ para campos quadrados, para um campo irregular e, por último, para a junção de 5 campos de uma simulação de um tratamento conformacional de câncer de próstata.

\subsubsection{Simulação Monte Carlo}

Com a finalidade de averiguar a viabilidade da técnica de CQ de transmissão proposta, foi utilizada uma simulação Monte Carlo, através do código PENELOPE (PENetration and Energy LOss of Positron and Electrons), versão 2008 (FERNÁNDEZVAREA e SALVAT, 2009) (SALVAT, FERNÁNDEZ-VAREA e SEMPAU, 2003). A aplicação desta ferramenta teve como objetivo principal averiguar a diferença entre as distribuições de dose adquiridas para duas distâncias fonte detector $(100 \mathrm{~cm}$ e $56,8 \mathrm{~cm})$ e para um mesmo tamanho de campo. Com a finalidade de reproduzir o experimento realizado, foi simulado o cabeçote do acelerador linear Oncor. A simulação do cabeçote proporciona a aquisição do espectro de um feixe de fótons de $6 \mathrm{MV}$ para os diferentes tamanhos de campos avaliados. Uma vez obtidos os referidos espectros, o processo de simulação torna-se vantajoso devido ao aumento na velocidade da simulação de interesse (SHEIKH-BAGHERI e ROGERS, 2002)(HINSON et al., 2008).

A simulação do cabeçote foi realizada pelo físico Francisco Sampaio e composta por alvo de ouro, colimador primário (chumbo), filtro achatador de feixe (inox), câmara de ionização (poliestireno e ar), espelho (ar e vidro) e colimadores secundários (chumbo), conforme esta apresentado na Figura 15. A aquisição do espectro foi simulada com um campo de $10 \mathrm{~cm}$ x $10 \mathrm{~cm}$ com $5.10^{8}$ histórias. A dimensão do campo mencionado faz referência à SSD de $100 \mathrm{~cm}$. 
A

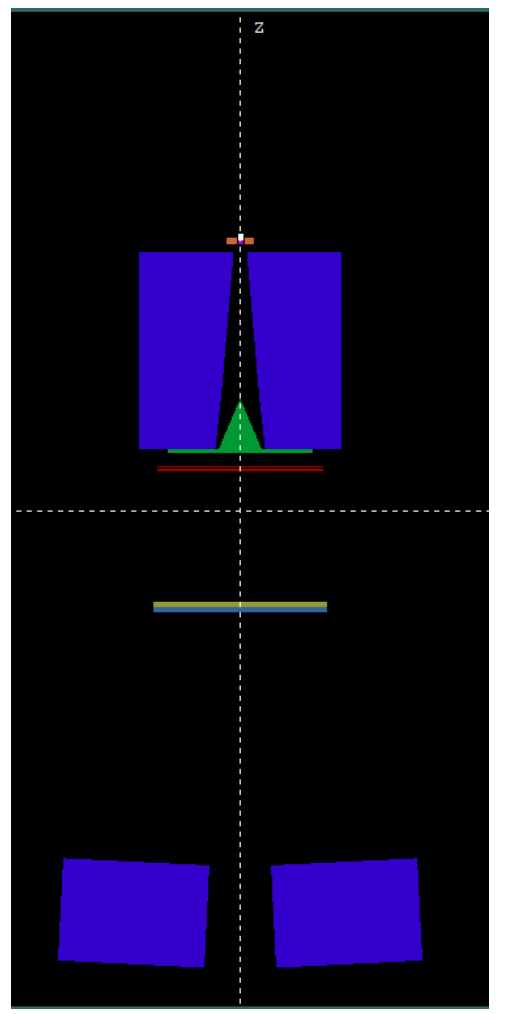

B

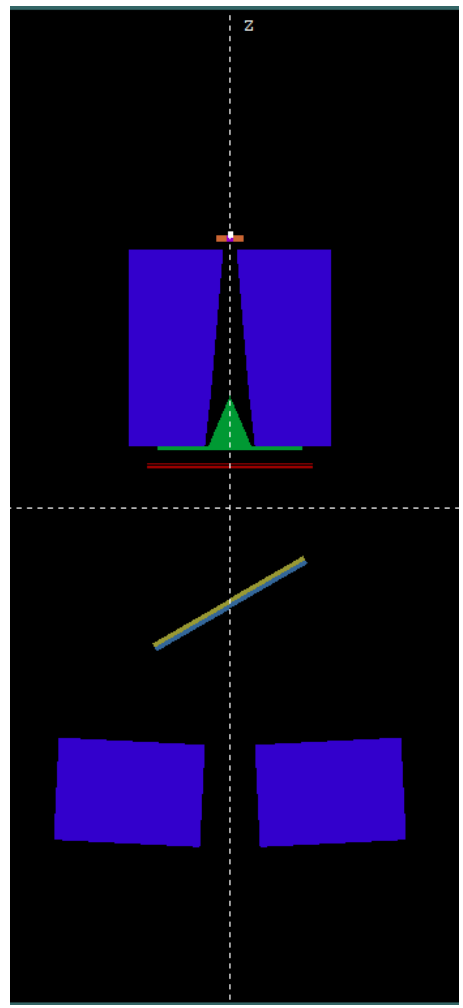

Figura 15 - Visualização das estruturas internas do cabeçote simulado (alvo em vermelho claro; colimador primário em azul, na região superior; filtro achatador em verde; câmara de ionização em vermelho; espelho em amarelo e azul claro e colimadores secundários em azul, na região inferior da imagem) através de um corte, (A) no eixo axial e (B) no eixo sagital.

Uma vez adquirido o espectro no campo $10 \mathrm{~cm} \mathrm{x} 10 \mathrm{~cm}$, realizaram-se três simulações com os campos $5 \mathrm{~cm}$ x $5 \mathrm{~cm}, 10 \mathrm{~cm}$ x $10 \mathrm{~cm}$ e $15 \mathrm{~cm}$ x $15 \mathrm{~cm}$, todas compostas por $1.10^{9}$ histórias, com o objetivo de constatar se o espectro gerado concordava com a do acelerador usado neste trabalho. Para isso, as simulações foram realizadas com objeto simulador de água com dimensões de $40 \mathrm{~cm}$ x $40 \mathrm{~cm}$ x $40 \mathrm{~cm}$, a uma distância de $100 \mathrm{~cm}$ da fonte, a fim de comparar a porcentagem de dose em profundidade (PDP) das simulações com as medidas de PDP realizadas no LINAC Oncor, com feixe $6 \mathrm{MV}$, em um objeto simulador composto por água, distância foco superfície de $100 \mathrm{~cm}$ e câmara de ionização CC13 da IBA Dosimetry.

Em seguida, foram realizadas simulações com $1.10^{9}$ histórias para avaliar as deposições de doses nas distâncias mencionadas e suas respectivas distribuições, no plano 
coronal, com objeto simulador de acrílico de $1 \mathrm{~cm}$ de espessura, através da função gama. A função gama foi realizada entre a distribuição de dose gerada a $56,8 \mathrm{~cm}$, localização do suporte acrílico do filme, com a distribuição de dose gerada a $100 \mathrm{~cm}$, localização da imagem tomográfica do objeto simulador de acrílico no TPS. Para aplicar a função gama, foi feito o corregistro das distribuições de dose magnificando-se a distribuição de dose encontrada com distância foco detector de $56,8 \mathrm{~cm}$ para o tamanho da matriz de dose com distância foco detector de $100 \mathrm{~cm}$. Os critérios usados na função gama foram variação da porcentagem máxima da dose 3\%, variação máxima da distância de $3 \mathrm{~mm}$ e corte de $10 \%$. Além disso, também foram aplicadas nas distribuições de dose uma convolução gaussiana, para suavizar e diminuir o ruído e uma quadruplicação no número de pontos, através de interpolações lineares, para melhorar o corregistro das distribuições e aumentar a quantidade de dados na avaliação; no início da simulação, os pontos mantinham-se a uma distância de $2 \mathrm{~mm}$ e, posteriormente, $0,5 \mathrm{~mm}$.

\subsubsection{Calibração das avaliações dosimétricas conformacionais}

Nesta fase do trabalho, a configuração para obter o conversor digital analógico (ADC, do inglês Analogue-to-digital converter) dos filmes digitalizados foi estabelecida através da irradiação com $0,50,100,150,200,250,300,400$ unidades monitoras e a calibração foi realizada no software OmniPro I'mrt, agrupando os valores de ADC do filme digitalizado com os valores de dose obtidos pelo TPS.

\subsubsection{Comparação entre as distribuições de dose calculadas no TPS e a adquirida pelo filme em campos quadrados e conformacionais}

Com a finalidade de avaliar a diferença entre os filmes irradiados na configuração proposta pelo trabalho e a distribuição de dose gerada pelo TPS na distância de $100 \mathrm{~cm}$, primeiramente realizou-se a exposição de três filmes com campos quadrados nas dimensões de $5 \mathrm{~cm}$ x $5 \mathrm{~cm}, 10 \mathrm{~cm}$ x $10 \mathrm{~cm}$ e $15 \mathrm{~cm}$ x $15 \mathrm{~cm}$. Os filmes digitalizados foram irradiados seguindo a metodologia da configuração proposta neste trabalho. Os filmes foram irradiados com 200 unidades monitoras e as distribuições encontradas pelas 
digitalizações foram comparadas com as distribuições de dose obtidas pelo TPS. Nesta fase do trabalho, a imagem do filme foi magnificada no software ImageJ, para possibilitar a comparação com a função gama. As funções gama foram obtidas no software OmniPro I'mrt com os seguintes critérios: variação percentual máxima da dose de $3 \%$, variação máxima da distância de $3 \mathrm{~mm}$ e corte de $20 \%$.

Em seguida, para avaliação de um campo irregular, mais complexo, simulou-se um campo conformacional de próstata no TPS. Este campo simulado no TPS foi primeiramente, transferido para a imagem tomográfica do objeto simulador com dimensões de $30 \mathrm{~cm}$ x $30 \mathrm{~cm} \times 1 \mathrm{~cm}$ e, em seguida, coletou-se a distribuição da dose no plano coronal para posteriormente ser comparado através da função gama com o filme irradiado no cabeçote do acelerador linear. O filme foi digitalizado 24 horas depois da irradiação no escâner Vidar e a função gama entre a distribuição de dose e o filme digitalizado foi realizada no software OmniPro I'mrt, com os mesmos critérios descritos nos campos quadrados.

Finalmente, realizou-se um planejamento conformacional de câncer de próstata com 5 campos coplanares, com angulações de gantry de $180^{\circ}, 260^{\circ}, 315^{\circ}, 45^{\circ}$ e $100^{\circ}$. Esta simulação de tratamento de próstata foi transferida para a imagem tomográfica do objeto simulador com dimensões de $30 \mathrm{~cm}$ x $30 \mathrm{~cm}$ x $1 \mathrm{~cm}$, porém, nesta transferência, todas as angulações do gantry foram modificadas para 0 grau, a fim de que todos os feixes ficassem perpendiculares ao objeto simulador, da mesma forma que o filme. É importante ressaltar que, no momento da irradiação, o filme posicionado no suporte acrílico estará sempre perpendicular ao feixe, obrigando, assim, na simulação, a colocar todos os campos perpendicularmente ao objeto simulador para que a distribuição de dose gerada pelo plano coronal do TPS possa ser comparada com a distribuição de dose encontrada pelo filme. Para essa avaliação, o mesmo filme foi irradiado com todos os campos do tratamento simulado. A função gama foi aplicada comparando a imagem digitalizada do filme com a distribuição de dose gerada pelo TPS nas condições descritas anteriormente. 


\subsection{Programa desenvolvido}

O programa foi desenvolvido no software MatLab (Mathworks, Natick, USA) para avaliações dosimétricas através da análise gama. Em uma primeira etapa, o programa aplica uma calibração na imagem que será analisada, associando os valores de dose correspondentes aos valores de pixels da distribuição obtida experimentalmente. Em seguida, ele realiza uma suavização na distribuição, através de convolução gaussiana, dobra o número de pontos com interpolações lineares e realiza transformações geométricas e de escala, como objetivo de alinhar as distribuições que serão comparadas. Por fim, o programa pode realizar uma normalização das duas distribuições de dose no mesmo ponto, a fim de obter a análise gama.

A primeira subfunção é a responsável pela calibração. Neste ponto, o programa abre a imagem para que o usuário possa associar manualmente os valores de pixel da distribuição medida com uma dose conhecida. A segunda subfunção aplica a calibração na imagem, transformando a distribuição de pixels em distribuição de dose bidimensional. Para isso, o programa é capaz de abrir a imagem, aplicar a calibração e salvá-la. A terceira subfunção suaviza o ruído da distribuição de dose adquirida, aplicando, para isto, uma convolução gaussiana na distribuição bidimensional. A quarta subfunção dobra o número de pontos da distribuição, interpolando pontos entre as linhas e colunas com valores médios entre os pontos adjacentes. A quinta subfunção faz uma calibração geométrica manual que associa o número de pixels presentes em um intervalo a uma dimensão predefinida antes da digitalização do filme, porque, antes da digitalização, podem-se fazer duas marcas no filme, com distância conhecida entre elas e, assim, no programa desenvolvido, após a digitalização, o usuário pode associar o número de pixels que estão dentro deste intervalo a uma distância conhecida. A sexta subfunção realiza o deslocamento das distribuições através de uma transformação geométrica para o alinhamento e corregistro dos perfis gerados nos centros das distribuições dosimétricas. A Figura 16 apresenta os perfis gerados pelas distribuições geométricas produzidas no filme digitalizado (vermelho) e pelo sistema de planejamento (azul). Após o corregistro, a sétima subfunção normaliza as distribuições de dose dividindo todos os valores de cada distribuição pelo valor selecionado manualmente pelo usuário. Além disso, nesta função 
ainda existe uma área reservada para mostrar as coordenadas e as respectivas doses deste ponto de normalização.

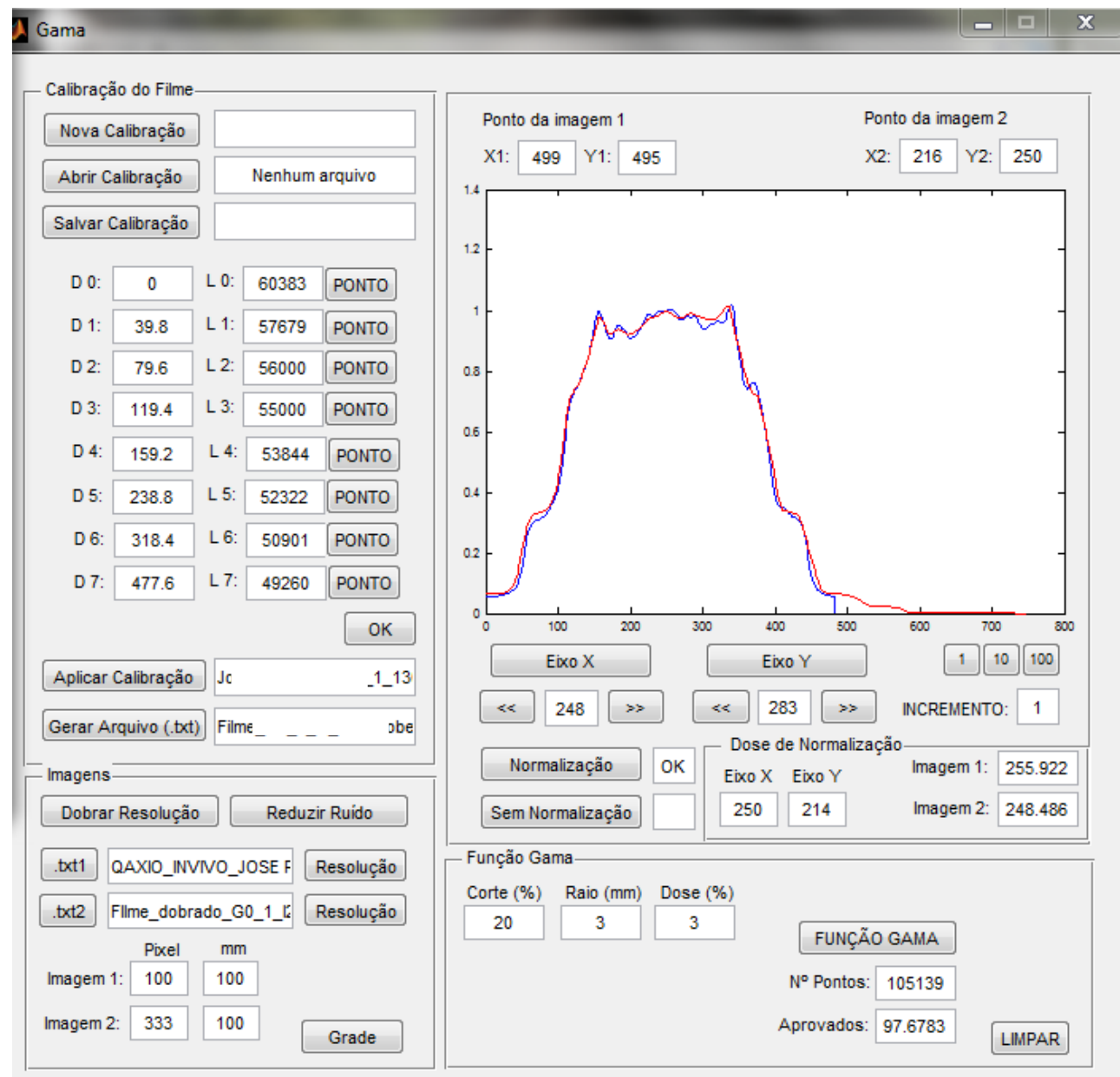

Figura 16 - Interface gráfica do programa desenvolvido

A última subfunção realiza a função gama utilizando os critérios estabelecidos manualmente pelo usuário, como o valor de corte, variação máxima da distância, e variação máxima da porcentagem da dose, além de exibir o número e a porcentagem de pontos que foram aprovados. A Figura 16 apresenta a interface do programa desenvolvido, enquanto Figura 17 apresenta o fluxograma deste programa. 


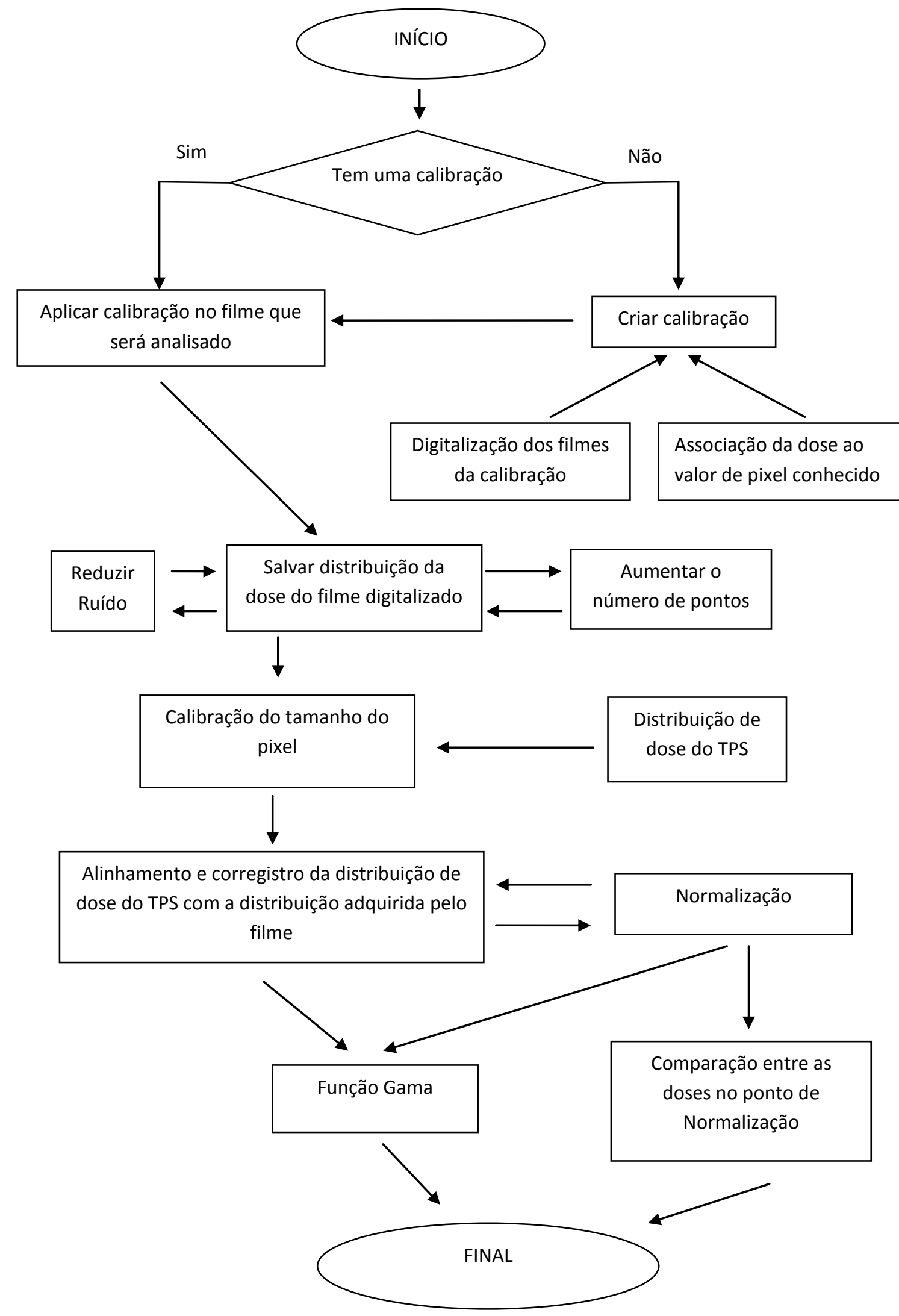

Figura 17 - Fluxograma do programa desenvolvido 


\subsubsection{Validação do programa desenvolvido}

A metodologia para validação do programa desenvolvido foi realizada através da comparação da análise da função gama entre o programa desenvolvido e o OmniPro I'mrt da empresa IBA Dosimetry. O programa OmniPro I'mrt foi usado em diversos estudos (HAN et al., 2010)(DOBLER et al., 2010)(SHARMA et al., 2010) e, por isso, é um programa consagrado para este tipo de análise de função gama, justificando assim sua escolha para validar o programa desenvolvido neste trabalho. Na validação do programa, utilizaram-se dois planejamentos de IMRT, a fim de gerar diversas distribuições de dose, um plano de próstata composto por 5 campos e outro plano de sistema nervoso central (SNC) composto por 7 campos, obtidos a partir do sistema de planejamento XiO. Para gerar distribuições de dose diferentes e compará-las com a original, formada pela junção de todos os campos, foram criadas distribuições diferentes em cada plano, retirando um dos campos. Ou seja, para o plano de próstata, além da distribuição original, foi gerada outra distribuição de dose sem o campo 1, outra distribuição de dose sem o campo 2 e outras distribuições sem os campos 3, 4 e 5, respectivamente. $\mathrm{O}$ mesmo procedimento foi realizado para gerar outras distribuições de dose através do plano do SNC, gerando 7 novas distribuições sem os campos 1, 2, 3, 4, 5, 6 e 7, respectivamente. A análise da função gama entre as distribuições de dose geradas sem um campo e a distribuição de dose original, formada por todos os campos de cada plano, foi realizada utilizando o programa desenvolvido e o OmniPro I'mrt.

\subsection{Estudo da metodologia em campos de IMRT}

A Figura 18 apresenta um esquema da metodologia de controle da qualidade de transmissão desenvolvida nesta fase do trabalho, mostrando como foram adquiridas as distribuições de dose dos tratamentos de IMRT com um filme radiocrômico posicionado no suporte acrílico acoplado ao acessório holder do LINAC durante todos os campos de irradiação do planejamento avaliado. Esses filmes foram calibrados para, posteriormente, realizar a análise gama através da comparação da distribuição de dose medida pelo filme com a esperada pelo TPS, como resultado da transferência do plano de IMRT em questão, 
com todos os campos posicionados com gantry na vertical, ou seja, perpendicularmente ao objeto simulador.

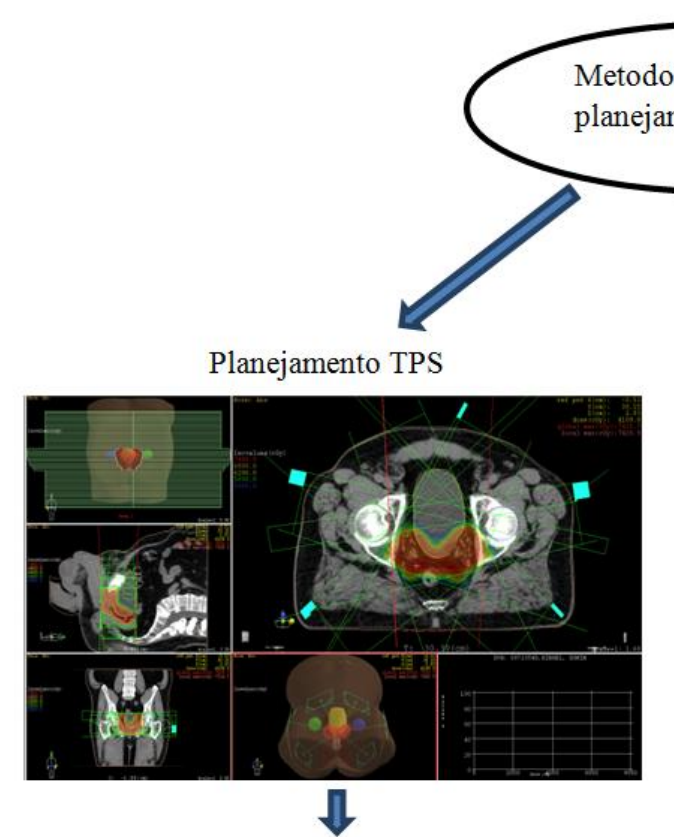

Plano exportado para o objeto simulador para gerar a distribuição de dose esperada

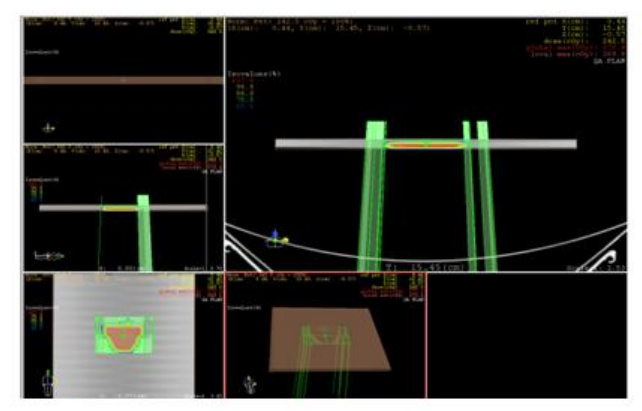

$\Downarrow$

Distribuição de dose TPS

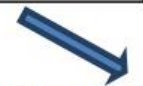

Programa desenvolvido, aplica a calibração nos valores de pixel do filme, magnifica e realiza a fusão com a distribuição de dose do TPS para função

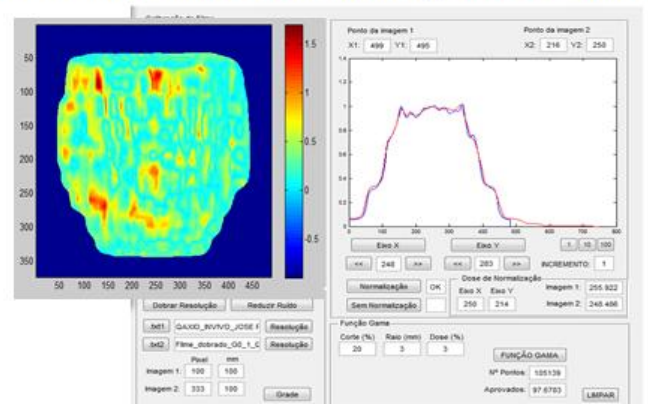

Figura 18 - Esquema da metodologia de controle da qualidade desenvolvido. À esquerda distribuição de dose gerada pelo TPS e à direita configuração da distribuição da dose encontrada pelo filme. Na região inferior da imagem pode-se observar a função gama 
Nesta fase do trabalho, a função gama foi realizada com critérios de variação máxima de distância de $3 \mathrm{~mm}$, variação máxima da porcentagem da dose de $3 \%$ e corte de $20 \%$. O controle da qualidade de transmissão foi considerado aprovado quando se obteve conjuntamente uma diferença de dose no ponto de normalização inferior a $5 \%$ e uma porcentagem de aprovação gama superior a $95 \%$.

\subsubsection{Calibração da avaliação dosimétrica da técnica de IMRT}

A calibração, nesta fase do trabalho, foi realizada irradiando o filme radiocrômico no suporte acrílico acoplado ao acessório holder do LINAC com 50, 100, 200, 400 e 600 unidades monitoras usando campo $10 \mathrm{~cm}$ x $10 \mathrm{~cm}$. A aplicação da calibração foi realizada pelo programa desenvolvido neste trabalho, agrupando-se os valores de pixel dos filmes digitalizados e os valores de dose obtidos pelo TPS com as mesmas UM com que os filmes foram irradiados.

\subsubsection{Validação da metodologia do controle da qualidade com filme no suporte acrílico}

A metodologia de controle da qualidade, nesta fase do trabalho, foi aplicada em 5 planos de IMRT para validar a técnica. Cada plano foi avaliado em cinco configurações diferentes, na primeira e na segunda todas as irradiações foram feitas com gantry a $0^{\circ}$, na terceira as irradiações foram feitas com as angulações de gantry reais do planejamento, na quarta as irradiações foram feitas com as angulações reais do gantry, mas com menos unidades monitoras que o planejado e, na quinta, as irradiações foram feitas com as angulações reais do gantry, porém, sem um dos campos. Assim, espera-se que as três primeiras configurações de irradiação sejam aprovadas pelos controles da qualidade e as duas últimas não. 


\subsubsection{Reprodutibilidade na digitalização}

Para verificar a reprodutibilidade na técnica de digitalização dos filmes, foi realizada uma série de $10 \mathrm{CQ}$ com a metodologia de transmissão proposta para IMRT e os resultados foram analisados utilizando duas digitalizações do mesmo filme em momentos distintos. A avaliação da reprodutibilidade foi feita com a comparação da diferença de dose no ponto de normalização e da função gama nas duas digitalizações.

\subsubsection{Reprodutibilidade do controle da qualidade de transmissão}

Para verificar a reprodutibilidade da técnica de controle da qualidade de transmissão proposta, a metodologia foi repetida duas vezes no controle da qualidade de 5 simulações de planejamentos de IMRT selecionados. A avaliação da reprodutibilidade foi feita comparando a diferença de dose no ponto de normalização e a função gama nas duas irradiações do mesmo planejamento.

\subsubsection{Comparação da metodologia do controle da qualidade de transmissão com a metodologia com outros sistemas dosimétricos}

O controle da qualidade de transmissão proposto foi comparado com o controle da qualidade padrão realizado com dois sistemas de dosimetria convencionais, o MatriXX com placas de água sólida para garantia do espalhamento e o filme radiocrômico posicionado entre o MatriXX e as placas de água sólida (Figura 19) . Os três dosímetros foram irradiados conjuntamente em uma única irradiação 


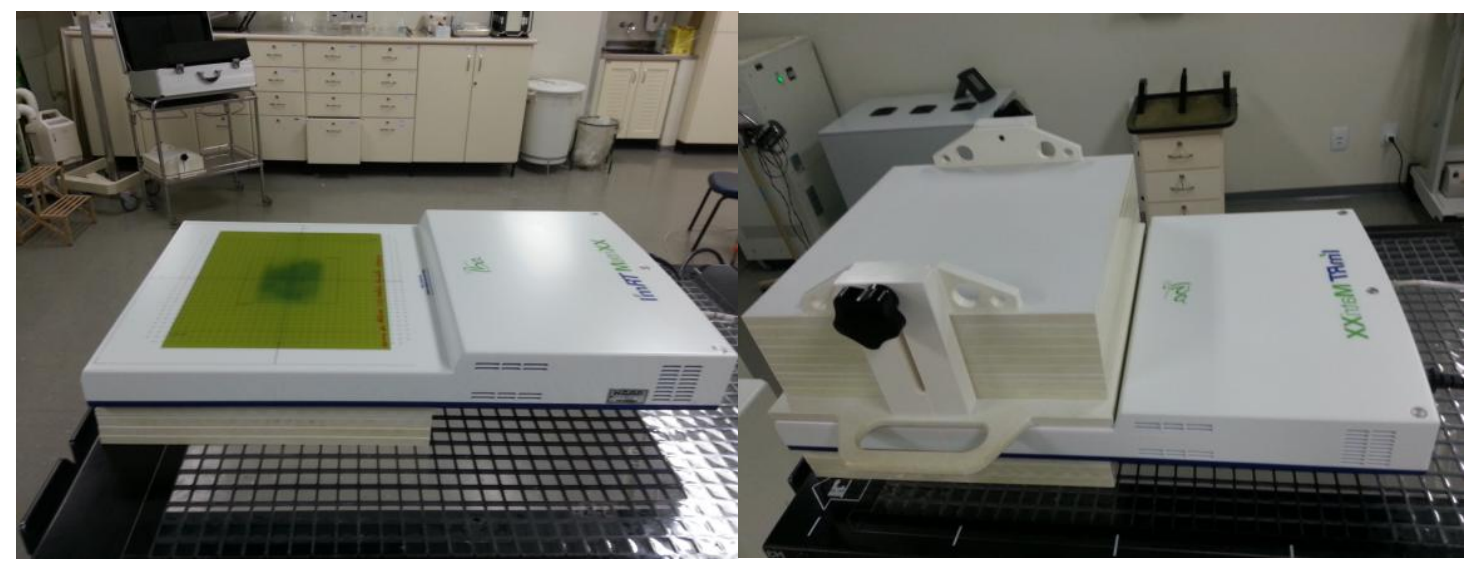

Figura 19 - À esquerda filme localizado acima do MatriXX. À direita configuração usada na irradiação

Para obtenção do resultado esperado pelo TPS para os dosímetros convencionais, foi realizada uma tomografia computadorizada do MatriXX com $10 \mathrm{~cm}$ de água sólida sobre ele e $5 \mathrm{~cm}$ sob o equipamento dosimétrico e, assim, todos os campos dos planos de tratamento simulados no TPS foram transferidos para esta imagem tomográfia, com gantry em $0^{\circ}$. Para a avaliação do resultado no MatriXX, a distribuição de dose do TPS foi determinada no centro do volume sensível do equipamento, enquanto que, no filme, a distribuição de dose foi determinada na superfície anterior do MatriXX. Nesta fase do trabalho, todos os controles da qualidade foram realizados no software OmniPro I'mrt considerando a absorção do suporte acrílico.

\subsection{Avaliações dosimétricas in vivo}

\subsubsection{Dados dos planejamentos}

Todos os planejamentos foram simulados no TPS XiO através das imagens tomográficas adquiridas no tomógrafo computadorizado (Brilliance Big Bore, Philips Medical Systems, Cleveland) em cortes de $3 \mathrm{~mm}$. Os 9 pacientes de próstata foram posicionados em decúbito dorsal, mãos sobre o tórax, suporte de joelhos e com preparo para proporcionar uma bexiga cheia e reto vazio. Os 3 pacientes de cabeça e pescoço foram posicionados com máscara de IMRT reforçada que imobiliza os ombros do paciente, em 
decúbito dorsal e braços ao lado do corpo com as mãos tracionadas para a posição longitudinal inferior. Finalmente, os 3 pacientes que trataram neoplasia no crânio foram posicionados de forma semelhante aos de cabeça e pescoço, mas usando uma máscara que imobilizava apenas a cabeça. As imagens tomográficas foram transferidas para o sistema de planejamento via DICOM. Após a transferência das imagens, os volumes alvo e os órgãos de risco foram delineados e o planejamento do tratamento simulado por um físico responsável.

Os planejamentos foram realizados em otimização inversa com incremento dos passos (do inglês Step Increment) de $0,5 \mathrm{~cm}$; critérios de convergência (do inglês Convergence Criterion) de 0,0001\%; número máximo de interações de 100; extensão de espalhamento (do inglês Scatter Extent) de 0,5 cm e margem de otimização de 0,5 cm. As segmentações das distribuições de dose dos campos foram realizadas pelas técnicas de SlidingWnd e Smart Sequence, dependendo do planejamento do paciente. Para a segmentação, na técnica de Smart Sequence, o número mínimo de unidades monitoras por segmento foi de 3; a área mínima do segmento variou entre 1 e $3 \mathrm{~cm}^{2}$ e o fator de supressão ficou entre 3 e 5 . Na técnica de SlidingWnd, o nível de intensidade usado foi 8 , com tamanho mínimo do segmento entre 1 e 3 . O algoritmo de cálculo usado em todos os planejamentos foi o Superposition, com grade de cálculo de $0,2 \mathrm{~cm}$.

\subsubsection{Programa de controle da qualidade no serviço de radioterapia}

O QA específico para os tratamentos de IMRT do serviço de radioterapia do Hospital das Clínicas da Faculdade de Medicina de Ribeirão Preto da Universidade de São Paulo (HCFMRP-USP) inicia-se com a transferência do planejamento do paciente, aprovado pelo médico radioterapeuta, para uma imagem tomográfica, no TPS, de um objeto simulador composto por um sistema dosimétrico bidimensional MatriXX Evolution (IBA Dosimetry) e placas de água sólida. Contudo, o cálculo da distribuição da dose, na imagem do MatriXX, foi realizado com todas as angulações do gantry deslocadas para 0 grau, pois a versão do MatriXX presente na instituição onde se realizou o estudo possui dependência angular e, assim, o feixe necessita interagir perpendicularmente ao volume sensível dos detectores. Após o cálculo realizado pelo TPS, no objeto simulador, transfere- 
se a distribuição dosimétrica do plano, referente ao volume sensível do detector, para o software OmniPro I'mrt. Em seguida, transfere-se também o plano do paciente, todos com gantry a $0^{\circ}$, para o sistema de registro e verificação (Lantis; Siemens Medical Systems Inc, USA) e, assim, pode-se realizar no LINAC o plano do controle da qualidade a ser analisado. Com os dados do planejamento, o LINAC Oncor realiza a irradiação com o MatriXX e as placas de água sólida devidamente posicionados. As ionizações coletadas pelo volume sensível do MatriXX são transferidas para o OmniPro I'mrt para formar a distribuição da dose que será comparada a partir da função gama (3\% de variação máxima da porcentagem de dose, $3 \mathrm{~mm}$ de variação máxima da distância, 10\% de corte) com os dados calculados pelo TPS.

Antes de realizar a irradiação do controle da qualidade, aguardam-se 30 minutos para o MatriXX entrar em estabilidade térmica e elétrica com o ambiente e, em seguida, irradia-se o dosímetro com campo de $27 \mathrm{~cm}$ x $27 \mathrm{~cm}$, tamanho de campo suficiente para enquadrar todos os detectores, com uma dose aproximada de $10 \mathrm{~Gy}$, afim de atingir a estabilidade intrínseca do dosímetro.

Ainda no QA, após aprovação do controle da qualidade pelo físico responsável, transcrevem-se os dados do planejamento para uma planilha e, em seguida, a planilha gera a ficha técnica que servirá de checagem de redundância para o técnico que realizar o tratamento, a qual possui dados dos campos de tratamento, dose prescrita, posicionamento do paciente, além de imagens informativas sobre o tratamento do paciente. Simultaneamente à criação da ficha técnica, transfere-se o plano do paciente do TPS para o sistema de registro e verificação Lantis. Por fim, um segundo físico verifica a ficha técnica, já criada, reavalia e aprova os campos para o tratamento no sistema de registro e verificação.

A realização dos filmes portais de verificação do isocentro e do posicionamento dos pacientes é a última etapa no programa de controle da qualidade na instituição onde se realizou o presente trabalho. Contudo, diversos autores descrevem que estas análises antes dos tratamentos podem ainda não garantir a liberação da dose no momento da terapêutica e, por isso, fica justificada uma avaliação dosimétrica no momento do tratamento (MANS et al., 2010). Sendo assim, este estudo acrescentou ao QA dos tratamentos radioterápicos aos pacientes envolvidos uma avaliação in vivo com filme radiocrômico posicionado no cabeçote do LINAC no momento do CQ individual e em três aplicações do tratamento. 
Neste estudo, o controle da qualidade convencional, usando o MatriXX e placas de água sólida, foi realizado com o filme radiocrômico posicionado no suporte acrílico acoplado ao LINAC. Em sua análise, foi considerada a atenuação do suporte acrílico através de uma divisão da dose medida no MatriXX pelo fator de transmissão do suporte. Para a análise da função gama entre os dados medidos e esperados pelo TPS, foi aplicada uma convolução descrita por Poppe e colaboradores (POPPE et al., 2007) na distribuição de dose liberada pelo TPS, para que cada ponto da matriz de dose recebesse a contribuição da dose referente à dimensão do detector do MatriXX, garantindo, assim, que as duas distribuições representassem os mesmos parâmetros de medida. Além disso, foi aumentado o número de pontos da distribuição de dose medida pelo MatriXX para a grade de $1 \mathrm{~mm}$, a mesma grade da distribuição de dose gerada pelo TPS.

\subsubsection{Dados da avaliação in vivo}

Para avaliação da técnica de transmissão in vivo, descrita neste trabalho, foram selecionados aleatoriamente 14 pacientes do Serviço de Radioterapia do HCFMRP-USP. Apenas foram excluídos os pacientes que possuíam campos de tratamento superiores a $15 \mathrm{~cm}$ x $15 \mathrm{~cm}$, devido à limitação no tamanho máximo do filme fixado ao soquete do suporte acrílico desenvolvido. Dentre os pacientes selecionados, 9 realizaram tratamentos de câncer de próstata, 3 de cabeça e pescoço e 3 de neoplasia cerebral. O número de segmentos dos planejamentos de câncer de próstata ficou entre 55 e 121, enquanto que os de cabeça e pescoço entre 100 e 121 e os de SNC entre 50 e 151.

Neste estudo, as distribuições de dose no TPS a serem comparadas com a distribuição de dose obtida com o filme radiocrômico foram coletadas em duas configurações distintas. Nos 8 primeiros pacientes, foram exportadas as distribuições de dose coletadas no centro da imagem tomográfica do objeto simulador com dimensões semelhantes ao suporte acrílico, e, nos outros 6, a distribuição da dose exportada foi coletada no plano tangente ao limite inferior da imagem tomográfica do objeto simulador no TPS. Esta variação ocorreu para que fosse avaliada a distribuição da dose calculada na região mais próxima do equilíbrio eletrônico em $1 \mathrm{~cm}$ de profundidade para o objeto simulador usado, lembrando que o equilíbrio eletrônico, ocorre para o feixe de $6 \mathrm{MV}$ em $1,3 \mathrm{~cm}$ de profundidade no acrílico. Para acompanhar as duas configurações usadas, foram 
realizadas duas calibrações, a primeira associando as doses do sistema de planejamento adquiridas no centro do objeto simulador e a segunda adquirindo as doses no limite inferior do objeto simulador. 
Capítulo 4 - Resultados e Discussões 


\section{RESULTADOS E DISCUSSÕES}

\subsubsection{Suporte acrílico e fator de transmissão}

A Tabela 1 apresenta os resultados das medidas realizadas com o MatriXX para aquisição do fator de transmissão. Na primeira coluna são apresentadas as doses medidas na ausência do suporte acrílico e, na segunda coluna, encontra-se as doses medidas com o suporte acoplado ao cabeçote do LINAC. A dose média encontrada sem o suporte acrílico foi de 81,10 cGy com desvio padrão de 0,05 cGy. A dose média com o suporte foi de 76,39 cGy com desvio padrão de 0,04 cGy. Desta forma, o fator de transmissão encontrado foi de 0,942, ou seja, o suporte desenvolvido absorve em torno de 5,8\% da irradiação. Este valor é semelhante ao encontrado por Poppe e colaboradores (POPPE et al., 2010) no estudo do coeficiente de absorção do sistema DAVID (PTW-Freiburg, Germany).

Tabela 1 - Resultados das medidas realizadas com o MatriXX para aquisição do fator de transmissão

\begin{tabular}{cc}
\hline $\begin{array}{c}\text { Leituras sem suporte } \\
\text { (cGy) }\end{array}$ & $\begin{array}{c}\text { Leituras com suporte } \\
\text { (cGy) }\end{array}$ \\
\hline 81,05 & 76,35 \\
81,06 & 76,39 \\
81,04 & 76,38 \\
81,14 & 76,35 \\
81,15 & 76,42 \\
81,13 & 76,43 \\
81,13 & 76,45 \\
\hline
\end{tabular}

\subsubsection{Digitalização}

Nesta seção, são apresentados os dados relativos às digitalizações de um filme irradiado na configuração de controle da qualidade de transmissão, com filme posicionado no meio do suporte acrílico acoplado ao LINAC Oncor. A imagem da Figura 20 é uma visualização de uma comparação com índice gama no software OmniPro I'mrt, na qual pode- 
se observar que o filme calibrado (retângulo na esquerda superior da imagem), possui uma dose menor na região inferior. Isto acontece quando o filme radiocrômico EBT2 é colocado sem nenhum preparo no escâner Vidar DiagnosticPro, do Serviço de Radioterapia do Hospital das Clínicas da Faculdade de Medicina de Ribeirão Preto (HCFMRP-USP).

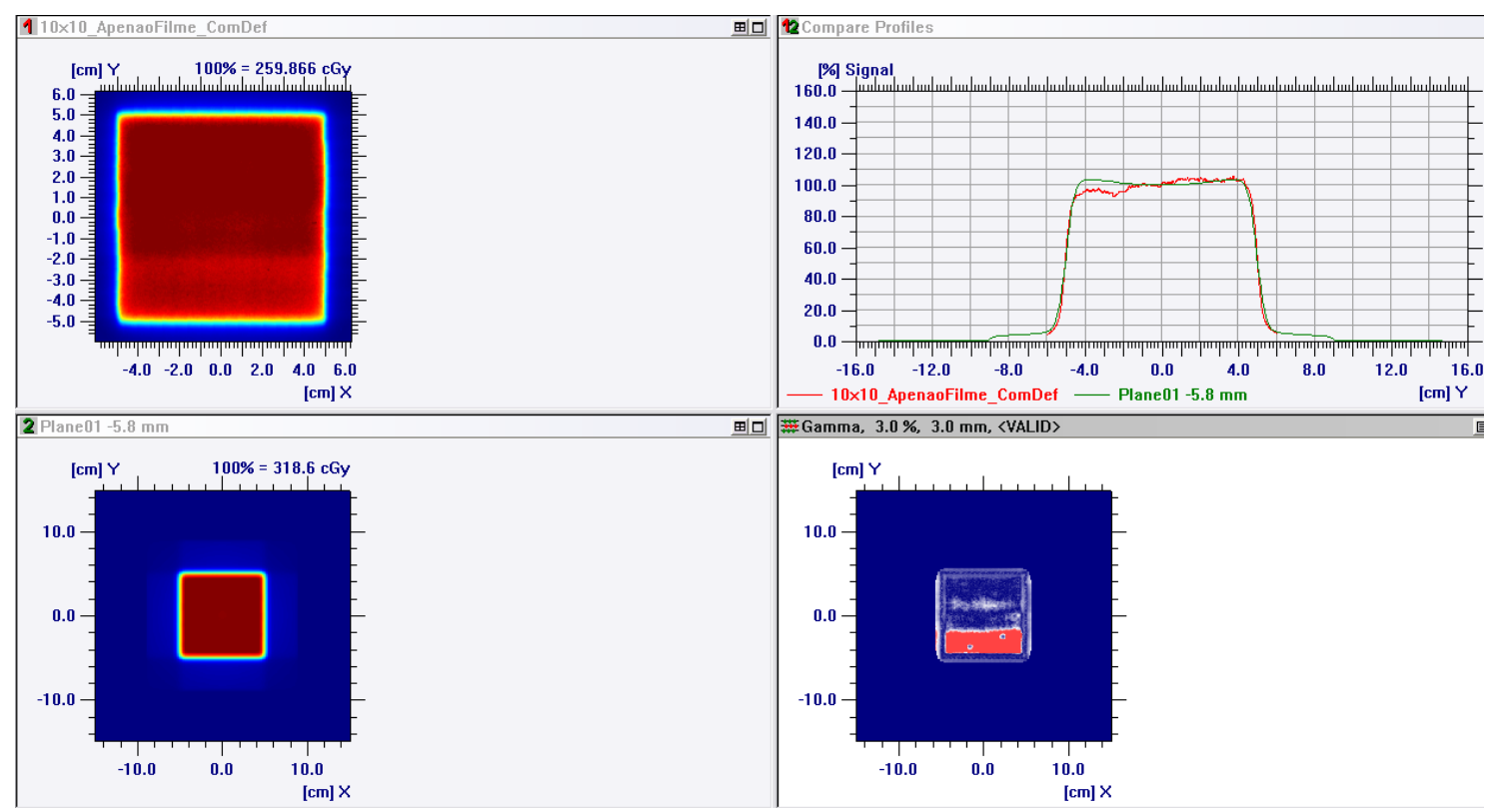

Figura 20 - Exemplo de problema encontrado na digitalização no escâner Vidar do Serviço de Radioterapia do HCFMRP-USP

Para resolver este problema, fez-se uma análise e comparou-se a função gama quando era colocada uma película envolta ao filme, um filme como moldura para dar apoio, definindo a região da digitalização na pré-digitalização e modificando sua posição. A Tabela 2 apresenta os resultados das funções gama. 
Tabela 2 - Resultado da função gama na comparação da matriz de dose liberada pelo TPS e as imagens digitalizadas nas diversas configurações

\begin{tabular}{lcc}
\hline \multicolumn{1}{c}{ Posicionamento do filme no Escâner } & G1 (\%) & G2 (\%) \\
\hline \hline Sem película; Sem filme de apoio; Com definição de área; Posição 0 & 97,4 & 97,3 \\
Sem película; Sem filme de apoio; Sem definição de área; Posição 0 & 97,2 & 96,8 \\
Sem película; Com filme de apoio; Com definição de área; Posição 0 & 98,7 & 97,7 \\
Com película; Com filme de apoio; Sem definição de área; Posição 0 & 99,1 & 98,9 \\
Com película; Com filme de apoio; Com definição de área; Posição 0 & 99,8 & 99,9 \\
Com película; Com filme de apoio; Com definição de área; Posição 90 & 99,8 & 99,9 \\
Com película; Com filme de apoio; Com definição de área; Posição 180 & 99,9 & 99,4 \\
Com película; Com filme de apoio; Com definição de área; Posição 270 & 99,9 & 99,7 \\
Com película; Com filme de apoio; Com definição de área; Posição 0; Invertido & 100,0 & 99,9 \\
Com película; Com filme de apoio; Com definição de área; Posição 90; Invertido & 100,0 & 99,9 \\
Com película; Com filme de apoio; Com definição de área; Posição 180; Invertido & 99,5 & 99,8 \\
Com película; Com filme de apoio; Com definição de área: Posição 270, Invertido & 99,8 & 99,1 \\
\hline
\end{tabular}

${ }^{1}$ Porcentagem de pontos aprovados na $1^{\circ}$ digitalização

${ }^{2}$ Porcentagem de pontos aprovados na $2^{\circ}$ digitalização

A média das diferenças percentuais entre as duas digitalizações foi de $0,22 \%$, com desvio padrão de $0,37 \%$, demostrando uma boa reprodutibilidade entre as digitalizações.

Uma observação importante é que, sanado o problema na digitalização, tendo em vista que a escolha da digitalização usada neste trabalho foi com película, com filme de apoio, com definição de área, posição 0 e invertido e, nesta configuração, o resultado da metodologia foi aprovado em praticamente $100 \%$ na função gama, pode-se concluir que existe uma concordância significativa entre a imagem do filme magnificado e a matriz de dados extraída do TPS, sugerindo a possibilidade de realizar o controle da qualidade da transmissão comparando a imagem do filme indexado ao cabeçote com a matriz de dose gerada pelo TPS, na distância de $100 \mathrm{~cm}$. 


\subsection{Estudo da metodologia de transmissão em campos quadrados e de planejamento conformacional}

\subsubsection{Simulação Monte Carlo}

Os gráficos das Figuras 21, 22 e 23 apresentam as comparações entre as PDP simuladas em Monte Carlo e as medidas de PDP determinadas com câmara de ionização no LINAC, com feixe de fótons de $6 \mathrm{MV}$ nos campos $5 \mathrm{~cm}$ x $5 \mathrm{~cm}, 10 \mathrm{~cm}$ x $10 \mathrm{~cm}, 15 \mathrm{~cm}$ x 15 $\mathrm{cm}$, respectivamente.

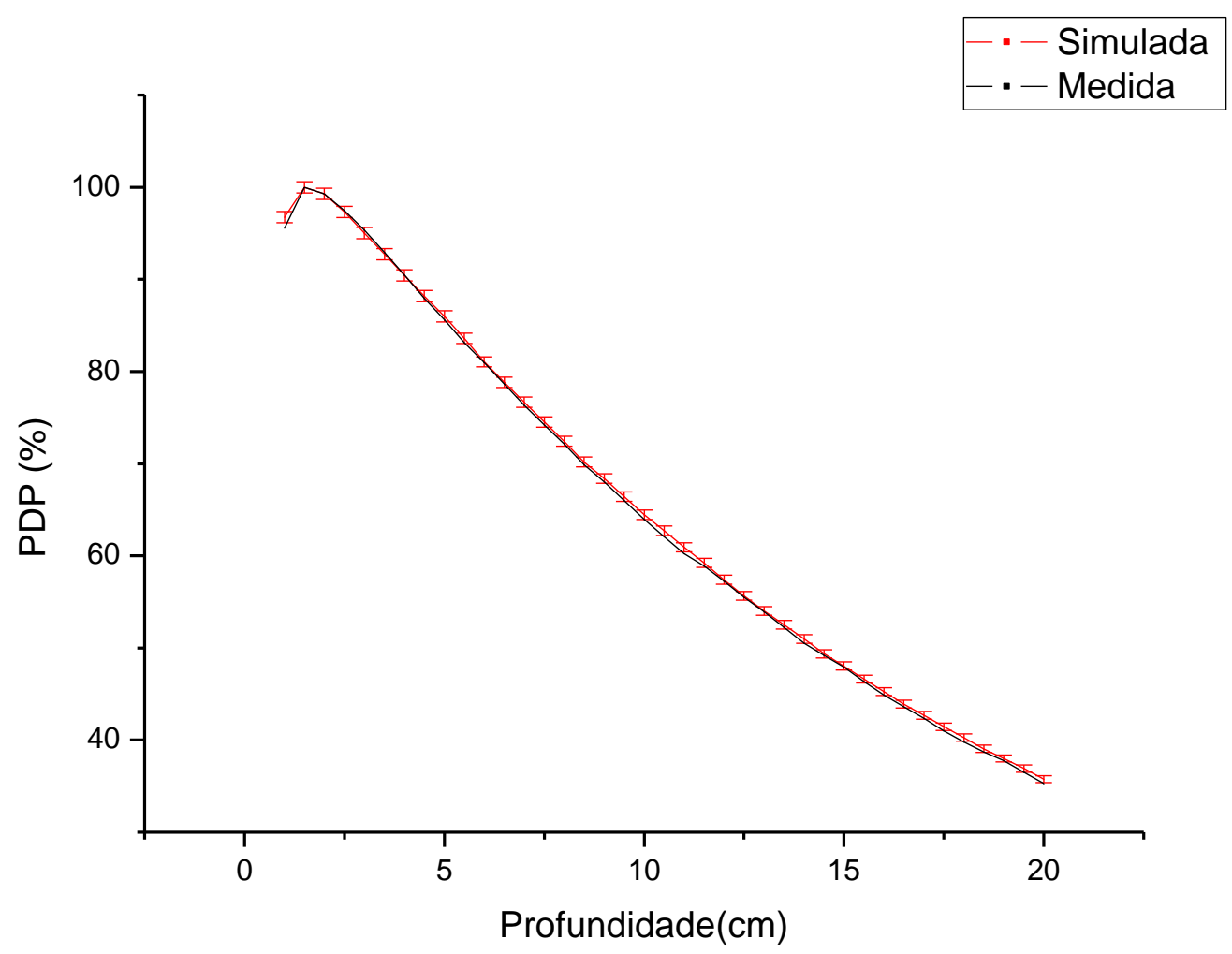

Figura 21 - Gráfico da comparação da PDP simulada em Monte Carlo e as medidas com câmaras de ionização no campo $5 \mathrm{~cm} \times 5 \mathrm{~cm}$.

A média dos desvios percentuais encontrados entre a PDP medida e a simulada para o campo de $5 \mathrm{~cm}$ x $5 \mathrm{~cm}$ foi de $0,52 \%$, com desvio padrão de $0,43 \%$. O maior desvio percentual foi de $1,1 \%$, enquanto o menor foi de $0 \%$. A incerteza máxima da simulação foi de $0,61 \%$. Estes resultados validam o espectro simulado para o campo de $5 \mathrm{~cm}$ x $5 \mathrm{~cm}$. 


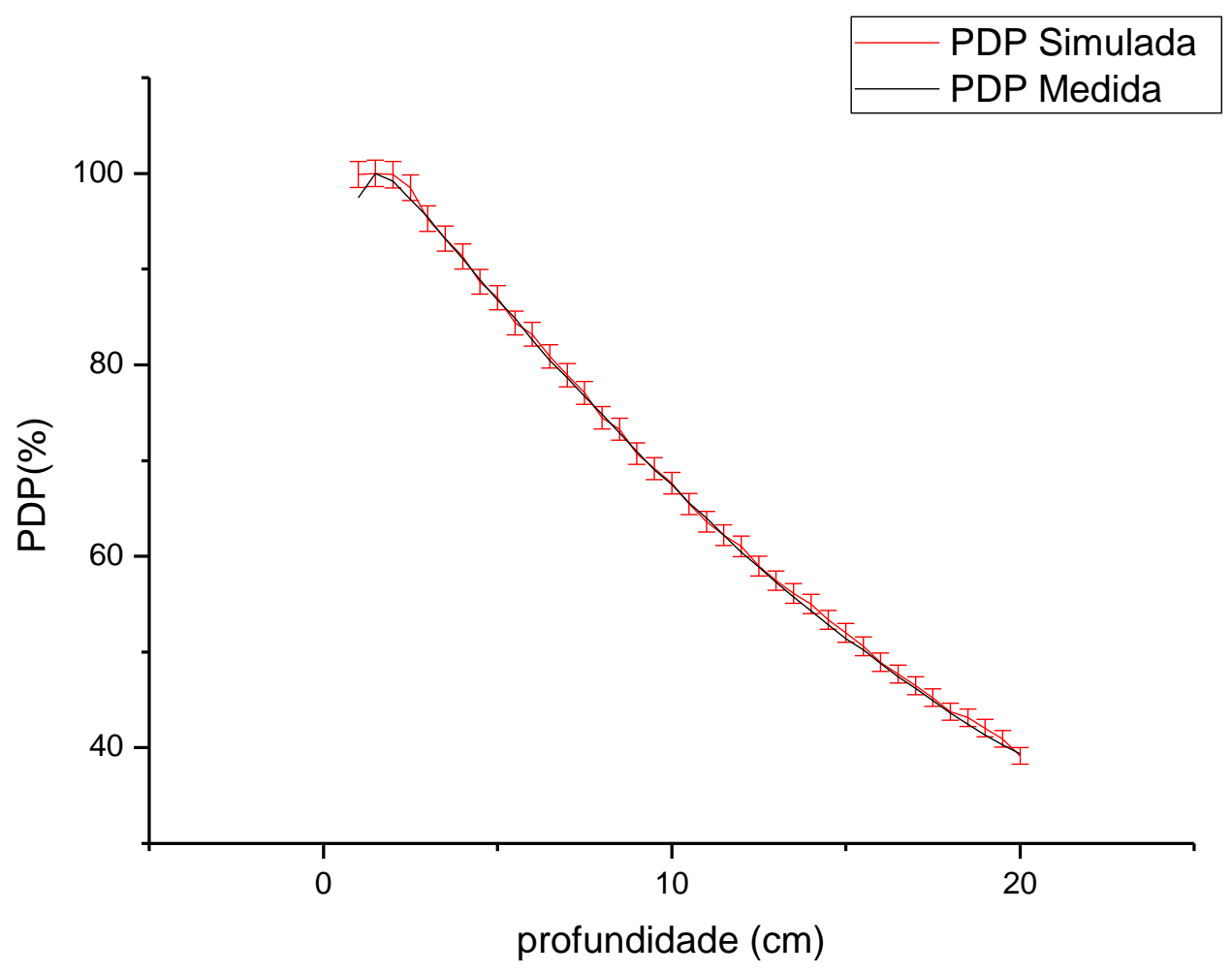

Figura 22 - Gráfico da comparação da PDP simulada em Monte Carlo e as medidas com câmaras de ionização no campo $10 \mathrm{~cm}$ x $10 \mathrm{~cm}$.

A média dos desvios percentuais das PDP entre os valores medidos e o simulados, para o campo $10 \mathrm{~cm}$ x $10 \mathrm{~cm}$ foi $0,78 \%$, com desvio padrão de $0,69 \%$, com apenas um desvio maior que $1,5 \%(2,5 \%)$ e o menor $0 \%$. A incerteza máxima na simulação foi de $1,37 \%$ e a mínima de $0,85 \%$, a média das incertezas ficou em $1,11 \%$. Com estes valores, pode-se concluir que há semelhança entre o feixe da simulação e o do LINAC envolvido neste trabalho, validando, assim, o espectro para o campo $10 \mathrm{~cm}$ x $10 \mathrm{~cm}$. 


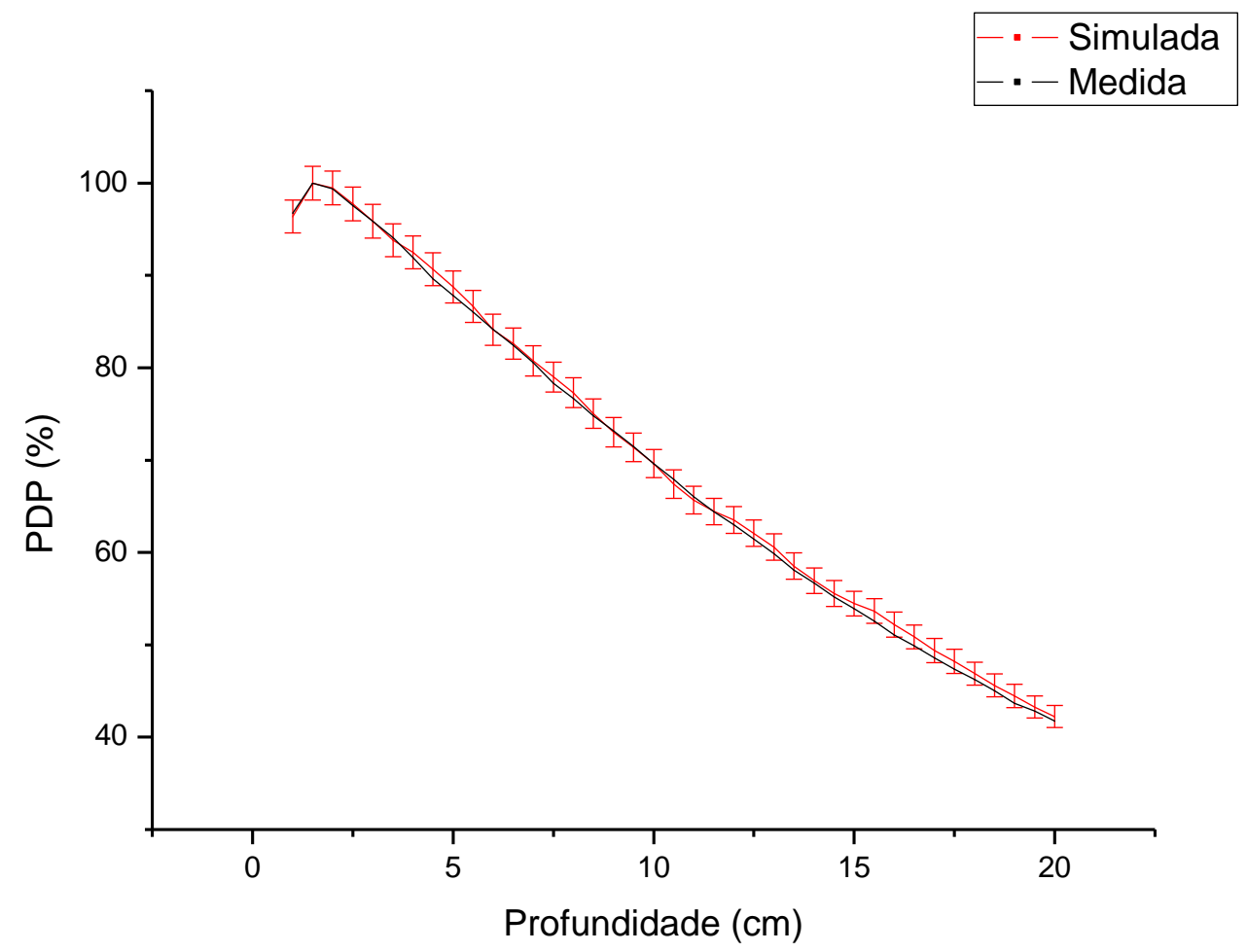

Figura 23 - Gráfico da comparação da PDP simulada em Monte Carlo e as medidas com câmaras de ionização no campo $15 \mathrm{~cm} \times 15 \mathrm{~cm}$.

A média dos desvios percentuais encontradas na PDP entre a simulação calculada e as medidas realizadas no LINAC para o campo de $15 \mathrm{~cm}$ x $15 \mathrm{~cm}$ foi de $0,67 \%$, com desvio padrão de $0,75 \%$. Houve apenas um desvio percentual superior a $2 \%$. A incerteza máxima da simulação foi de $1,82 \%$. Estes resultados também validam o espectro da simulação para o campo $15 \mathrm{~cm} \times 15 \mathrm{~cm}$.

As imagens das Figuras 24, 25 e 26 apresentam as funções gama das simulações Monte Carlo realizadas com o programa desenvolvido em Matlab, entre o plano coronal da distribuição de dose localizada a $56,8 \mathrm{~cm}$ da fonte e a distribuição de dose posicionada a $100 \mathrm{~cm}$ da fonte, para os campos de $5 \mathrm{~cm} \times 5 \mathrm{~cm}, 10 \mathrm{~cm}$ x $10 \mathrm{~cm}$ e $15 \mathrm{~cm}$ x $15 \mathrm{~cm}$, respectivamente. Na Figura 24 à esquerda, pode-se avaliar graficamente a função gama. Na imagem à direita, observa-se que há uma concordância entre o perfil da distribuição de dose magnificada e a distribuição de dose do plano coronal obtida a $100 \mathrm{~cm}$. Nas regiões inferiores à direita, pode-se observar os critérios usados e a porcentagem de pontos aprovados na análise da função gama. 


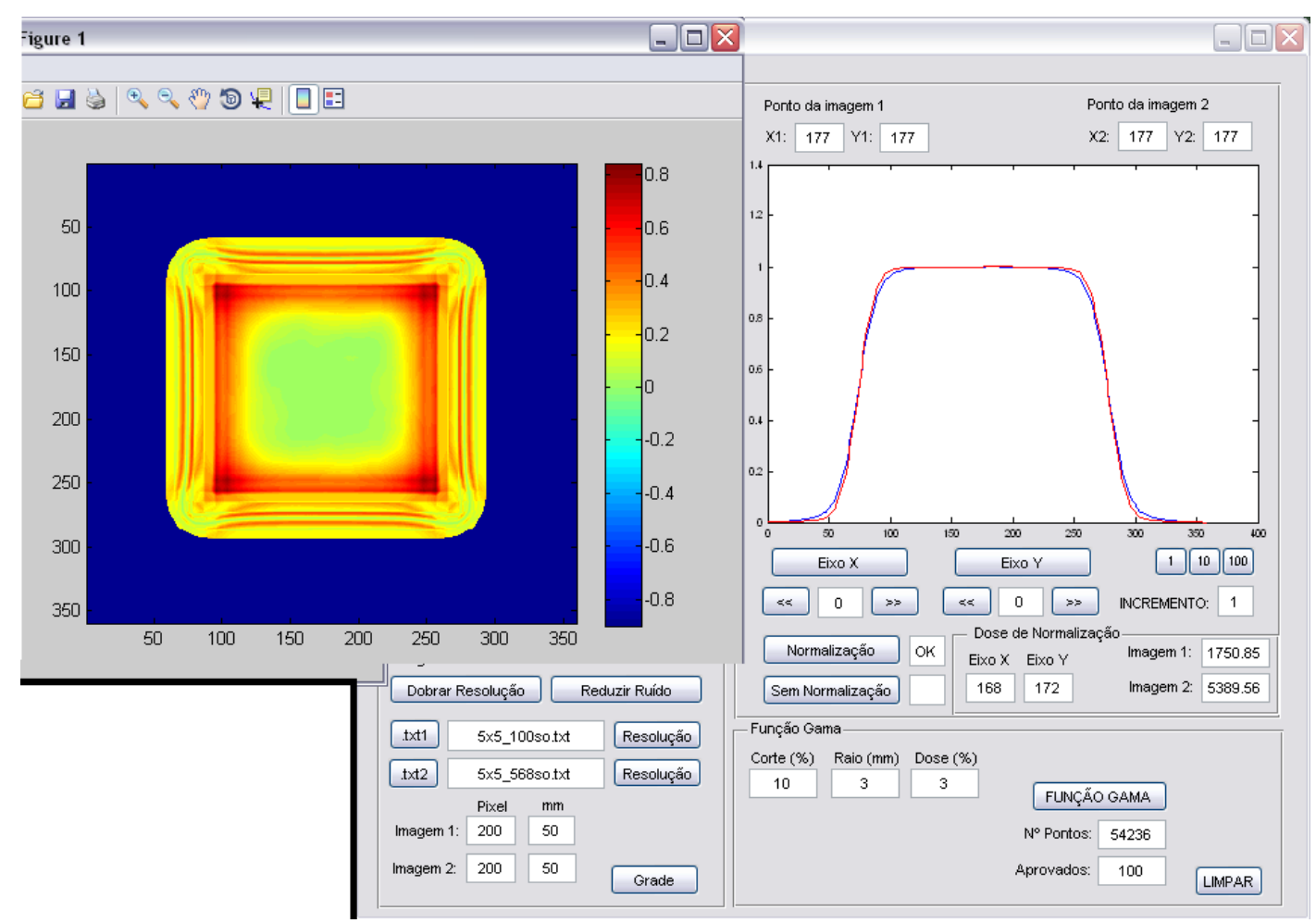

Figura 24 - Função gama comparando o corte coronal da simulação Monte Carlo a 56,8 cm com a distribuição de dose posicionada a $100 \mathrm{~cm}$ para o campo de $5 \mathrm{~cm}$ x $5 \mathrm{~cm}$

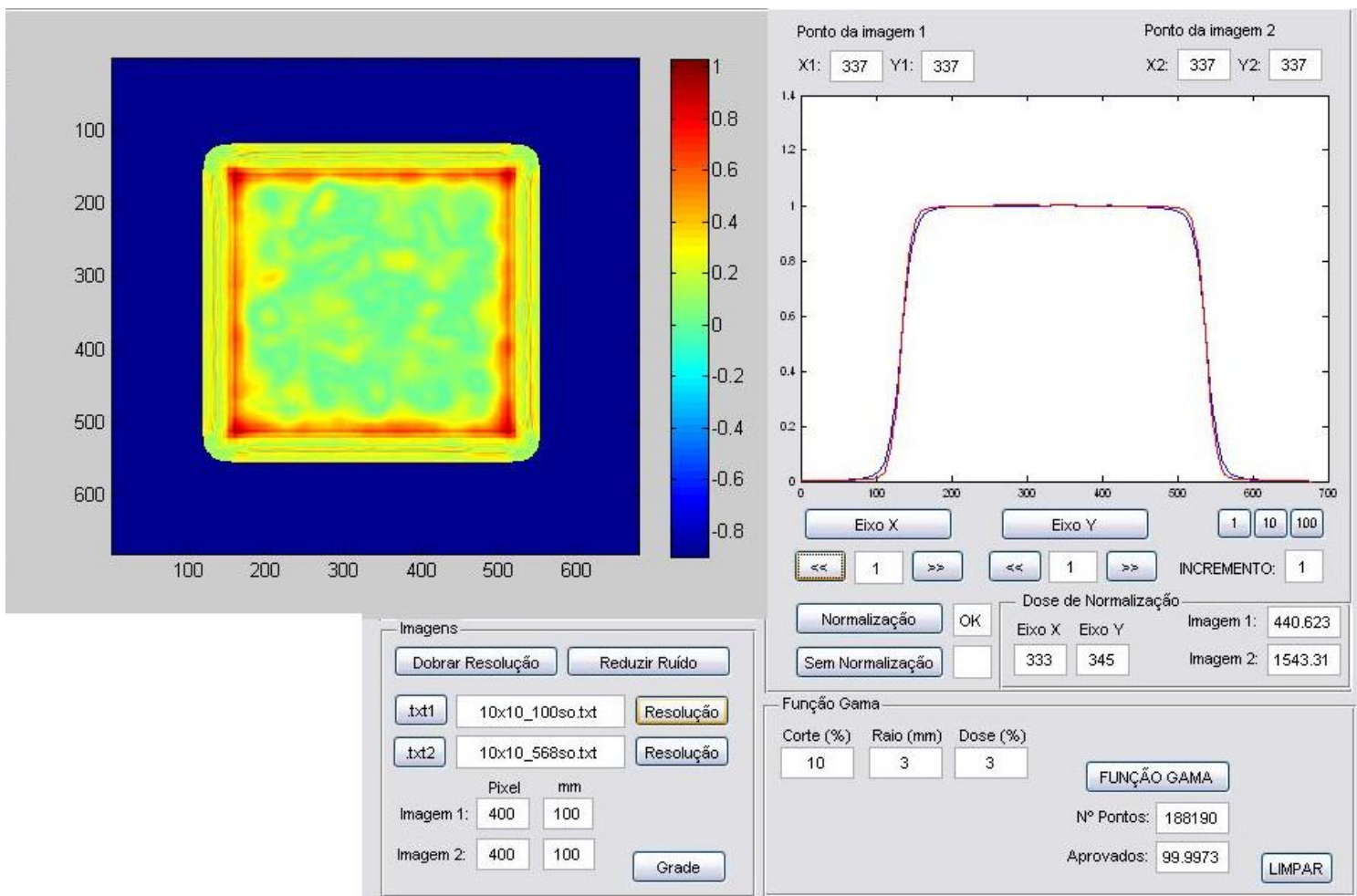

Figura 25 - Função gama comparando o corte coronal da simulação Monte Carlo a 56,8 cm com a distribuição de dose posicionada a $100 \mathrm{~cm}$ para o campo de $10 \mathrm{~cm}$ x $10 \mathrm{~cm}$ 


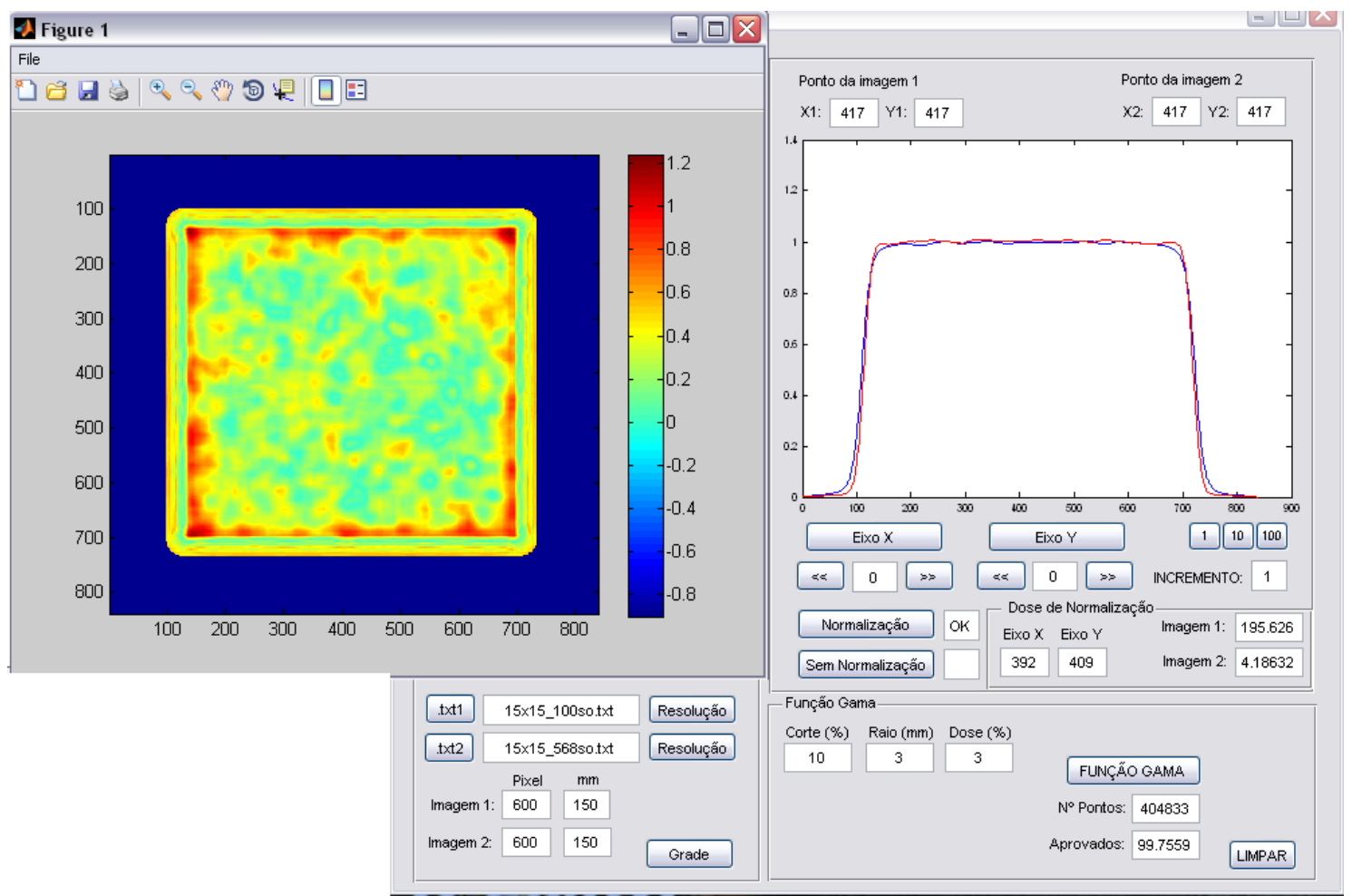

Figura 26 - Função gama comparando o corte coronal da simulação Monte Carlo a 56,8 cm com a distribuição de dose posicionada a $100 \mathrm{~cm}$ para o campo de $15 \mathrm{~cm}$ x $15 \mathrm{~cm}$

A porcentagem dos pontos aprovados no campo de $5 \mathrm{~cm}$ x $5 \mathrm{~cm}$ foi $100 \%$, enquanto no campo de $10 \mathrm{~cm}$ x $10 \mathrm{~cm}$ foi 99,99\% e, no de $15 \mathrm{~cm}$ x $15 \mathrm{~cm}, 99,75 \%$. Sendo assim, a média dos pontos aprovados na função gama foi de $99,92 \pm 0,14 \%$. Isto permite concluir que a distribuição relativa da dose não se modifica significativamente para a geometria empregada neste trabalho quando varia a distância de $56,8 \mathrm{~cm}$ para $100 \mathrm{~cm}$ e, assim, a metodologia de controle da qualidade de transmissão proposta neste trabalho com o dosímetro fixado ao cabeçote pode ser empregada.

\subsubsection{Calibração para as avaliações dosimétricas com campos quadrados e conformacionais}

A Figura 27 apresenta a curva de calibração dos filmes radiocrômicos realizados no software OmniPro I'mrt usados no controle da qualidade de transmissão para as avaliações 
dosimétricas com campos quadrados e conformacionais. Como era esperado, a resposta do filme radiocrômico não é linear com a dose absorvida (BUTSON et al., 2003).

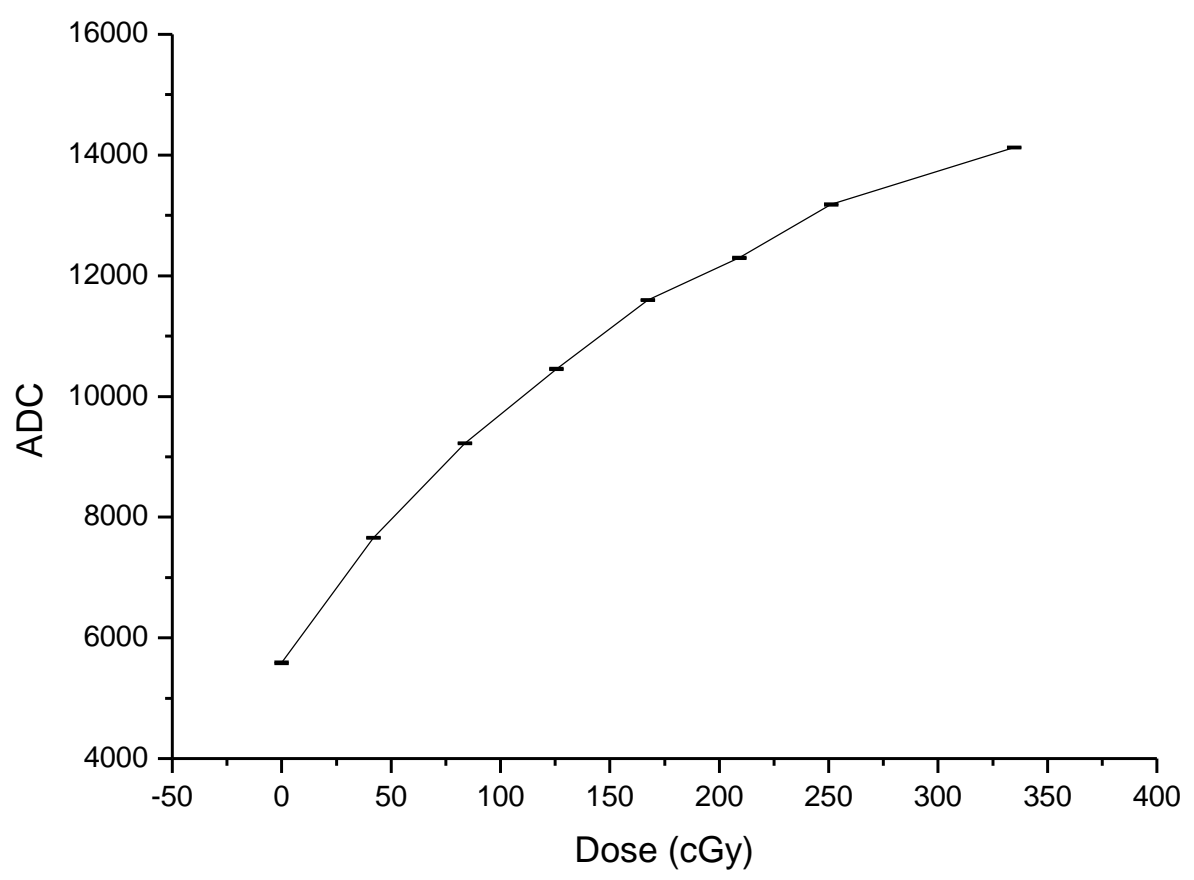

Figura 27 - Calibração associando o conversor digital analógico (ADC) dos filmes digitalizados com as dose calculadas pelo TPS, onde as barras de erro correspondem ao desvio padrão das medidas.

\subsubsection{Comparação entre a distribuição de dose calculada pelo TPS e a adquirida pelo filme}

A Tabela 3 apresenta a comparação entre o valor calculado pelo TPS e o medido pelo filme, a média dos pontos aprovados na função gama foi de $99,85 \%$, com desvio padrão de 0,26\%; a média das diferenças percentuais das doses no ponto de normalização foi de $-1,41 \%$, com desvio padrão de $2,69 \%$. Pode-se observar que os valores encontrados na função gama são semelhantes aos encontrados na simulação Monte Carlo, reafirmando, assim, a concordância entre a distribuição de dose gerada no acessório holder e a gerada no objeto simulador com dimensões semelhantes ao suporte acrílico, porém na distância de $100 \mathrm{~cm}$. 
Tabela 3 - Resultado da comparação entre a distribuição de dose gerada pelo TPS e a distribuição de dose gerada pelo filme.

\begin{tabular}{ccccc}
\hline $\begin{array}{c}\text { Configuração da } \\
\text { Irradiação }\end{array}$ & ${\text { Gama }(\%)^{1}}$ & ${\text { Filme }(\mathbf{c G y})^{2}}$ & ${\text { TPS }(\mathbf{c G y})^{3}}$ & ${\text { Desvio }(\%)^{4}}^{4}$ \\
\hline \hline $5 \mathrm{~cm} \times$ x $5 \mathrm{~cm}$ & 100,0 & 150,3 & 156,7 & $-4,1$ \\
$10 \mathrm{~cm}$ x $10 \mathrm{~cm}$ & 99,9 & 168,0 & 168,9 & $-0,5$ \\
$15 \mathrm{~cm}$ x $15 \mathrm{~cm}$ & 99,4 & 178,2 & 175,3 & 1,6 \\
Campo Irregular & 99,9 & 155,9 & 163,0 & $-4,3$ \\
Conformacional & 99,9 & 250,3 & 249,6 & 0,3 \\
\hline${ }^{1}$ Porcentagem de pontos aprovados na função gama & & \\
${ }^{2}$ Dose no ponto de normalização referente ao filme & & \\
${ }^{3}$ Dose no ponto de normalização referente ao TPS &
\end{tabular}

\subsection{Programa desenvolvido}

Os dados apresentados na Tabela 4 representam as comparações das funções gama realizadas no OmniPro I'mrt e no programa desenvolvido para as simulações de planejamento de próstata, comparando as distribuições de dose originais do plano com a distribuição gerada sem um dos campos. Da mesma forma, é apresentado na Tabela 5 o resultado dos pontos aprovados na função gama e seus desvios percentuais referentes às distribuições geradas no plano de sistema nervoso central (SNC).

Relativamente ao plano de próstata, a média das diferenças entre as funções gama encontradas no programa OmniPro I'mrt e no programa desenvolvido, foi de 0,04\%, com desvio padrão de $0,36 \%$, enquanto a média dos desvios da comparação gama, referente ao plano do SNC, foi de $-0,16 \%$, com desvio padrão de $0,34 \%$. 
Tabela 4 - Resultado das diferenças percentuais no caso de IMRT de próstata entre as funções gama realizadas no programa desenvolvido e o OmniPro I'mrt

\section{COMPARAÇÃO GAMA (IMRT DE PRÓSTATA)}

\begin{tabular}{ccccc}
\hline $\begin{array}{c}\text { Campo } \\
\text { Excluído }\end{array}$ & $\begin{array}{c}\text { Critérios Gama } \\
(\boldsymbol{\%} ; \boldsymbol{\%} ; \mathbf{m m})^{1}\end{array}$ & $\begin{array}{c}\text { OmniPro I'mrt } \\
(\boldsymbol{\%})^{2}\end{array}$ & $\begin{array}{c}\text { Programa Desenvolvido } \\
(\boldsymbol{\%})^{3}\end{array}$ & $\begin{array}{c}\text { Diferença } \\
(\boldsymbol{\%})^{4}\end{array}$ \\
\hline \hline 1 & $10 ; 3 ; 3$ & 92,4 & 92,4 & $-0,1$ \\
2 & $10 ; 3 ; 3$ & 83,5 & 83,4 & $-0,1$ \\
3 & $10 ; 3 ; 3$ & 79,3 & 80,0 & 0,7 \\
4 & $10 ; 3 ; 3$ & 79,2 & 79,9 & 0,7 \\
5 & $10 ; 3 ; 3$ & 83,5 & 83,5 & $-0,1$ \\
\hline 1 & $10 ; 2 ; 2$ & 80,8 & 80,4 & $-0,4$ \\
2 & $10 ; 2 ; 2$ & 63,4 & 63,2 & $-0,2$ \\
3 & $10 ; 2 ; 2$ & 65,8 & 65,5 & $-0,2$ \\
4 & $10 ; 2 ; 2$ & 68,9 & 68,6 & $-0,4$ \\
5 & $10 ; 2 ; 2$ & 67,3 & 67,2 & $-0,2$ \\
\hline 1 & $10 ; 4 ; 4$ & 96,6 & 96,5 & $-0,0$ \\
2 & $10 ; 4 ; 4$ & 90,7 & 90,7 & $-0,0$ \\
3 & $10 ; 4 ; 4$ & 86,3 & 86,5 & 0,3 \\
4 & $10 ; 4 ; 4$ & 85,4 & 86,1 & 0,7 \\
5 & $10 ; 4 ; 4$ & 91,0 & 91,0 & $-0,1$ \\
\hline
\end{tabular}

${ }^{1}$ Critérios: percentual de corte; variação máxima da porcentagem de dose; variação máxima da distância

${ }^{2}$ Porcentagem de pontos aprovados na função gama para o programa OmniPro I'mrt

${ }^{3}$ Porcentagem de pontos aprovados no programa desenvolvido neste trabalho 
Tabela 5 - Resultado das diferenças no caso de IMRT de SNC entre as funções gama realizadas no programa desenvolvido e o OmniPro I'mrt

\begin{tabular}{|c|c|c|c|c|}
\hline \multicolumn{5}{|c|}{ COMPARAÇÃO GAMA (IMRT SNC) } \\
\hline $\begin{array}{c}\text { Campo } \\
\text { Excluído } \\
\end{array}$ & $\begin{array}{c}\text { Critérios Gama } \\
(\% ; \% ; \mathbf{m m})^{1}\end{array}$ & $\begin{array}{c}\text { OmniPro I'mrt } \\
(\%)^{2} \\
\end{array}$ & $\begin{array}{c}\text { Programa Gama } \\
(\%)^{3} \\
\end{array}$ & $\begin{array}{c}\text { Diferença } \\
(\%) \\
\end{array}$ \\
\hline 1 & $10 ; 3 ; 3$ & 93,3 & 93,3 & 0,0 \\
\hline 2 & $10 ; 3 ; 3$ & 94,9 & 94,9 & 0,0 \\
\hline 3 & $10 ; 3 ; 3$ & 91,8 & 91,8 & 0,0 \\
\hline 4 & $10 ; 3 ; 3$ & 89,2 & 88,8 & $-0,4$ \\
\hline 5 & $10 ; 3 ; 3$ & 92,9 & 92,9 & 0,0 \\
\hline 6 & $10 ; 3 ; 3$ & 91,7 & 91,6 & $-0,1$ \\
\hline 7 & $10 ; 3 ; 3$ & 84,1 & 83,8 & $-0,3$ \\
\hline 1 & $10 ; 2 ; 2$ & 80,7 & 80,7 & 0,0 \\
\hline 2 & $10 ; 2 ; 2$ & 86,3 & 86,3 & 0,0 \\
\hline 3 & $10 ; 2 ; 2$ & 77,2 & 77,1 & $-0,1$ \\
\hline 4 & $10 ; 2 ; 2$ & 74,6 & 74,3 & $-0,3$ \\
\hline 5 & $10 ; 2 ; 2$ & 78,3 & 78,3 & 0,0 \\
\hline 6 & $10 ; 2 ; 2$ & 75,5 & 75,3 & $-0,2$ \\
\hline 7 & $10 ; 2 ; 2$ & 59,1 & 57,6 & $-1,5$ \\
\hline 1 & $10 ; 4 ; 4$ & 97,7 & 97,7 & 0,0 \\
\hline 2 & $10 ; 4 ; 4$ & 97,8 & 97,8 & 0,0 \\
\hline 3 & $10 ; 4 ; 4$ & 95,6 & 95,6 & 0,0 \\
\hline 4 & $10 ; 4 ; 4$ & 94,1 & 93,7 & $-0,5$ \\
\hline 5 & $10 ; 4 ; 4$ & 97,0 & 97,0 & 0,0 \\
\hline 6 & $10 ; 4 ; 4$ & 96,4 & 96,4 & 0,0 \\
\hline 7 & $10 ; 4 ; 4$ & 93,1 & 93,1 & 0,0 \\
\hline
\end{tabular}

TCritérios: percentual de corte; variação máxima da porcentagem de dose; variação máxima da distância

${ }^{2}$ Porcentagem de pontos aprovados na função gama para o programa OmniPro I'mrt

${ }^{3}$ Porcentagem de pontos aprovados no programa desenvolvido neste trabalho

O programa desenvolvido neste trabalho mostra resultados na análise da função gama satisfatórios em relação aos resultados obtidos pelo programa OmniPro I'mrt, com uma diferença média, no total dos casos analisados, de $-0,08 \%$, com um desvio padrão de 0,2\%. Não foi possível avaliar a razão dessas diferenças, devido ao fato do OmniPro I'mrt possuir código fechado. Ainda assim pode ser considerado que o programa desenvolvido mostrou-se eficiente na análise da função gama entre duas as distribuições de dose, já que as diferenças são estatisticamente insignificantes e não prejudicarão a avaliação nos procedimentos de um controle da qualidade. 


\subsection{Estudo da metodologia em campos de IMRT}

\subsubsection{Calibração para a avaliação dosimétrica da técnica de IMRT}

A curva de calibração dos filmes usados no controle da qualidade proposto nesta fase do trabalho relaciona os valores de pixel dos filmes em função das doses fornecidas pelo TPS (Figura 28). Como esperado, a resposta do filme radiocrômico não é linear com a dose absorvida (BUTSON et al., 2003).

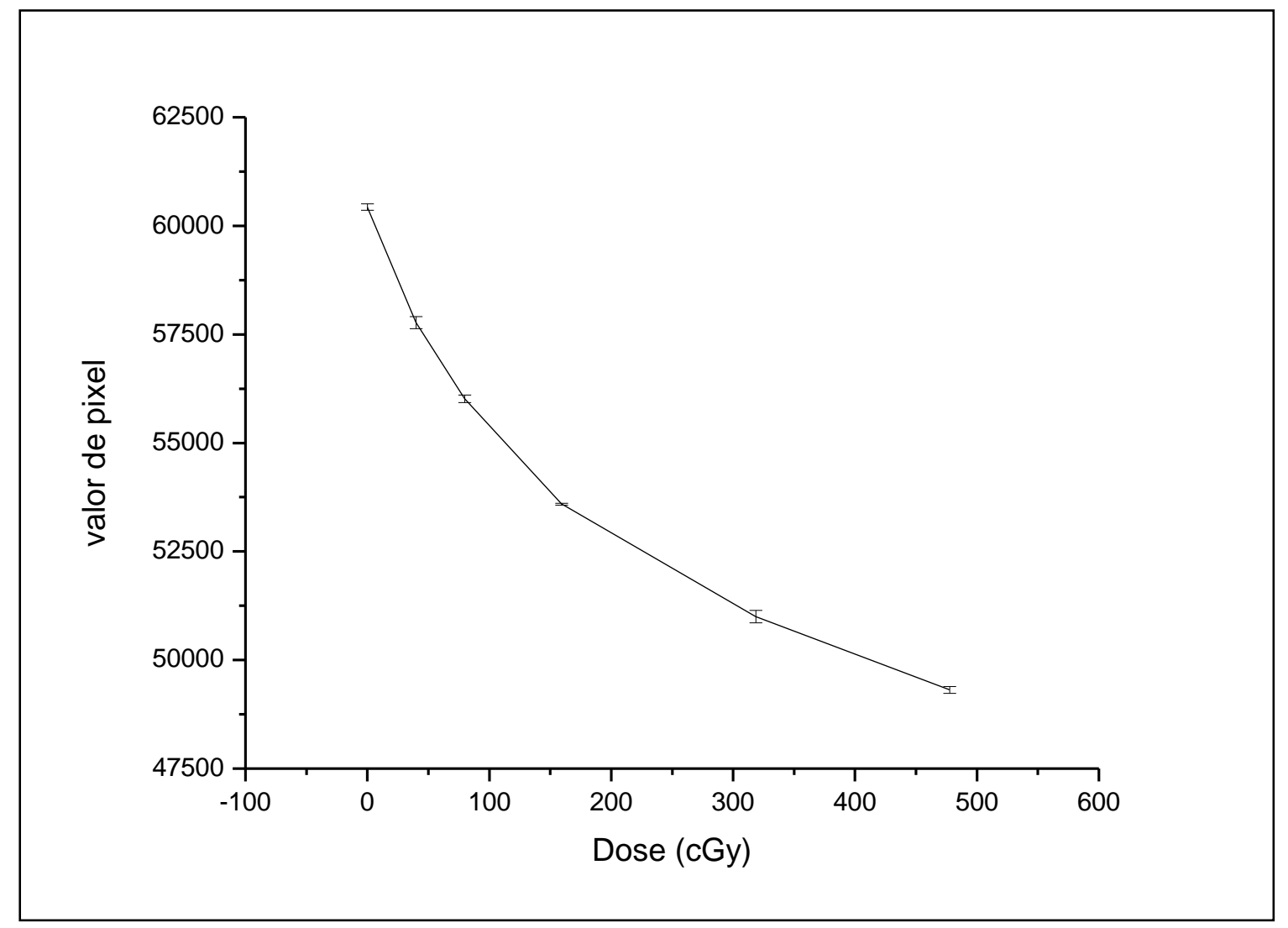

Figura 28 - Calibração associando os valores de pixel dos filmes digitalizados com as dose descritas pelo TPS, onde as barras de erro correspondem ao desvio padrão das medidas 


\subsubsection{Validação da metodologia do controle da qualidade com filme no suporte acrílico}

A Tabela 6 apresenta os dados do controle da qualidade realizado em 5 simulações de planejamento e tratamento de IMRT. Vale destacar que como critérios estabelecidos neste trabalho para aprovação dos controles da qualidade de transmissão, o desvio percentual entre a dose no TPS e no filme, nos pontos de normalização, deve ser menor que $5 \%$ e a porcentagem dos pontos aprovados na função gama maior que $95 \%$. No caso de falha em algum destes critérios, o teste é considerado reprovado.

A Tabela 6 apresenta os resultados do controle da qualidade proposto agrupados em função da configuração da irradiação. A $1^{\mathrm{a}}$ e $2^{\mathrm{a}}$ irradiações correspondem aos planos de tratamento reais, mas com gantry a $0^{\circ}$; a $3^{\text {a }}$ irradiação corresponde ao plano de tratamento com as angulações do gantry reais do planejamento; a $4^{\mathrm{a}}$ irradiação corresponde ao tratamento executado com um número reduzido de unidades monitoras; e a $5^{\text {a }}$ irradiação corresponde ao tratamento real executado com um campo a menos.

Pode-se observar na tabela 6 que o controle da qualidade proposto concordou em 24 das 25 configurações testadas, ou seja, em 96\% dos resultados, o que valida a metodologia proposta. Com relação à configuração em que o controle da qualidade falhou, não se pode garantir que a metodologia proposta seja falha, uma vez que a inconsistência aconteceu em apenas uma configuração avaliada, podendo-se atribuir a diferença de dose encontrada a uma pequena oscilação na resposta do LINAC naquele instante. 
Tabela 6 - Resultados do controle da qualidade proposto agrupados em função da configuração da irradiação

\begin{tabular}{|c|c|c|c|c|c|c|}
\hline & $\begin{array}{c}\text { Planejamento } \\
\text { Analisado }\end{array}$ & $\begin{array}{c}\text { Dose XiO } \\
\text { (cGy) }{ }^{1}\end{array}$ & $\begin{array}{c}\text { Dose Filme } \\
{\text { (cGy })^{2}}^{2}\end{array}$ & $\begin{array}{c}\text { Desvio } \\
(\%)^{3}\end{array}$ & $\begin{array}{c}\text { Gama } \\
(\%)^{4}\end{array}$ & Resultado \\
\hline \multicolumn{7}{|c|}{ Controles da Qualidade Aprovados } \\
\hline \multirow{5}{*}{ 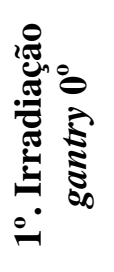 } & 1 & 245,6 & 247,5 & 0,8 & 99,9 & Aprovado \\
\hline & 2 & 185,7 & 176,9 & $-4,7$ & 99,0 & Aprovado \\
\hline & 3 & 253,0 & 253,0 & 0,0 & 98,4 & Aprovado \\
\hline & 4 & 230,2 & 230,0 & $-0,1$ & 98,9 & Aprovado \\
\hline & 5 & 207,5 & 198,7 & $-4,2$ & 96,8 & Aprovado \\
\hline \multirow{5}{*}{ 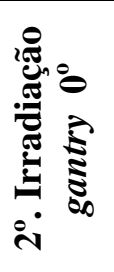 } & 1 & 245,3 & 242,2 & $-1,3$ & 98,3 & Aprovado \\
\hline & 2 & 185,7 & 182,0 & $-2,0$ & 99,7 & Aprovado \\
\hline & 3 & 255,9 & 248,5 & $-2,9$ & 97,7 & Aprovado \\
\hline & 4 & 230,2 & 232,8 & 1,1 & 100,0 & Aprovado \\
\hline & 5 & 197,9 & 191,5 & $-3,2$ & 96,6 & Aprovado \\
\hline \multirow{5}{*}{ 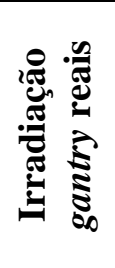 } & 1 & 245,9 & 250,7 & 2,0 & 97,9 & Aprovado \\
\hline & 2 & 173,5 & 166,7 & $-3,9$ & 96,7 & Aprovado \\
\hline & 3 & 252,8 & 252,9 & 0,0 & 98,6 & Aprovado \\
\hline & 4 & 230,2 & 230,1 & 0,0 & 99,4 & Aprovado \\
\hline & 5 & 207,5 & 195,9 & $-5,6$ & 95,5 & Reprovado \\
\hline \multicolumn{7}{|c|}{ Controles da Qualidade Reprovados } \\
\hline \multirow{5}{*}{ 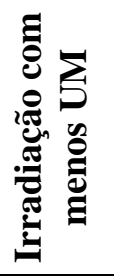 } & 1 & 245,8 & 217,8 & $-11,4$ & 96,9 & Reprovado \\
\hline & 2 & 173,5 & 137,5 & $-20,7$ & 99,7 & Reprovado \\
\hline & 3 & 252,6 & 159,6 & $-36,8$ & 98,2 & Reprovado \\
\hline & 4 & 230,2 & 197,1 & $-14,4$ & 97,1 & Reprovado \\
\hline & 5 & 208,7 & 165,8 & $-20,6$ & 99,8 & Reprovado \\
\hline \multirow{5}{*}{ 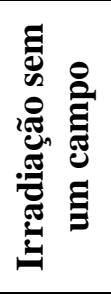 } & 1 & 245,7 & 220,1 & $-10,4$ & 92,9 & Reprovado \\
\hline & 2 & 185,7 & 148,9 & $-19,8$ & 99,5 & Reprovado \\
\hline & 3 & 252,8 & 226,4 & $-10,4$ & 47,3 & Reprovado \\
\hline & 4 & 230,2 & 219,6 & $-4,6$ & 51,0 & Reprovado \\
\hline & 5 & 208,5 & 159,1 & $-23,7$ & 70,2 & Reprovado \\
\hline
\end{tabular}

\footnotetext{
${ }^{1}$ Dose no sistema de planejamento XiO no ponto de normalização

${ }^{2}$ Dose obtida no filme

${ }^{3}$ Desvios percentuais entre as doses medidas pelo filme e calculadas pelo TPS no ponto de normalização

${ }^{4}$ Porcentagem de pontos aprovados na função gama
}

A Figura 29 apresenta a imagem da distribuição de fluência do campo retirado do paciente 2 no estudo da irradiação sem um dos campos, onde se pode observar que o campo em questão não apresenta um gradiente elevado de dose, não modificando significativamente a fluência da distribuição de dose alcançada pelo somatório de todos os campos, justificando assim a alta porcentagem de aprovação na avaliação do índice gama quando esse campo foi 
retirado do controle da qualidade de transmissão. Entretanto, o controle foi reprovado, pois a diferença da dose no ponto de normalização foi de 19,8\%. É importante ressaltar que este valor está de acordo com o esperado, já que o plano em questão possui 5 campos e, desta forma, o campo retirado contribui com aproximadamente $20 \%$ da dose total.

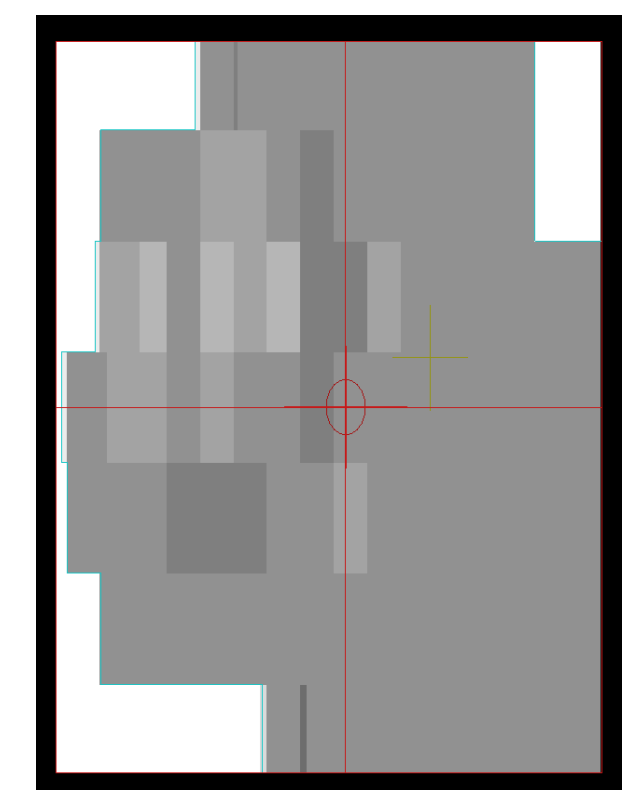

Figura 29 - Distribuição de fluência do campo retirado do paciente 2 no estudo da irradiação sem um campos

A Figura 30 apresenta a distribuição de fluência relativa ao campo retirado do paciente 4, no estudo da irradiação sem um dos campos. É importante lembrar que os pontos de normalização foram adquiridos no centro da distribuição e, como este campo contribui pouco com a dose nessa região, a diferença da dose no ponto de normalização deve ser pequena com sua ausência. Justificando, portanto, a pequena variação da dose de $-4,6 \%$ encontrada neste estudo. Contudo, o controle foi reprovado, como esperado, pela variação significativa da distribuição da dose na avaliação global, tendo em vista que apenas $51 \%$ dos pontos foram aprovados na função gama. 


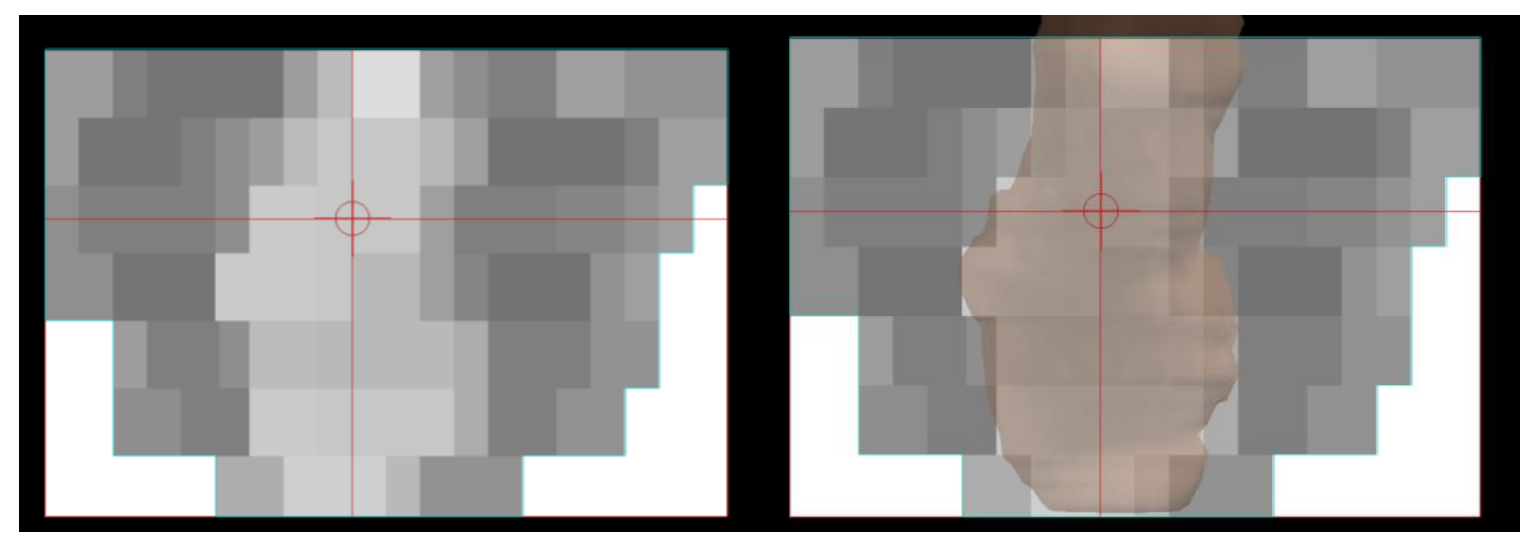

Figura 30 - Distribuição da fluência relativa ao campo posterior (gantry 180) do paciente 4. À esquerda a distribuição sem a imagem de projeção da próstata e à direita com a imagem projetada do órgão de risco em questão

A metodologia de controle da qualidade de transmissão proposta nesta fase do trabalho teve o objetivo de verificar uma simulação da distribuição de dose entregue in vivo pelo acelerador, após as aprovações dos controles da qualidade convencionais, ou seja, assume-se que o plano de tratamento que está sendo avaliado já foi aprovado no controle da qualidade individual dos planejamentos e, assim, deveria ser aprovado também na simulação in vivo. Dessa forma, caso o teste não seja aprovado na metodologia de transmissão proposta, o usuário não deve anular o plano imediatamente e sim reavaliá-lo.

\subsubsection{Reprodutibilidade na digitalização na técnica de IMRT}

Os resultados da reprodutibilidade na digitalização dos filmes nos controles da qualidade realizados nas 10 simulações de planejamentos de IMRT com as duas digitalizações dos filmes para a diferença de dose no ponto de normalização esperada pelo TPS e obtida pelo filme estão apresentados na Tabela 7, enquanto que os dados da função gama obtidos na comparação entre as distribuições de dose esperada pelo TPS e obtida pelo filme, estão apresentados na Tabela 8 . 
Tabela 7 - Resultado do desvio percentual da dose esperada pelo TPS e obtida pelo filme no ponto de normalização para as duas digitalizações do filme

\begin{tabular}{|c|c|c|c|}
\hline $\begin{array}{c}\text { Planejamento } \\
\text { Analisado }\end{array}$ & $\begin{array}{c}\text { Desv. Dose Dig. } 1 \\
(\%)^{1}\end{array}$ & $\begin{array}{c}\text { Desv. Dose Dig. } 2 \\
(\%)^{2}\end{array}$ & $\begin{array}{c}\text { Diferença } \\
\text { Dig.1 x Dig. } 2^{3}\end{array}$ \\
\hline 1 & 0,8 & 0,5 & $-0,3$ \\
\hline 2 & $-4,7$ & $-3,8$ & 0,9 \\
\hline 3 & 0,0 & 0,0 & 0,0 \\
\hline 4 & $-0,1$ & 0,0 & 0,1 \\
\hline 5 & $-4,2$ & $-4,3$ & $-0,1$ \\
\hline 6 & $-1,3$ & $-1,3$ & 0,0 \\
\hline 7 & $-2,0$ & $-2,6$ & $-0,6$ \\
\hline 8 & $-2,9$ & $-1,3$ & 1,6 \\
\hline 9 & 1,1 & 1,7 & 0,5 \\
\hline 10 & $-3,2$ & $-3,4$ & $-0,1$ \\
\hline
\end{tabular}

\footnotetext{
${ }^{1}$ Desvio percentual de dose encontrada na $1^{\circ}$ digitalização do filme

${ }^{2}$ Desvio percentual de dose encontrada na $2^{\circ}$ digitalização

${ }^{3}$ Diferença entre as duas digitalizações
}

Tabela 8 - Resultado da função gama na comparação entre as distribuições de dose esperada pelo TPS e obtida pelo filme para as duas digitalizações

\begin{tabular}{cccc}
\hline $\begin{array}{c}\text { Planejamento } \\
\text { Analisado }\end{array}$ & $\begin{array}{c}\text { Gama Dig. 1 } \\
\mathbf{( \% )}^{1}\end{array}$ & $\begin{array}{c}\text { Gama Dig. 2 } \\
\mathbf{( \% )}^{2}\end{array}$ & $\begin{array}{c}\text { Diferença } \\
\text { Gama Dig. 1 x Dig. 2 }^{3}\end{array}$ \\
\hline \hline 1 & 99,9 & 99,9 & 0,0 \\
2 & 99,0 & 98,1 & 0,9 \\
3 & 98,4 & 99,4 & $-1,0$ \\
4 & 98,9 & 98,9 & 0,0 \\
5 & 96,8 & 96,6 & 0,2 \\
6 & 98,3 & 99,7 & $-1,4$ \\
7 & 99,7 & 99,3 & 0,4 \\
8 & 97,7 & 99,0 & $-1,3$ \\
9 & 100,0 & 99,8 & 0,2 \\
10 & 96,6 & 98,3 & $-1,7$ \\
\hline
\end{tabular}

\footnotetext{
${ }^{1}$ Porcentagem de pontos aprovados na função gama referente à $1^{\text {a }}$ digitalização do filme

${ }^{2}$ Porcentagem de pontos aprovados na função gama referente à $2^{\text {a }}$ digitalização

${ }^{3}$ Diferença entre as duas porcentagens da função gama
}

Na Tabela 7 observa-se uma boa reprodutibilidade nas digitalizações, já que o desvio médio nas doses nos pontos de normalização foi de $0,20 \%$, com desvio padrão de $0,66 \%$. O mesmo acontece na Tabela 8, que evidencia uma boa reprodutibilidade entre as funções gama para as diferentes digitalizações, tendo em vista que o desvio médio foi de $-0,37 \%$, com desvio padrão de $0,90 \%$. 


\subsubsection{Reprodutibilidade do controle da qualidade de transmissão na técnica de IMRT}

Os resultados do controle da qualidade efetuado nos 5 planejamentos de IMRT realizados nas duas irradiações, para a diferença de dose no ponto de normalização esperada pelo TPS e obtida pelo filme, estão apresentados na Tabela 9 e, para a função gama na comparação entre as distribuições de dose esperadas pelo TPS e obtidas pelo filme, os resultados estão apresentados na Tabela 10.

Tabela 9 - Desvios percentuais entre a dose no ponto de normalização esperada pelo TPS e obtida pelo filme nas duas irradiações com o filme no suporte

\begin{tabular}{|c|c|c|c|}
\hline $\begin{array}{c}\text { Planejamento } \\
\text { Analisado } \\
\end{array}$ & $\begin{array}{c}\text { Desv. Dose Irrad. } 1 \\
(\%)^{1}\end{array}$ & $\begin{array}{c}\text { Desv. Dose Irrad. } 2 \\
(\%)^{2}\end{array}$ & $\begin{array}{c}\text { Diferença } \\
\text { Irrad. } 1 \text { x Irrad. } 2(\%) \\
\end{array}$ \\
\hline 1 & 0,8 & $-1,3$ & 2,0 \\
\hline 2 & $-4,7$ & $-2,0$ & $-2,7$ \\
\hline 3 & 0,0 & $-2,9$ & 2,9 \\
\hline 4 & $-0,1$ & 1,1 & $-1,2$ \\
\hline 5 & $-4,2$ & $-3,2$ & $-1,0$ \\
\hline
\end{tabular}

\footnotetext{
${ }^{1}$ Porcentagem de pontos aprovados na $1^{\mathrm{a}}$ irradiação

${ }^{2}$ Porcentagem de pontos aprovados na $2^{\mathrm{a}}$ irradiação

${ }^{3}$ Diferença entre as duas irradiações
}

Tabela 10 - Resultado da função gama na comparação entre as distribuições de dose esperada pelo TPS e obtida pelo filme para as duas irradiações

\begin{tabular}{cccc}
\hline $\begin{array}{c}\text { Planejamento } \\
\text { Analisado }\end{array}$ & $\begin{array}{c}\text { Gama Irrad. 1 } \\
(\boldsymbol{\%})^{1}\end{array}$ & $\begin{array}{c}\text { Gama Irrad. 2 } \\
(\boldsymbol{\%})^{2}\end{array}$ & $\begin{array}{c}\text { Diferença } \\
\text { Gama Irrad. 1 x Irrad. 2 (\%) })^{3}\end{array}$ \\
\hline \hline 1 & 99,9 & 98,3 & 1,6 \\
2 & 99,0 & 99,7 & $-0,7$ \\
3 & 98,4 & 97,7 & 0,7 \\
4 & 98,9 & 100,0 & $-1,1$ \\
5 & 96,8 & 96,6 & 0,2 \\
\hline
\end{tabular}

\footnotetext{
${ }^{1}$ Porcentagem de pontos aprovados na $1^{\mathrm{a}}$ irradiação

${ }^{2}$ Porcentagem de pontos aprovados na $2^{\text {a }}$ irradiação

${ }^{3}$ Diferença entre as duas irradiações
} 
O desvio médio entre as doses no ponto de normalização para a irradiação 1 e a irradiação 2, com o filme no suporte acrílico para a metodologia utilizada neste trabalho, foi de $-0,01$, com desvio padrão de 2,37. É importante lembrar que os dois controles da qualidade são independentes e os pontos de normalização são escolhidos manualmente pelo usuário em cada caso. Em geral, mesmo que o usuário deseje, como é o caso deste trabalho, esses pontos não estarão no mesmo lugar e isso pode explicar o desvio padrão maior, porém não afetou significativamente o valor da função gama. A diferença média entre as funções gama, no filme, entre as duas irradiações, foi de $0,14 \%$, com desvio padrão de $1,08 \%$.

\subsubsection{Comparação entre o controle da qualidade de transmissão e de outros sistemas dosimétricos na técnica de IMRT}

A fim de verificar se a metodologia de controle da qualidade de transmissão proposta neste trabalho está de acordo com os resultados obtidos por metodologias de controle da qualidade padrão e aceitas atualmente, comparou-se a porcentagem de pontos aprovados na análise gama no controle da qualidade de transmissão proposto com as porcentagens de pontos aprovados na análise gama das distribuições de dose obtidas com outros dois sistemas utilizados atualmente, o MatriXX e o filme radiocrômico no isocentro do LINAC coberto por placas de água sólida.

\subsubsection{Comparação entre os controles da qualidade de transmissão e do MatriXX}

Na Tabela 11 estão apresentados os percentuais de pontos aprovados nas análises gama no controle da qualidade de transmissão proposto e no controle da qualidade realizado com o MatriXX, além das diferenças entre ambas. Os dados revelam a semelhança entre os resultados, justificada pela diferença média de $-0,22 \%$, com apenas um desvio acima de $3 \%$. A maior diferença encontrada foi de 4,9\% entre a função gama do MatriXX e da metodologia proposta com filme, valor este que pode ser justificado pela baixa resolução espacial do MatriXX e, principalmente, pelo equilíbrio eletrônico lateral e alcance máximo dos elétrons secundários, que contribuem significativamente para a distorção do sinal em gradientes 
elevados, como os que são apresentados com detectores com dimensões semelhantes às proporcionadas pelo MatriXX (POPPE et al., 2007).

Tabela 11 - Comparação entre os percentuais de pontos aprovados na análise gama no controle da qualidade de transmissão proposto e no controle da qualidade realizado com o MatriXX

\begin{tabular}{|c|c|c|c|}
\hline $\begin{array}{c}\text { Planejamento } \\
\text { Analisado }\end{array}$ & $\begin{array}{c}\text { CQ transmissão } \\
(\%)^{1}\end{array}$ & $\begin{array}{c}\text { MatriXX } \\
(\%)^{2}\end{array}$ & $\begin{array}{c}\text { Diferença } \\
(\%)^{3}\end{array}$ \\
\hline 1 & 99,9 & 95,0 & 4,9 \\
\hline 2 & 99,0 & 100,0 & $-1,0$ \\
\hline 3 & 98,4 & 99,5 & $-1,1$ \\
\hline 4 & 98,9 & 100,0 & $-1,1$ \\
\hline 5 & 96,8 & 99,6 & $-2,8$ \\
\hline
\end{tabular}

\footnotetext{
${ }^{1}$ Porcentagem de pontos aprovados na análise gama na metodologia de transmissão proposta;

${ }^{2}$ Porcentagem de pontos aprovados na análise gama no controle da qualidade realizado com o MatriXX

${ }^{3}$ Diferença entre os dois controles da qualidade
}

\subsubsection{Comparação entre o controle da qualidade de transmissão e do filme no isocentro}

$\mathrm{Na}$ Tabela 12 estão apresentados os percentuais de pontos aprovados nas análises gama no controle da qualidade de transmissão proposto e no controle da qualidade realizado com filme radiocrômico no isocentro, além das diferenças entre ambas. Pode-se observar a semelhança entre os resultados, justificada pela diferença média entre as funções gama nas duas metodologias de $-1,06 \%$, com desvio padrão de 0,67 . Este resultado, obtido com alta resolução espacial com filme nas duas metodologias estudadas, corrobora a justificativa apresentada na abordagem das diferenças encontradas na comparação das funções gama entre o controle da qualidade de transmissão proposto e o controle da qualidade realizado pelo MatriXX, ou seja, a baixa resolução espacial, relativa à dimensão dos detectores e à distância entre os mesmos. 
Tabela 12 - Comparação entre os percentuais de pontos aprovados na análise gama no controle da qualidade de trasmissão proposto e no controle da qualidade realizado com o filme radiocrômico no isocentro

\begin{tabular}{cccc}
\hline $\begin{array}{c}\text { Planejamento } \\
\text { analisado }\end{array}$ & $\begin{array}{c}\text { CQ transmissão } \\
(\mathbf{\%})^{\mathbf{1}}\end{array}$ & $\begin{array}{c}\text { Filme no Isocentro } \\
(\mathbf{\%})^{\mathbf{2}}\end{array}$ & $\begin{array}{c}\text { Diferença } \\
(\boldsymbol{\%})^{\mathbf{3}^{3}}\end{array}$ \\
\hline \hline 1 & 99,9 & 100,0 & $-0,1$ \\
2 & 99,0 & 99,8 & $-0,8$ \\
3 & 98,4 & 99,8 & $-1,4$ \\
4 & 98,9 & 100,0 & $-1,1$ \\
5 & 96,8 & 98,7 & $-1,9$ \\
\hline
\end{tabular}

1- porcentagem de pontos aprovados na análise gama na metodologia de transmissão proposta

2- porcentagem de pontos aprovados na análise gama no controle da qualidade realizado com o filme radiocrômico no isocentro

3- diferença entre os dois controles da qualidade

\subsection{Estudo da avaliações dosimétricas in vivo}

\subsubsection{Calibrações para as avaliações dosimétricas in vivo}

As Figuras 31 e 32 apresentam as curvas de calibração dos filmes usados nas avaliações in vivo. A Figura 29 descreve a curva de calibração referente às distribuições coletadas no centro das imagens tomográficas presentes no TPS, enquanto a Figura 30 apresenta a curva de calibração referente à distribuição da dose gerada pelo TPS, no limite inferior da imagem tomográfica do objeto simulador de $1 \mathrm{~cm}$ de espessura. Como era esperado, as respostas dos filmes radiocrômicos não é linear com a dose absorvida (BUTSON et al., 2003). 


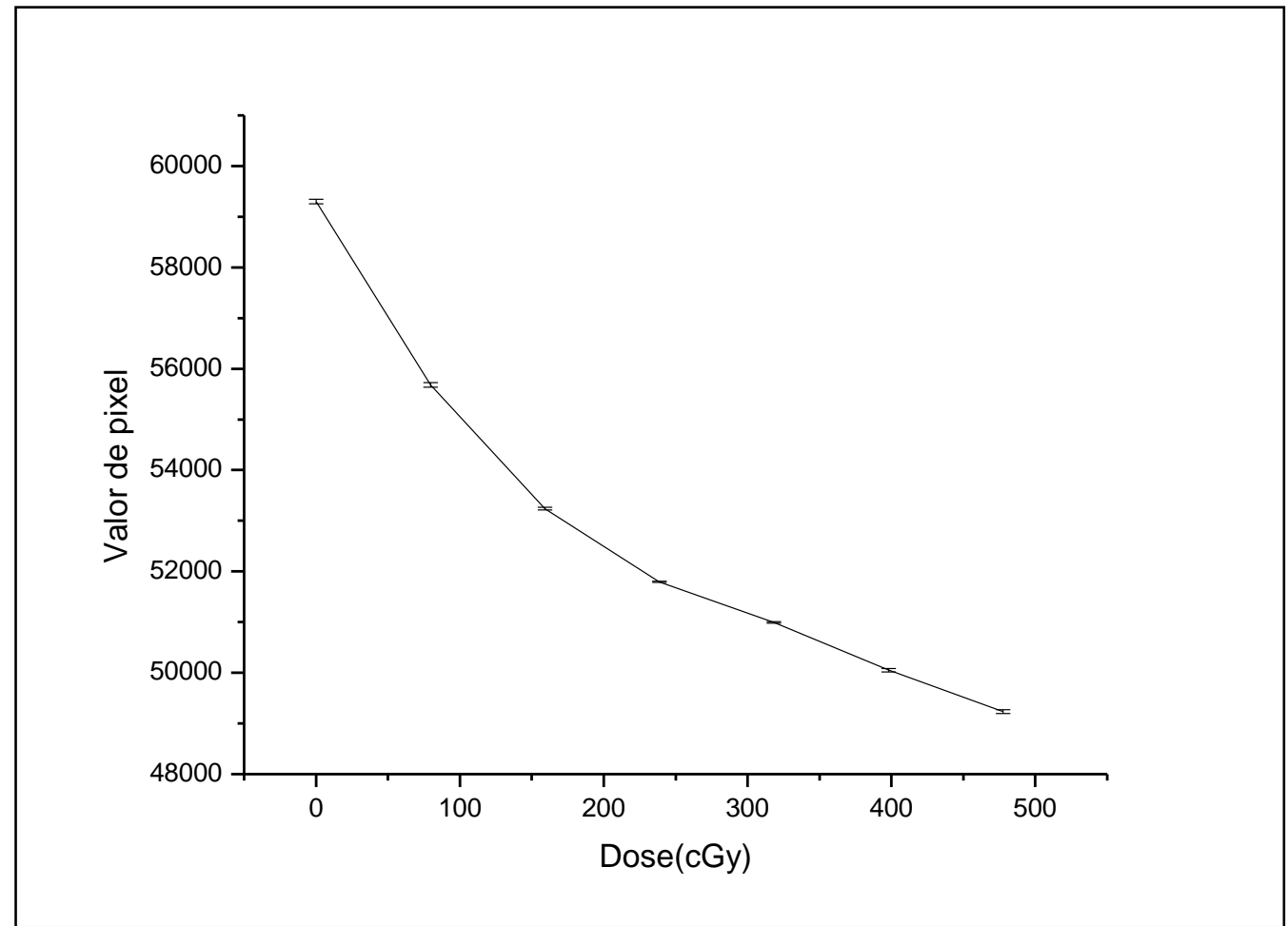

Figura 31 - Calibração associando os valores de pixel dos filmes digitalizados com as dose coletadas no meio da imagem do objeto simulador no TPS, onde as barras de erro correspondem ao desvio padrão das medidas.

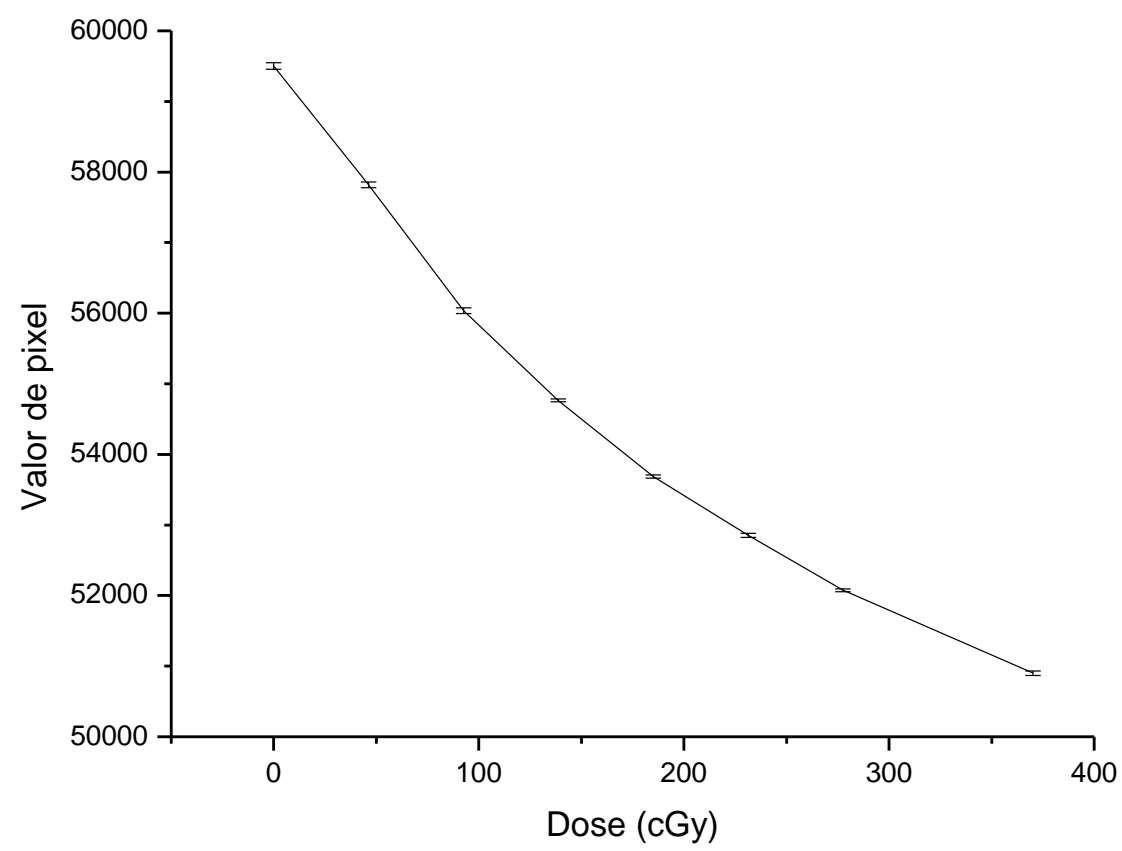

Figura 32 - Calibração associando os valores de pixel dos filmes digitalizados com as dose coletadas no limite inferior do objeto simulador no TPS, onde as barras de erro correspondem ao desvio padrão das medidas 


\subsubsection{Avaliações in vivo}

As Tabelas 13 e 14 apresentam os resultados da avaliação in vivo dos pacientes tratados na técnica de IMRT. Na Tabela 13 estão os resultados da avaliação da distribuição de dose obtida no centro da imagem tomográfica do objeto simulador no TPS, enquanto na Tabela 14 estão os resultados referentes à distribuição de dose adquirida na região inferior da imagem do objeto simulador. Convém enfatizar que, em ambas as tabelas, o resultado (aprovado ou reprovado) foi obtido pela aplicação dos critérios definidos pela metodologia, ou seja, o desvio da dose inferior a $5 \%$ e a porcentagem de pontos aprovados na função gama superior a $95 \%$.

Na Tabela 13, a média dos desvios percentuais da dose no ponto de normalização foi de 0,7\% e apenas 7 desvios foram superiores a 3\%. A média das funções gama foi de 97,4\%, com desvio padrão de 1,2\%. Observa-se que apenas 1 resultado foi reprovado em 32 analisados, ou seja, obteve-se aproximadamente $97 \%$ de aprovação, ainda pode-se notar que a variação na dose que ultrapassou o limite do critério estabelecido neste trabalho foi de apenas $0,4 \%$, corresponde à diferença entre o valor da dose no ponto de normalização $(5,4 \%)$ e o critério de aceitação é (5\%). É importante ressaltar que, quando um controle da qualidade falha, não se deve eliminar o plano de imediato, mas sim reavalia-lo; no caso do paciente 6 , para o qual houve uma reprovação no segundo controle da qualidade de transmissão in vivo, os outros controles da qualidade foram aprovados, inclusive o "In vivo 3", que foi realizado em um dia subsequente. Assim, pode-se concluir que a diferença foi devida a uma pequena variação momentânea e pontual em alguns dos componentes do LINAC.

Na Tabela 14, pode-se observar que todos os controles da qualidade foram aprovados, confirmando a validade da técnica de avaliação in vivo. A média dos desvios percentuais das doses no ponto de normalização foi $-0,7 \%$, com desvio padrão de 2,2\%. Apenas 2 desvios foram superiores a $3 \%$ e a média das funções gama foi de $99,1 \%$, com desvio padrão de $1,1 \%$. 
Tabela 13 - Resultados da avaliação in vivo referentes à distribuição da dose coletada no centro da imagem do objeto simulador no TPS

\begin{tabular}{|c|c|c|c|c|c|c|}
\hline $\begin{array}{c}\text { Paciente } \\
\text { Analisado }\end{array}$ & Aplicação ${ }^{1}$ & $\begin{array}{c}\text { Dose } \\
\text { Filme }\end{array}$ & $\begin{array}{l}\text { Dose } \\
\text { XiO }^{3}\end{array}$ & $\begin{array}{c}\text { Desvio } \\
(\%)^{4}\end{array}$ & $\underset{(\%)^{5}}{\text { Gama }}$ & Resultado $^{6}$ \\
\hline \multirow{4}{*}{ 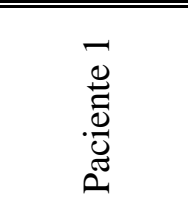 } & QA & 214,1 & 206,6 & 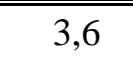 & 97,6 & $\mathrm{AP}$ \\
\hline & In vivo 1 & 214,0 & 203,8 & 5,0 & 99,4 & AP \\
\hline & In vivo 2 & 214,1 & 204,8 & 4,5 & 99,5 & $\mathrm{AP}$ \\
\hline & In vivo 3 & 214,1 & 208,4 & 2,7 & 98,9 & $\mathrm{AP}$ \\
\hline \multirow{4}{*}{ 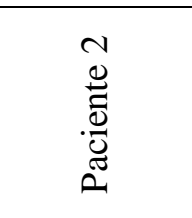 } & QA & 194,1 & 195,7 & $-0,8$ & 96,5 & $\mathrm{AP}$ \\
\hline & In vivo 1 & 194,0 & 192,4 & 0,8 & 95,5 & $\mathrm{AP}$ \\
\hline & In vivo 2 & 196,0 & 200,9 & $-2,4$ & 96,5 & AP \\
\hline & In vivo 3 & 193,8 & 196,5 & $-1,4$ & 97,7 & AP \\
\hline \multirow{4}{*}{ 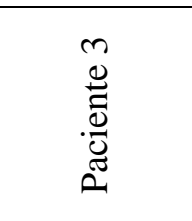 } & QA & 161,5 & 155,4 & 3,9 & 98,2 & $\mathrm{AP}$ \\
\hline & In vivo 1 & 162,5 & 165,2 & $-1,6$ & 98,2 & $\mathrm{AP}$ \\
\hline & In vivo 2 & 162,3 & 158,1 & 2,7 & 97,7 & AP \\
\hline & In vivo 3 & 162,0 & 162,0 & 0,0 & 97,0 & $\mathrm{AP}$ \\
\hline \multirow{4}{*}{ 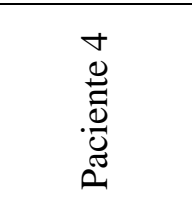 } & QA & 294,8 & 285,1 & 3,4 & 97,1 & $\mathrm{AP}$ \\
\hline & In vivo 1 & 294,5 & 294,0 & 0,2 & 98,1 & AP \\
\hline & In vivo 2 & 296,0 & 288,2 & 2,7 & 97,4 & $\mathrm{AP}$ \\
\hline & In vivo 3 & 295,1 & 293,5 & 0,5 & 95,7 & $\mathrm{AP}$ \\
\hline \multirow{4}{*}{ 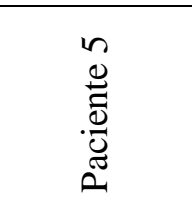 } & QA & 323,3 & 330,5 & $-2,2$ & 95,5 & $\mathrm{AP}$ \\
\hline & In vivo 1 & 324,6 & 330,7 & $-1,8$ & 95,5 & $\mathrm{AP}$ \\
\hline & In vivo 2 & 323,6 & 323,9 & $-0,1$ & 96,3 & $\mathrm{AP}$ \\
\hline & In vivo 3 & 323,6 & 330,8 & $-2,2$ & 97,3 & AP \\
\hline \multirow{4}{*}{ 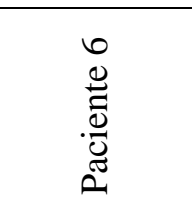 } & QA & 160,4 & 159,0 & 0,9 & 99,5 & $\mathrm{AP}$ \\
\hline & In vivo 1 & 160,5 & 160,7 & $-0,1$ & 97,5 & $\mathrm{AP}$ \\
\hline & In vivo 2 & 160,3 & 152,1 & 5,4 & 96,1 & $\mathrm{RP}$ \\
\hline & In vivo 3 & 160,4 & 163,1 & $-1,7$ & 97,3 & $\mathrm{AP}$ \\
\hline \multirow{4}{*}{ 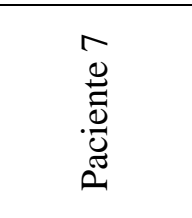 } & QA & 196,4 & 200,6 & $-2,1$ & 98,1 & $\mathrm{AP}$ \\
\hline & In vivo 1 & 196,4 & 202,8 & $-3,2$ & 99,0 & AP \\
\hline & In vivo 2 & 195,4 & 191,5 & 2,0 & 98,5 & $\mathrm{AP}$ \\
\hline & In vivo 3 & 196,4 & 195,5 & 0,5 & 98,1 & $\mathrm{AP}$ \\
\hline \multirow{4}{*}{ 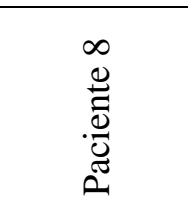 } & QA & 256,4 & 250,0 & 2,6 & 97,2 & AP \\
\hline & In vivo 1 & 256,2 & 255,9 & 0,1 & 96,6 & AP \\
\hline & In vivo 2 & 256,3 & 252,1 & 1,7 & 95,4 & $\mathrm{AP}$ \\
\hline & In vivo 3 & 256,7 & 262,1 & $-2,1$ & 97,1 & $\mathrm{AP}$ \\
\hline
\end{tabular}

\footnotetext{
Momento da avaliação: "QA": avaliação realizada juntamente com o controle da qualidade convencional; "In vivo": avaliação no momento da terapêutica

${ }^{2}$ A coluna "Dose Filme" descreve a dose encontrada no filme

${ }^{3}$ Dose encontrada pela distribuição referente ao TPS

${ }^{4}$ Desvio percentual entre a dose no filme e a dose no $\mathrm{XiO}$

${ }^{5}$ Porcentagem dos pontos aprovados na função gama

${ }^{6}$ Resultado do controle da qualidade: "AP" = aprovado; "RP" = reprovado
} 
Tabela 14 - Resultados da avaliação in vivo referentes à distribuição da dose coletada na região inferior da imagem do objeto simulador no TPS

\begin{tabular}{|c|c|c|c|c|c|c|}
\hline $\begin{array}{c}\text { Paciente } \\
\text { Analisado } \\
\end{array}$ & Aplicação ${ }^{1}$ & $\begin{array}{c}\text { Dose } \\
\text { Filme }^{2} \\
\end{array}$ & $\begin{array}{c}\text { Dose } \\
\mathrm{XiO}^{3} \\
\end{array}$ & $\begin{array}{c}\text { Desvio } \\
(\%)^{4} \\
\end{array}$ & $\begin{array}{c}\text { Gama } \\
(\%)^{5}\end{array}$ & Resultado $^{6}$ \\
\hline \multirow{4}{*}{$\begin{array}{l}a \\
\stackrel{0}{0} \\
\frac{\vec{d}}{\tilde{\sigma}} \\
\tilde{a}\end{array}$} & QA & 284,5 & 290,5 & $-2,1$ & 99,5 & AP \\
\hline & In vivo 1 & 286,4 & 289,1 & $-0,9$ & 100,0 & $\mathrm{AP}$ \\
\hline & In vivo 2 & 280,9 & 288,6 & $-2,7$ & 100,0 & AP \\
\hline & In vivo 3 & 283,2 & 289,7 & $-2,2$ & 99,4 & $\mathrm{AP}$ \\
\hline \multirow{4}{*}{ 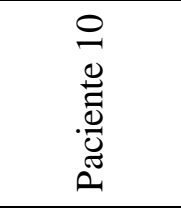 } & QA & 257,8 & 245,7 & 4,9 & 97,5 & $\mathrm{AP}$ \\
\hline & In vivo 1 & 275,0 & 278,0 & $-1,1$ & 99,9 & $\mathrm{AP}$ \\
\hline & In vivo 2 & 262,1 & 272,5 & $-3,8$ & 97,8 & $\mathrm{AP}$ \\
\hline & In vivo 3 & 270,5 & 274,8 & $-1,6$ & 99,7 & $\mathrm{AP}$ \\
\hline \multirow{4}{*}{ 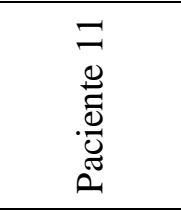 } & QA & 326,4 & 320,8 & 1,7 & 99,9 & $\mathrm{AP}$ \\
\hline & In vivo 1 & 315,5 & 318,7 & $-1,0$ & 99,9 & $\mathrm{AP}$ \\
\hline & In vivo 2 & 326,0 & 320,0 & 1,9 & 99,4 & $\mathrm{AP}$ \\
\hline & In vivo 3 & 317,9 & 320,1 & $-0,7$ & 99,6 & $\mathrm{AP}$ \\
\hline \multirow{4}{*}{ 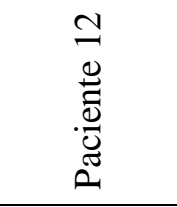 } & QA & 299,1 & 294,4 & 1,6 & 99,8 & $\mathrm{AP}$ \\
\hline & In vivo 1 & 290,5 & 294,7 & $-1,4$ & 99,4 & $\mathrm{AP}$ \\
\hline & In vivo 2 & 294,7 & 294,8 & 0,0 & 99,9 & $\mathrm{AP}$ \\
\hline & In vivo 3 & 288,4 & 295,2 & $-2,3$ & 99,9 & AP \\
\hline \multirow{4}{*}{ 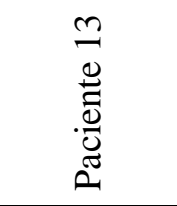 } & QA & 306,5 & 298,4 & 2,7 & 96,7 & $\mathrm{AP}$ \\
\hline & In vivo 1 & 300,3 & 298,6 & 0,6 & 99,9 & $\mathrm{AP}$ \\
\hline & In vivo 2 & 291,9 & 299,0 & $-2,4$ & 99,9 & $\mathrm{AP}$ \\
\hline & In vivo 3 & 307,4 & 299,4 & 2,7 & 99,3 & AP \\
\hline \multirow{4}{*}{ 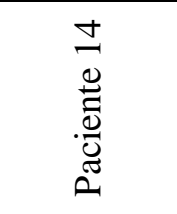 } & QA & 348,6 & 355,7 & $-2,0$ & 96,1 & $\mathrm{AP}$ \\
\hline & In vivo 1 & 354,4 & 361,0 & $-1,8$ & 99,2 & $\mathrm{AP}$ \\
\hline & In vivo 2 & 343,9 & 354,4 & $-3,0$ & 99,1 & $\mathrm{AP}$ \\
\hline & In vivo 3 & 343,5 & 353,8 & $-2,9$ & 97,2 & AP \\
\hline
\end{tabular}

'Momento da avaliação: "QA": avaliação realizada juntamente com o controle da qualidade convencional; "In vivo": avaliação no momento da terapêutica

${ }^{2}$ A coluna "Dose Filme" descreve a dose encontrada no filme

${ }^{3}$ Dose encontrada pela distribuição referente ao TPS

${ }^{4}$ Desvio percentual entre a dose no filme e a dose no $\mathrm{XiO}$

${ }^{5}$ Porcentagem dos pontos aprovados na função gama

${ }^{6}$ Resultado do controle da qualidade: "AP": aprovado; "RP”: reprovado

Analisando os resultados das Tabelas 13 e 14, pode-se verificar que apenas 1 controle foi reprovado em 56 analisados, ou seja, obteve-se uma aprovação superior a $98 \%$. As diferenças encontradas foram mínimas entre as médias dos desvios da dose entre os controles que usaram a distribuição de dose proveniente do centro do objeto simulador e da região inferior. Entretanto, convém notar que 7 desvios na dose foram maiores que $3 \%$ entre os pacientes 1 a 8 (Tabela 13), enquanto que entre os pacientes 9 a 14 as ocorrências foram de apenas 2 (Tabela 14). Outro ponto importante é que a média das funções gama na Tabela 14 
$(99,1 \%)$ foi superior ao da Tabela $13(97,4 \%)$. Esses dados ainda não comprovam que coletar a distribuição da dose na região mais próxima do equilíbrio eletrônico seja melhor, ressaltando-se a importância de um estudo mais aprofundado com relação a este aspecto.

$\mathrm{Na}$ Tabela 15, pode-se observar a diferença entre os controles da qualidade convencionais, com o MatriXX, e o controle da qualidade de transmissão sugerido por este trabalho. É importante ressaltar que ambos os controles foram irradiados conjuntamente considerando a atenuação no feixe devido ao suporte acrílico.

Tabela 15 - Resultados das comparações entre o controle da qualidade convencional e o controle da qualidade de transmissão proposto neste trabalho

\begin{tabular}{|c|c|c|c|c|c|c|c|}
\hline Paciente & $\begin{array}{l}\text { Desv. } \\
\text { TPSxTrans } \\
(\%)^{1}\end{array}$ & $\begin{array}{c}\text { Desv. } \\
\text { TPSxMatriX } \\
(\%)^{2}\end{array}$ & $\begin{array}{l}\text { Dif. } \\
\text { Dose } \\
(\%)^{3}\end{array}$ & $\begin{array}{c}\text { Gama } \\
\text { Trans } \\
(\%)\end{array}$ & $\begin{array}{c}\text { Gama } \\
\text { MatriX } \\
(\%)\end{array}$ & $\begin{array}{c}\text { Dif. Gama } \\
(\%)^{6}\end{array}$ & Resultado $^{7}$ \\
\hline 1 & 3,6 & 0,5 & $-3,2$ & 97,6 & 97,3 & $-0,3$ & concorda \\
\hline 2 & $-0,8$ & $-1,5$ & $-0,7$ & 96,5 & 96,6 & 0,1 & concorda \\
\hline 3 & 3,9 & 1,2 & $-2,7$ & 98,2 & 98,7 & 0,5 & concorda \\
\hline 4 & 3,4 & 2,1 & $-1,3$ & 97,1 & 97,4 & 0,3 & concorda \\
\hline 5 & $-2,2$ & $-1,5$ & 0,7 & 95,5 & 99,6 & 4,1 & concorda \\
\hline 6 & 0,9 & $-4,1$ & $-5,0$ & 99,5 & 99,5 & 0,0 & concorda \\
\hline 7 & $-2,1$ & $-2,8$ & $-0,7$ & 98,1 & 97,5 & $-0,6$ & concorda \\
\hline 8 & 2,6 & $-3,0$ & $-5,5$ & 97,2 & 97,6 & 0,4 & concorda \\
\hline 9 & $-2,1$ & 0,2 & 2,3 & 99,5 & 99,9 & 0,4 & concorda \\
\hline 10 & 4,9 & $-1,8$ & $-6,7$ & 97,5 & 98,4 & 0,9 & concorda \\
\hline 11 & 1,7 & $-0,2$ & $-1,9$ & 99,9 & 99,2 & $-0,7$ & concorda \\
\hline 12 & 1,6 & 0,0 & $-1,6$ & 99,8 & 99,8 & 0,0 & concorda \\
\hline 13 & 2,7 & $-2,0$ & $-4,7$ & 96,7 & 97,6 & 0,9 & concorda \\
\hline 14 & $-2,0$ & 0,3 & 2,3 & 96,1 & 99,1 & 3,0 & concorda \\
\hline
\end{tabular}

\footnotetext{
${ }^{1}$ Desvio percentual entre a dose calculada pelo TPS e o filme acoplado no suporte acrílico

${ }^{2}$ Desvio percentual entre a dose no TPS e no MatriXX

${ }^{3}$ Diferença entre os desvios percentuais de dose (TPS-Transmissão e TPS-MatriXX)

${ }^{4}$ Porcentagem de pontos aprovados na função gama na metodologia de transmissão proposta por este estudo

${ }^{5}$ Porcentagem de pontos aprovados na função gama do MatriXX

${ }^{6}$ Diferença entre os pontos aprovados na função gama (metodologia de transmissão proposta e MatriXX)

${ }^{7}$ Resultado, em termos de concordância de CQ entre os métodos de controle da qualidade de transmissão e MatriXX
}

A média da diferença dos desvios da dose no ponto de normalização entre os dos controles foi de $2,1 \%$, com desvio padrão de $2,8 \%$, e a média das diferenças das funções gama foi de $0,6 \%$, com desvio padrão de $1,3 \%$. É importante ressaltar que, a coordenada do ponto de normalização do controle da qualidade de transmissão é diferente da coordenada do ponto 
de normalização do controle da qualidade com o MatriXX, ou seja, como os controles são independentes (CQ Transmissão e CQ MatriXX), os pontos de normalização foram determinados em lugares distintos, o que pode explicar o valor elevado do desvio padrão da diferença dos desvios da dose no ponto de normalização. Contudo, o resultado principal é que ambos concordaram com os resultados dos controles da qualidade, tendo em vista que nos dois casos todos os controles da qualidade foram aprovados.

\subsection{Discussões adicionais}

Ao final deste trabalho, comprovamos a eficácia da metodologia da avaliação in vivo, que apresenta a grande vantagem de avaliar a liberação da dose no momento da terapêutica, identificando e evitando a propagação da maioria dos erros associados ao tratamento, tendo em vista que, mesmo com o controle da qualidade pré-tratamento aprovado, erros podem acontecer durante a aplicação do tratamento, como descreveu o estudo de Mans e colaboradores (MANS et al., 2010). No entanto, vale destacar que a principal limitação da dosimetria in vivo é o fato de uma pequena parcela da dose já ter sido liberada no paciente antes da detecção do erro. Por outro lado, uma vantagem do método proposto por este estudo é que ele determina tanto a dose no eixo central quanto a distribuição da dose ao longo de todo o tratamento e, principalmente, não possuir limitação quanto à angulação do gantry e do tamanho máximo do campo, tendo em vista que é possível estabelecer a metodologia com segmentos de filmes maiores, capaz de avaliar campos extensos, como $30 \mathrm{~cm} \mathrm{x} 40 \mathrm{~cm}$. Esta última vantagem é importante porque os métodos que utilizam EPID possuem a limitação intrínseca da dimensão máxima do volume sensível dos detectores.

Diversas publicações descrevem recomendações que devem ser aplicadas aos controles da qualidade em IMRT (EZZELL et al., 2009)(HARDING e GOMEZ, 2006)(EZZELL et al., 2003). Estas recomendações costumam dividir o QA do IMRT em três etapas: avaliação independente das unidades monitoras, verificação das transferências dos dados do planejamento e análise da liberação da dose pelo aparelho. Na instituição onde se desenvolveu este estudo, a verificação das unidades monitoras não são calculadas por outro sistema de planejamento independente para a avaliação das unidades monitoras, como é recomendado, porém o controle da qualidade pré-tratamento utiliza as mesmas unidades monitoras do planejamento e, com isso, caso o cálculo não esteja adequado a inconsistência 
será detectada no controle da qualidade individual antes do tratamento. Ainda nesta análise, todas as unidades monitoras são avaliadas por dois físicos, para assegurar que a ficha de tratamento esteja em conformidade com o planejado. Com relação à verificação da transferência de dados, na instituição do estudo, um físico independente avalia a transferência de dados do TPS para o sistema de registro e verificação que o físico anterior transferiu via DICOM RT; esta avaliação é apenas da unidade monitora total e quantidade de segmentos total e, assim, embora seja recomendado pelos órgãos citados acima, a instituição não considera viável a avaliação da unidade monitora por segmento. Ainda é importante ressaltar que os controles da qualidade não seriam aprovados caso existisse algum desvio significativo entre as unidades monitoras dos segmentos. Desta forma, a recomendação deste estudo é realizar o controle da qualidade descrito pela instituição, adicionando a avaliação in vivo, pois, neste último procedimento, pode-se analisar as três recomendações simultaneamente, tendo em vista que a avaliação in vivo detecta se as unidades monitoras não estão adequadas, se as transferências de dados foi realizada corretamente e se a liberação da dose está inadequada.

Algumas das publicações relacionadas ao programa de controle da qualidade em radioterapia costumam enfatizar o controle da qualidade pré-tratamento. Nossa recomendação é que as novas publicações insiram em seus estudos a avaliação in vivo de transmissão descrita neste trabalho, tendo em vista que é bastante eficaz na avaliação dos tratamentos e ainda possui baixo custo e alta aplicação prática.

A aplicação desta metodologia de controle da qualidade com filme radiocrômico posicionado no suporte situado na saída do feixe de radiação deve ser realizada com a observação de que o suporte acrílico utilizado neste estudo, especialmente confeccionado para essas avaliações, absorve aproximadamente $5,8 \%$ da dose, o que torna necessária uma correção na exposição a ser aplicada. Vale destacar que isto não é um fator limitante à utilização desta técnica, especialmente porque é possível fazer a correção na dose aplicada; acrescenta-se que a metodologia proposta apresenta uma atenuação semelhante à praticada com o sistema DAVID da PTW (POPPE et al., 2010), e com outro dosímetro da IBA (VENKATARAMAN et al., 2009) e que é inferior à dos outros métodos propostos utilizando o MatriXX (GODART et al., 2011). No entanto, uma vez estabelecida esta metodologia, pode-se buscar um refinamento do método através da confecção de um suporte com uma menor atenuação do feixe. 
Em média, na instituição avaliada, os pacientes de IMRT realizam de 6 a 8 filmes portais durante todo o tratamento, o que equivale a uma dose extra de 30 cGy, aproximadamente. Esta quantidade é equivalente à dose absorvida por 3 aplicações usando o suporte acrílico confeccionado neste trabalho, justificando assim o número três controles da qualidade de transmissão.

Outra observação importante a ser feita é que o objeto simulador usado no TPS para avaliação das doses e distribuições de dose esperadas possui dimensões menores que a profundidade de build-up do feixe usado. Sabe-se que, nesta região, os sistemas de planejamento não possuem cálculo acurado (DOGAN e GLASGOW, 2003), porém, para a metodologia proposta, isto não foi uma limitação, desde que o método de cálculo usado pelo TPS na determinação da distribuição da dose no IMRT seja o mesmo usado para fazer a calibração. Contudo, a diferença dos resultados encontrados nas Tabelas 13 e 14 sugerem um estudo mais aprofundado, tendo em vista que os desvios e as funções gama apresentaram resultados um pouco melhores para o estudo que coletou a distribuição de dose próxima da região de equilíbrio eletrônico.

Uma limitação desta metodologia no controle da qualidade do tratamento de IMRT é o fato desta metodologia não avaliar o posicionamento do paciente, desta forma a mesma deve ser associada a outras modalidades de controle para possibilitar a determinação do posicionamento, como, por exemplo, os filmes portais ou técnicas de radioterapia guiada por imagem (IGRT, do inglês Image-Guided Radiation Therapy).

Este trabalho torna-se importante por viabilizar uma metodologia para verificações in vivo, até o momento não estabelecida para a IMRT, através de dosímetros comercialmente utilizados, que possuem baixo custo quando comparando a outros equipamentos comerciais, além de alta aplicação prática. Vale destacar que as técnicas mais modernas de tratamento radioterápico, como o V-MAT (do inglês Volumetric-Modulated Arc Therapy), desenvolvem as aplicações com feixes rotacionais e os dosímetros tradicionalmente utilizados em controle da qualidade oferecem limitações angulares. Sendo assim, uma vez estabelecida esta metodologia, ela poderá ser aplicada nas técnicas radioterápicas mais modernas, já que não oferece dificuldades com a angulação do gantry. 
Capítulo 5 - Conclusões 


\section{CONCLUSÕES}

Com base nos resultados encontrados na Seção 4.1.2, Digitalização, pode-se concluir que o filme radiocrômico é adequado para avaliações dosimétricas, tendo em vista que, na metodologia da digitalização sugerida, houve concordância de $100 \%$ dos pontos na função gama, quando comparou-se a distribuição da dose do filme com a distribuição do sistema de planejamento.

Com os resultados encontrados na Seção 4.2, Estudo da Metodologia de Transmissão em Campos Quadrados e de Planejamento Conformacional, avaliando tanto a simulação Monte Carlo quanto as irradiações, pode-se concluir que a diferença entre a distribuição de dose do TPS e do filme são pequenas e, desta forma, é viável criar uma metodologia para verificação dosimétrica de transmissão utilizando um filme radiocrômico acoplado ao cabeçote do acelerador, através da comparação da distribuição da dose gerada pelo TPS usando objeto simulador de geometria semelhante ao suporte acrílico com aquela gerada pelo filme e, assim, elaborar um programa de controle da qualidade de transmissão in vivo para técnicas modernas de teleterapia.

Na Seção 4.4.2, Estudo da Metodologia em Campos de IMRT, foram simuladas 15 configurações de tratamentos de IMRT corretos e 10 configurações com algum desvio na dose administrada, de forma a verificar se a metodologia proposta seria capaz de identificar esses desvios. O controle da qualidade proposto concordou com o esperado em 24 simulações, apresentando apenas um resultado diferente, ou seja, uma concordância de $96 \%$ com o esperado. Comprovou-se, assim, a eficácia da metodologia.

A metodologia de digitalização, nas Seções 4.4.3, Reprodutibilidade na Digitalização na Técnica de IMRT, e 4.4.4, Reprodutibilidade do Controle da Qualidade de Transmissão na Técnica de IMRT, mostrou-se reprodutível para duas digitalizações do mesmo filme, observando-se, também reprodutibilidade no controle da qualidade de transmissão, que também foi analisada entre duas exposições do mesmo planejamento. Para os dois testes, as flutuações encontradas são da ordem das flutuações estatísticas. 
As comparações dos resultados obtidos com a metodologia proposta e com os controles da qualidade realizados com outros dosímetros já estabelecidos nesta aplicação também foram satisfatórias, podendo-se destacar apenas uma diferença máxima de 4,9\%, encontrada entre o controle da qualidade realizada com o MatriXX e o sugerido por nosso trabalho. Contudo, esta diferença pode ser explicada pela baixa resolução espacial, pela dimensão dos detectores e pela distância entre os detectores do MatriXX, tendo em vista que, como constou na Seção 4.4.5, Comparação entre o Controle da Qualidade de Transmissão e de Outros Sistemas Dosimétricos na Técnica de IMRT, não foram aplicadas as correções descritas por Poppe e colaboradores (POPPE et al., 2007), da forma como como foi aplicada na Seção 4.5, Avaliação Dosimétrica in Vivo.

Os resultados encontrados na referida Seção 4.5 concordam com o previsto em $98 \%$ dos casos avaliados, comprovando, assim, a validade da técnica e confirmando a validade da metodologia de controle da qualidade de transmissão in vivo com filme radiocrômico posicionado no cabeçote do LINAC e, como ela não oferece dificuldades com o deslocamento angular do gantry, ela poderá ser aplicada em técnicas teleterápicas mais modernas. 
Capítulo 6. Referências Bibliográficas 


\section{REFERÊNCIAS BIBLIOGRÁFICAS}

ALMEIDA, C. E. Bases Físicas de um Programa de Garantia de Qualidade em IMRT. [S.1: s.n.], 2012. p. 267

ALNAWAF, H. et al. Scanning orientation and polarization effects for XRQA radiochromic film. Physica medica PM an international journal devoted to the applications of physics to medicine and biology official journal of the Italian Association of Biomedical Physics AIFB, v. 26, p. 216-219, 2010.

AMARAL, L. L. et al. Uma metodologia para verificação dosimétrica in vivo em radioterapia estereotáxica. Revista Brasileira de Física Médica, v. 6, n. 3, p. 129-132, 2012.

MCCURDY, B. et al. Commissioning and validation of a novel measurement-based IMRT QA method, incorporating dose recalculation on patient CT data. MedPhys, v. 35, n. 11, 2008.

BANCI BUONAMICI, F. et al. An intercomparison between film dosimetry and diode matrix for IMRT quality assurance. Medical Physics, v. 34, n. 4, p. 1372, doi:10.1118/1.2713426, 2007.

BARBI, G. L. et al. Caracterização de um sistema eletrônico de aquisição de imagem portal para dosimetria em radioterapia. Revista Brasileira de Física Médica, v. 6, n. 2, p. 45-49, 2012.

BASKAR, R. et al. Cancer and radiation therapy: current advances and future directions. International Journal of Medical Sciences, v. 9, p. 193-9, doi:10.7150/ijms.3635, 2012.

BAUS, W. et al. Rules and regulations applying to incidents in radiotherapy. Strahlentherapie und Onkologie. [S.1: s.n.], 2012.

BUCCIOLINI, M.; BANCI BUONAMICI, F. e CASATI, M. Verification of IMRT fields by film dosimetry. Medical Physics, v. 31, n. 1, p. 161, doi:10.1118/1.1631093, 2004.

BUSHONG SC. Radiologic science for technologist $\square:$ physics, biology, and protection. 9. ed. [S.1.]: Mosby/Elsevier, 2008.

BUTSON, M. J. et al. Radiochromic film for medical radiation dosimetry. Materials Science and Engineering: R: Reports, v. 41, n. 3-5, p. 61-120, doi:10.1016/S0927-796X(03)00034-2, 2003.

BUTSON, M. J.; CHEUNG, T. e YU, P. K. N. Scanning orientation effects on Gafchromic EBT film dosimetry. Australasian physical engineering sciences in medicine supported by the 
Australasian College of Physical Scientists in Medicine and the Australasian Association of Physical Sciences in Medicine, v. 29, p. 281-284, 2006.

CASANOVA BORCA, V. et al. Dosimetric characterization and use of GAFCHROMIC EBT3 film for IMRT dose verification. Journal of applied clinical medical physics / American College of Medical Physics, v. 14, p. 4111, 2013.

CHEUNG, T.; BUTSON, M. J. e YU, P. K. N. Independence of calibration curves for EBT Gafchromic films of the size of high-energy X-ray fields. Applied radiation and isotopes $\square$ : including data, instrumentation and methods for use in agriculture, industry and medicine, $\mathrm{v}$. 64, n. 9, p. 1027-30, doi:10.1016/j.apradiso.2006.04.006, 2006.

CIOCCA, M. et al. In vivo dosimetry using radiochromic films during intraoperative electron beam radiation therapy in early-stage breast cancer. Radiotherapy and Oncology, v. 69, n. 3, p. 285-289, doi:10.1016/j.radonc.2003.09.001, 2003.

COSSET, J. M. e GOURMELON, P. Accidents in radiotherapy: historical account. Cancer radiotherapie $\square$ : journal de la Societe francaise de radiotherapie oncologique, v. 6 Suppl 1, p. 166s-170s, 2002.

COSTA, A. M. et al. In vivo dosimetry with thermoluminescent dosimeters in external photon beam radiotherapy. Applied radiation and isotopes $\square$ : including data, instrumentation and methods for use in agriculture, industry and medicine, v. 68, n. 4-5, p. 760-2, doi:10.1016/j.apradiso.2009.09.039, 2010.

CRIJNS, W. et al. Calibrating page sized Gafchromic EBT3 films. Medical physics, v. 40, p. 012102, doi:10.1118/1.4771960, 2013.

DESROCHES, J.; BOUCHARD, H. e LACROIX, F. Technical Note: Potential errors in optical density measurements due to scanning side in EBT and EBT2 Gafchromic film dosimetry. Medical Physics, v. 37, n. 4, p. 1565, doi:10.1118/1.3355895, 2010.

DEVIC, S. Radiochromic film dosimetry: past, present, and future. Physica medica PM an international journal devoted to the applications of physics to medicine and biology official journal of the Italian Association of Biomedical Physics AIFB, v. 27, p. 122-134, 2011.

DOBLER, B. et al. Hybrid plan verification for intensity-modulated radiation therapy (IMRT) using the 2D ionization chamber array I'mRT MatriXX--a feasibility study. Physics in medicine and biology, v. 55, p. N39-N55, doi:10.1088/0031-9155/55/2/N02, 2010.

DOGAN, N. e GLASGOW, G. P. Surface and build-up region dosimetry for obliquely incident intensity modulated radiotherapy 6 MV x rays. Medical Physics, v. 30, p. 3091-3096, 2003.

DULIU, O. G. In vivo dosimetry measurements for breast radiation treatments. v. 64, n. 3, p. 728-736, 2012.

EBONGUE, A. N. et al. A method of increasing the film intrinsic robustness of radiochromic film dosimetry. Physics in medicine and biology, v. 57, p. N445-56, doi:10.1088/00319155/57/22/N445, 2012. 
ELSHAIKH, M. et al. Advances in radiation oncology. Annual review of medicine, v. 57, p. 19-31, doi:10.1146/annurev.med.57.121304.131431, 2006.

ENGSTRÖM, P. E. et al. In vivo dose verification of IMRT treated head and neck cancer patients. Acta oncologica (Stockholm, Sweden), v. 44, n. 6, p. 572-8, doi:10.1080/02841860500218983, 2005.

EZZELL, G. A. et al. Guidance document on delivery, treatment planning, and clinical implementation of IMRT: report of the IMRT Subcommittee of the AAPM Radiation Therapy Committee. Medical physics, v. 30, p. 2089-2115, doi:10.1118/1.1591194, 2003.

EZZELL, G. A. et al. IMRT commissioning: multiple institution planning and dosimetry comparisons, a report from AAPM Task Group 119. Medical physics, v. 36, p. 5359-5373, doi:10.1118/1.3238104, 2009.

FERNÁNDEZ-VAREA, J. M. e SALVAT, F. Overview of physical interaction models for photon and electron transport used in Monte Carlo codes. Metrologia. [S.1: s.n.], 2009.

KHAN, F. The physics of radiation therapy. 4. ed. Philadelphia: [s.n.], 2010.

FURNARI, L. Controle de qualidade em radioterapia Quality assurance in radiotherapy. v. 3, n. 1, p. 77-90, 2009.

GIRARD, F.; BOUCHARD, H. e LACROIX, F. Reference dosimetry using radiochromic film. Journal of applied clinical medical physics American College of Medical Physics, v. 13, p. 3994, 2012.

GODART, J. et al. Reconstruction of high-resolution 3D dose from matrix measurements: error detection capability of the COMPASS correction kernel method. Physics in medicine and biology, v. 56, n. 15, p. 5029-43, doi:10.1088/0031-9155/56/15/023, 2011.

HAN, Z. et al. Evaluation of MatriXX for IMRT and VMAT dose verifications in peripheral dose regions. Medical Physics, v. 37, n. 7, p. 3704, doi:10.1118/1.3455707, 2010.

HARDER, D. Comments on "The influence of a novel transmission detector on $6 \mathrm{MV}$ x-ray beam characteristics". Physics in medicine and biology, v. 55, n. 3, p. L1-2; author reply L34, doi:10.1088/0031-9155/55/3/L01, 2010.

HARDING, E. K. e GOMEZ, S. ICRU Report 83 Prescribing, Recording, and Reporting Photon-Beam Intensity-Modulated Radiation Therapy (IMRT). Journal of the ICRU, v. 48, p. 121-129, doi:10.1093/jicru/ndn001, 2006.

HERZEN, J. et al. Dosimetric evaluation of a 2D pixel ionization chamber for implementation in clinical routine. Physics in medicine and biology, v. 52, n. 4, p. 1197-208, doi:10.1088/0031-9155/52/4/023, 2007.

HINSON, W. H. et al. Photon spectral characteristics of dissimilar 6 MV linear accelerators. Medical physics, v. 35, p. 1698-1702, doi:10.1118/1.2900001, 2008. 
ISLAM, M. K. et al. An integral quality monitoring system for real-time verification of intensity modulated radiation therapy. Medical Physics, v. 36, n. 12, p. 5420, doi:10.1118/1.3250859, 2009.

KATHIRVEL, M. et al. Critical appraisal of the accuracy of Acuros-XB and Anisotropic Analytical Algorithm compared to measurement and calculations with the compass system in the delivery of RapidArc clinical plans. Radiation oncology (London, England), v. 8, n. 1, p. 140, doi:10.1186/1748-717X-8-140, 2013.

LEE, K. Y.; FUNG, K. K. L. e KWOK, C. S. Application of high-resolution radiochromic film dosimetry in verifying a small-field stereotactic radiosurgery plan. Applied radiation and isotopes $\square$ : including data, instrumentation and methods for use in agriculture, industry and medicine, v. 64, n. 8, p. 934-9, doi:10.1016/j.apradiso.2006.03.011, 2006.

LOW, D. A. et al. A technique for the quantitative evaluation of dose distributions. Medical Physics, v. 25, p. 656-661, 1998.

LOW, D. A. et al. Dosimetry tools and techniques for IMRT. Medical Physics, v. 38, p. 1313-1338, 2011.

MANS, a. et al. Catching errors with in vivo EPID dosimetry. Medical Physics, v. 37, n. 6, p. 2638, doi:10.1118/1.3397807, 2010.

MARZI, H. e LIAN, Y. J. Optimization in radiosurgery treatment planning. 2011 IEEE International Systems Conference, p. 579-583, doi:10.1109/SYSCON.2011.5929035, 2011.

MCDERMOTT, L. N. et al. Replacing pretreatment verification with in vivo EPID dosimetry for prostate IMRT. International journal of radiation oncology, biology, physics, v. 67, n. 5, p. 1568-77, doi:10.1016/j.ijrobp.2006.11.047, 2007.

MIJNHEER, B. State of the art of in vivo dosimetry. Radiation protection dosimetry, v. 131, n. 1, p. 117-22, doi:10.1093/rpd/ncn231, 2008.

MOHAMMADKARIM, A. et al. A method to improve the accuracy of diode in vivo dosimetry for external megavoltage photon beams filtered by wedges. Journal of Theoretical and Applied Physics, v. 7, n. 1, p. 13, doi:10.1186/2251-7235-7-13, 2013.

MOYLAN, R.;; ALAND, T. e KAIRN, T. Dosimetric accuracy of Gafchromic EBT2 and EBT3 film for in vivo dosimetry. Australasian physical \& engineering sciences in medicine, v. 36, p. 331-7, doi:10.1007/s13246-013-0206-0, 2013.

MYERS, P. et al. VMAT monthly QA using two techniques: 2D ion chamber array with an isocentric gantry mount and an in vivo dosimetric device attached to gantry. Journal of Radiotherapy in Practice, p. 1-7, doi:10.1017/S1460396912000556, 2013.

NAKAGUCHI, Y. et al. Dose verification of IMRT by use of a COMPASS transmission detector. Radiological physics and technology, v. 5, n. 1, p. 63-70, doi:10.1007/s12194-0110137-y, 2012. 
OLDHAM, M. Radiation physics and applications in therapeutic medicine. Physics Education, v. 36, n. 6, p. 460-467, doi:10.1088/0031-9120/36/6/303, 2001.

PAGE, R. F. et al. Towards using a Monolithic Active Pixel Sensor for in vivo beam monitoring of Intensity Modulated Radiotherapy. Nuclear Instruments and Methods in Physics Research Section A: Accelerators, Spectrometers, Detectors and Associated Equipment, p. 1-4, doi:10.1016/j.nima.2013.05.144, 2013.

PALIWAL, B. R. A consistency monitor for radiation therapy treatments. Medical Physics, v. 23, n. 10, p. 1805, doi:10.1118/1.597762, 1996.

PAPPAS, E. et al. Small SRS photon field profile dosimetry performed using a PinPoint air ion chamber, a diamond detector, a novel silicon-diode array (DOSI), and polymer gel dosimetry. Analysis and intercomparison. Medical Physics, v. 35, p. 4640-4648, 2008.

POLEDNIK, M. et al. Evaluation of calculation algorithms implemented in different commercial planning systems on an anthropomorphic breast phantom using film dosimetry. Strahlentherapie und Onkologie $\square$ : Organ der Deutschen Röntgengesellschaft ... [et al], v. 183, n. 12, p. 667-72, doi:10.1007/s00066-007-1775-1, 2007.

POPPE, Bjoern et al. Two-dimensional ionization chamber arrays for IMRT plan verification. Medical Physics, v. 33, p. 1005, doi:10.1118/1.2179167, 2006.

POPPE, B et al. DAVID--a translucent multi-wire transmission ionization chamber for in vivo verification of IMRT and conformal irradiation techniques. Physics in medicine and biology, v. 51, n. 5, p. 1237-48, doi:10.1088/0031-9155/51/5/013, 2006.

POPPE, B. et al. Spatial resolution of 2D ionization chamber arrays for IMRT dose verification: single-detector size and sampling step width. Physics in Medicine and Biology, v. 52, p. 2921-2935, 2007.

POPPE, B. et al. Clinical performance of a transmission detector array for the permanent supervision of IMRT deliveries. Radiotherapy and oncology $\square$ : journal of the European Society for Therapeutic Radiology and Oncology, v. 95, n. 2, p. 158-65, doi:10.1016/j.radonc.2009.12.041, 2010.

REINHARDT, S. et al. Comparison of Gafchromic EBT2 and EBT3 films for clinical photon and proton beams. Medical Physics. [S.1: s.n.], 2012.

SALVAT, F.; FERNÁNDEZ-VAREA, J. M. e SEMPAU, J. PENELOPE, a code system for Monte Carlo simulation of electron and photon transport. In: PROCEEDINGS OF A WORKSHOP/TRAINING COURSE, OECD/NEA. Anais... [S.1: s.n.], 2003.

SHARMA, D. S. et al. Portal dosimetry for pretreatment verification of IMRT plan: a comparison with 2D ion chamber array. Journal of applied clinical medical physics / American College of Medical Physics, v. 11, n. 4, p. 3268, 2010.

SHEIKH-BAGHERI, D. e ROGERS, D. W. O. Monte Carlo calculation of nine megavoltage photon beam spectra using the BEAM code. Medical Physics, v. 29, p. 391-402, 2002. 
SOARES, C. G. Radiochromic film dosimetry. Radiation Measurements, v. 41, p. S100S116, doi:10.1016/j.radmeas.2007.01.007, 2006.

VENKATARAMAN, S. et al. The influence of a novel transmission detector on 6 MV x-ray beam characteristics. Physics in medicine and biology, v. 54, n. 10, p. 3173-83, doi:10.1088/0031-9155/54/10/014, 2009.

WILCOX, E. E. e DASKALOV, G. M. Evaluation of GAFCHROMIC® EBT film for CyberKnife® dosimetry. Medical Physics, v. 34, p. 1967, doi:10.1118/1.2734384, 2007.

WILCOX, E. E. e DASKALOV, G. M. Accuracy of dose measurements and calculations within and beyond heterogeneous tissues for $6 \mathrm{MV}$ photon fields smaller than $4 \mathrm{~cm}$ produced by Cyberknife. Medical Physics, v. 35, p. 2259-2266, 2008.

WILLIAMS, M. V. Improving patient safety in radiotherapy by learning from near misses, incidents and errors. The British journal of radiology, v. 80, p. 297-301, doi:10.1259/bjr/29018029, 2007.

WORLD HEALTH ORGANIZATION (WHO). Radiotherapy risk profile. . [S.l: s.n.], 1988.

ZEIDAN, O. A. et al. Characterization and use of EBT radiochromic film for IMRT dose verification. Medical Physics, v. 33, p. 4064-4072, 2006.

ZIJTVELD, M. VAN et al. Portal dose image prediction for in vivo treatment verification completely based on EPID measurements. Medical Physics, v. 36, n. 3, p. 946, doi:10.1118/1.3070545, 2009. 